\title{
Canadian Pain Society Conference May 12 - 15, 2010, Calgary, Alberta
}

\section{WEDNESDAY MAY 12, 2010}

\section{5:15 PM - SYMPOSIUM}

\section{1}

\section{BREAKING BARRIERS IN BREAKTHROUGH CANCER PAIN}

Chair: Neil Hagen

Speakers: Neil Hagen, MD; Dr Dwight Moulin, MD; Dr Bruno

\section{Gagnon, MD}

Neil Hagen, MD, Head, Cancer Pain and Symptom Control Clinic, Tom Baker Cancer Centre, Professor and Head, Division of Palliative Medicine, University of Calgary, Calgary, Alberta; Dwight Moulin, MD, Professor, Departments of Clinical Neurosciences/Oncology, Earl Russell Chair Pain Research, University of Western Ontario; Medical Director of Pain and Symptom Management, London Regional Cancer Program, Head of the Division of Neurology, Victoria Campus, London Health Sciences Centre, London, Ontario; Bruno Gagnon, MD, Assistant Professor, Department of Medicine, Clinical Scientist, Division of Clinical Epidemiology, McGill University, Montreal, Quebec

Learning Objectives:

1. Review the pathophysiology and characteristics of breakthrough cancer pain, its prevalence and its distinction from baseline pain.

2. Discuss the current management of breakthrough cancer pain in Canada, its strengths and its limitations.

3. List attributes of a new class of drugs - rapid onset opioids - and outline how they are used in clinical practice.

BRIEF DESCRIPTION: Breakthrough cancer pain is phenomenologically distinct from persistent chronic cancer pain, and requires different management strategies. While baseline cancer pain is typically fairly steady, breakthrough cancer pain is commonly sudden in onset, typically reaching peak intensity after about 3 minutes. Episodes of breakthrough cancer pain can be predictable, but in approximately $80 \%$ of patients, breakthrough pain occurs unpredictably. (1) Physicians treating cancer patients need to undertake a proper assessment of pain in order to ensure appropriate pain management. Results from one survey suggested that only $25 \%$ of patients with breakthrough pain are satisfied with pain control compared to $78 \%$ of patients without breakthrough pain. (1) Difficulties in identifying breakthrough pain, and the availability of new emerging therapy justify the need for attention to gaps in current diagnosis and treatment, and implementation of measures to reduce these gaps.

\section{REFERENCES}

1. Portenoy RK, Payne D, Jacobsen P. Breakthrough pain: characteristics and impact in patients with cancer pain. Pain. 1999;81(1-2):129-134.

\section{$1 \mathrm{~A}$}

\section{PATHOPHYSIOLOGY AND CHARACTERISTICS OF BREAKTHROUGH CANCER PAIN}

Dwight Moulin, MD

Departments of Clinical Neurosciences/Oncology, University of Western Ontario; Medical Director of Pain and Symptom Management, London Regional Cancer Program; Medical Director of Pain and Symptom Management, London Regional Cancer Program, Head of the Division of Neurology, Victoria Campus, London Health Sciences Centre, London, Ontario

\section{B}

\section{MANAGING BREAKTHROUGH CANCER PAIN - CURRENT} PRACTICE, GAPS IN TREATMENT MANAGEMENT

Bruno Gagnon, MD

Assistant Professor, Department of Medicine, Clinical Scientist, Division of Clinical Epidemiology, McGill University, Montreal, Quebec

\section{C}

BREAKTHROUGH IN TREATING BREAKTHROUGH CANCER PAIN - A NEW THERAPEUTIC OPTION

Neil Hagen, MD

Head, Cancer Pain and Symptom Control Clinic, Tom Baker Cancer Centre, Professor and Head, Division of Palliative Medicine, University of Calgary, Calgary, Alberta

\section{PAIN EDUCATION DAY THURSDAY MAY 13, 2010}

\section{9:15 AM - KEYNOTE SPEAKER}

\section{2} PHENOMICS OF PAIN IN HUMANS AND RODENT MODELS Chair: Michael McGillion Speaker: Ze'ev Seltzer

Ze'ev Seltzer, Professor of Genetics, Faculty of Dentistry, Professor of Physiology, Faculty of Medicine (X-appt), University of Toronto Centre for the Study of Pain; University of Toronto Centre for International Health (Dalla Lana School of Public Health); Toronto Rehabilitation Institute, Toronto, Ontario

Learning Objectives:

1. Attendants will learn that the Human Genome Project has the capacity to revolutionize pain medicine in our lifetime, if sufficiently supported. This presentation will highlight the potential gains that pain patients may expect in the post genomic era. 2. Attendants will learn that without appropriately collected pain phenotypes - this costly operation may fail. This stresses the need for a rigorous study on pain phenomics. Moreover, a consensus must be reached soon about the phenotyping tools that interested research groups should use in order to facilitate replications, comparisons and meta-analysis.

3. Attendants will be acquainted with suggested phenomic guidelines, tools and data collection strategies for genetic dissection of neuropathic pain in human and rodent models.

BRIEF DESCRIPTION: The vast majority of the reported studies on pain genetics used "having/not having chronic pain" or "pain intensity (using VAS or NRS)" as the only phenotypes used in the genetic association analysis. While patients would certainly appreciate having pharmacogenomically based novel treatments that could diminish the intensity of their pain, chronic pain, however, is a much more complex experience than the intensity of the pain. Patients complain about many other sensory discriminative aspects of the pain that bother them and that they wish their doctor could treat, such as the frequency and duration of pain episodes, the area where the pain is felt. Likewise, patients would appreciate if some medicine would prevent the pain from appearing spontaneously or following a natural stimulus, and preventing pain induced or aggravated by movement, sympathetic arousal, sleep deprivation, and certain moods. Furthermore, if a painkiller could affect the quality of the pain by substituting the unbearable quality they have, say, terrible electrical shocks paroxysms, by another bearable quality, that alone might be appreciated no less than affecting the intensity alone. So, limiting the genetic association to intensity alone - misses much on the treatment potential genetics could bring to pain medicine, by addressing patients' needs in the emotive/aversive and cognitive/evaluative aspects of the pain that affect functionality, participation, and quality of life. Pain phenomics is the research field that asks what the pain phenotypes for genetic association should be. While this research field has not been born as of yet, investigators comprising multi-center groups invest years and financial resources to collect a sufficiently powered cohort for a genetic study, followed by years on genotyping and analysis, without a comprehensive phenotypic coverage of the syndrome under study. The presentation by Dr. Seltzer will address this problem, and offer phenomic guidelines, tools and data collection strategies for genetic dissection of neuropathic pain in human and rodent models. 


\section{1:00 AM - PLENARY}

\section{3}

\section{CONTRIBUTIONS OF THE CNS TO FUNCTIONAL PAIN SYNDROMES}

Chair: Petra Schweinhardt

Speakers: Karen D Davis, PhD; Herta Flor, PhD; Petra Schweinhardt, MD, PhD

Karen D Davis, PhD, Toronto Western Research Institute, University Health Network, Toronto, Ontario; Herta Flor, PhD, Central Institute of Mental Health and University of Heidelberg; Petra Schweinhardt, MD, PhD, McGill University, Montreal, Quebec

WORKSHOP OBJECTIVE: Chronic pain syndromes that are not primarily nociceptive or neuropathic in nature, i.e. for which no clear underlying cause can be found, affect a large proportion of chronic pain patients. Different classification systems refer to such chronic pain syndromes with unclear origin as "functional", "somatoform", or "psychological". Functional pain syndromes affect a variety of different body parts and organs, such as the gastrointestinal track (irritable bowel syndrome), the urinary tract (interstitial cystitis) or the musculoskeletal system (fibromyalgia). In recent years, neuroscientific research has made important progress in the conceptualization and understanding of functional pain syndromes. Through the use of brain imaging methods, such as Positron Emission Tomography (PET) and Magnetic Resonance Imaging (MRI), substantial evidence for CNS alterations of patients with functional pain syndromes has been provided - despite the diagnostic prerequisite that no organic cause underlies functional pain syndromes. Since altered functional, structural and biochemical alterations are found particularly in brain regions related to pain processing and pain modulation, it is possible that such alterations represent maladaptive changes that contribute to the generation and maintenance of pain. In addition to pain, patients with functional pain often experience other symptoms in addition to pain, such as emotional disturbances, fatigue and cognitive difficulties. The understanding of pathophysiological CNS changes underlying those concomitant symptoms, and their interactions with an altered pain processing network, will be of paramount importance in the future. This workshop will provide a detailed overview of neuroscientific advances regarding functional pain syndromes and potential pathophysiological mechanisms that might underlie pain chronification. The workshop will have both a methodological as well as a topical focus: through the examples of fibromyalgia, irritable bowel syndromes, and the much neglected topic of functional pain in children, it will be demonstrated how different imaging techniques reveal CNS alterations in functional pain syndromes and how they advance our understanding of underlying pathophysiology.

Learning Objectives:

1. To gain an understanding of 1) functional and structural brain abnormalities exhibited by patients with irritable bowel syndrome, 2) the importance of the methodological approach of "percept-related fMRI" in the study of chronic pain, and 3) the balance of pre-existing and disease-driven CNS abnormalities in IBS.

2. To obtain an understanding of the role of the central nervous system and psychological factors in chronic pain in children.

3. To learn about 1) the functional significance of brain alterations for pain and other symptoms in fibromyalgia, and 2) the overlap between CNS alterations if functional pain syndromes and other stress-related disorders.

\section{$3 A$}

\section{CNS ABNORMALITIES IN PATIENTS WITH IRRITABLE BOWEL SYNDROME}

Karen D Davis, PhD

Toronto Western Research Institute, University Health Network, Toronto, Ontario

BRIEF DESCRIPTION: Psychophysical and brain imaging data suggest that CNS abnormalities contribute to functional pain disorders such as irritable bowel syndrome (IBS). Individual factors may impact effective treatment in such chronic pain patients. This presentation will discuss data derived from percept-related functional MRI that point to central abnormalities in IBS in several brain regions, including the insula and cingulate cortex. More recent structural MRI data will also be presented that corroborate the fMRI findings and additionally demonstrate both gray matter and white matter abnormalities in areas implicated in pain, emotion, and stress responses. Finally, the issue of disease-driven brain plasticity versus pre-existing vulnerabilities related to personality traits such as pain catastrophizing and neuroticism in IBS will be discussed in light of new structural imaging data.

\section{B}

\section{PSYCHOBIOLOGICAL ASPECTS OF CHRONIC PAIN IN CHILDREN}

\section{Herta Flor, PhD}

Central Institute of Mental Health and University of Heidelberg BRIEF DESCRIPTION: Psychobiological approaches to the understanding of pain emphasize that the development of recurrent pain involves activity-induced alterations in pain sensitivity and related central nervous system changes and is promoted by hypervigilance to pain as well as maladaptive cognitions such as catastrophizing. In a series of studies, we have investigated changes in pain sensitivity using quantitative sensory testing entailing two pain modalities and two testing sites (thenar, pain site) as well as electroencephalographic measures or functional magnetic resonance imaging. In children with recurrent migraine and abdominal pain we have observed changes in pain sensitivity, which were rather specific for the type of pain the children and adolescents were experiencing. Children with migraine showed thermal and mechanical hyperalgesia. By contrast, there was no evidence for altered somatic pain sensitivity in children with recurrent abdominal pain. In light of previous reports, this suggests that children with recurrent abdominal pain may have heightened visceral pain sensitivity, but unaltered somatic pain sensitivity. Moreover, they report higher pain catastrophizing than children with migraine. Interestingly, using a modified oddball standards paradigm, we were able to demonstrate that, regardless of its origin, recurrent pain in children and adolescents is associated with the allocation of automatic attention to painful and non painful somatosensory stimuli. The experience of early childhood pain and ensuing deficits in pain inhibitory systems may also be important for the development of pain in children although longitudinal studies are lacking. The obtained findings will be discussed from a psychobiological perspective and clinical implications will be drawn.

\section{$3 C$}

BRAIN ALTERATIONS IN FIBROMYALGIA

Petra Schweinhardt, MD, PhD

McGill University, Montreal, Canada

BRIEF DESCRIPTION: This talk will provide a detailed overview of the functional, structural, and biochemical brain alterations that are found in fibromyalgia. It will be demonstrated that some of these brain changes overlap with findings in patients with stress-related disorders, such as post-traumatic stress disorder or depression. This might point at etiological commonalities of functional pain syndromes and stress-related disorders. Moreover, it will be examined how CNS alterations observed in fibromyalgia relate to the symptoms commonly experienced by the patients with an emphasis on pain and dyscognition.

\section{2:00 PM - SESSION 101}

\section{4}

NATIONAL GUIDELINE DEVELOPMENT - SAFE AND EFFECTIVE USE OF OPIOIDS FOR CHRONIC NON-CANCER PAIN

Chair: Andrea D Furlan

Speakers: Andrea D Furlan, MD PhD; Angela Mailis-Gagnon, MD MSc; Clarence Weppler, B.Sc Pharm

Andrea D Furlan, MD PhD, Institute for Work \& Health; Angela Mailis-Gagnon, MD MSc, Comprehensive Pain Program, University Health Network, Toronto, Ontario; Clarence Weppler, B.Sc Pharm, College of Physicians and Surgeons of Alberta

WORKSHOP OBJECTIVE: To inform participants about development and implementation by the National Opioid Use Guideline Group (NOUGG) of the guideline for safe and effective use of opioids for chronic non-cancer pain.

Learning Objectives:

1. Be aware of the methodology used to develop the NOUGG guideline 
2. Gain knowledge about the guideline recommendations

3. Be aware of actions underway to implement the guideline to practice

\section{A}

THE DEVELOPMENT OF THE NOUGG'S GUIDELINE FOR SAFE AND EFFECTIVE USE OF OPIOIDS FOR CHRONIC NON-CANCER PAIN

Andrea D Furlan, MD PhD

Institute for Work \& Health, Toronto, Ontario

BRIEF DESCRIPTION: In 2000, the College of Physicians and Surgeons of Ontario (CPSO) released the 'Evidence-based Recommendations for Medical Management of Chronic Non-malignant Pain'. Building on efforts underway to update this CPSO material, in late 2007 the National Opioid Use Guideline Group (NOUGG) took on responsibility to develop and implement a Canadian guideline. NOUGG engaged a research team to update the guideline's methods, a task that involved two new literature searches and subsequent revision of practice recommendations to reflect new evidence. In addition, NOUGG facilitated the work of a national advisory panel of first responders to the draft guideline, using a facilitated consensus process to add expert opinion to the guideline. Recommendations for practice were developed to be useful - address questions and concerns that mirror real clinical issues, and evidence-based - accompanied by explanation of the evidence that supports the recommendation.

\section{B}

KEY MESSAGES FROM THE NOUGG GUIDELINE FOR SAFE AND EFFECTIVE USE OF OPIOIDS FOR CHRONIC NONCANCER PAIN

Angela Mailis-Gagnon, MD MSc

Comprehensive Pain Program, University Health Network, Toronto, Ontario

BRIEF DESCRIPTION: Review recommendations that address several themes:

- Deciding to initiate opioid therapy

- Conducting an opioid trial

- Monitoring long-term opioid therapy

- Treating specific populations

- Managing opioid misuse and addiction

\section{C}

\section{IMPLEMENTING THE NOUGG GUIDELINE TO PRACTICE}

\section{Clarence Weppler, B.Sc Pharm}

College of Physicians and Surgeons of Alberta

BRIEF DESCRIPTION: From its inception, NOUGG saw guideline development as only a first step. NOUGG articulated an additional goal to "Develop and implement a knowledge transfer strategy that ensures the guideline moves into practice as a useful decision-making tool for physicians who treat patients with chronic non-cancer pain". An effective implementation plan was required to make it feasible and easy for physicians to use the guideline in demanding day-to-day practice environments. NOUGG members started work on implementation while the guideline was still in development, and sought support from national partners with experience in knowledge transfer. Early on, NOUGG completed a scan to identify the 'potential' that existed across Canada to implement the guideline to practice. Information derived from this scan was organized into eight categories:

1. College-driven practice enhancement services and programs

2. Web-based potential

3. Prescription monitoring systems

4. Academic partners

5. Provincial or regional initiatives (including provincial health ministries)

6. Multi-stakeholder initiatives (potential 'allies')

7. First Nations initiatives

8. National initiatives

Working with numerous partners, NOUGG developed national and local approaches to support implementation of the guideline to practice.

\section{2:00 PM - SESSION 102}

5

\section{USING THE ALBERTA PRIMARY CARE LOW BACK PAIN GUIDELINE IN PRACTICE}

Chair: Paul Taenzer

Speaker: Ted Findlay, DO, CCFP; Christa Harstall, MHSA

Ted Findlay, DO, CCFP, Consultant Pain Physician, Alberta Health

Services Chronic Pain Clinic, Calgary; Christa Harstall, MHSA,

Director HTA, Institute of Health Economics, Edmonton, Alberta

WORKSHOP OBJECTIVE: Over their lifetimes nearly everyone will experience at least one episode of low back pain. While low back pain is typically self-limiting and resolves in a few days to several weeks, recurrent and chronic low back pain are common and lead to frequent consultations with primary care health professionals. Undergraduate programs for most health care disciplines provide minimal training in managing back pain and practicing professionals report little confidence in their ability to manage back pain.

Clinical practice guidelines are a strategy to summarize research evidence and expert opinion to assist health care providers with clinical decision making. The Alberta Primary Care Low Back Pain Guideline was developed by a multidisciplinary team of health care providers and researchers using a standardized procedure for adapting existing guidelines to new practice settings.

The workshop will use a multidisciplinary team of facilitators to engage with participants to work through a typical primary care case of low back pain. The intention is to direct the discussion to sharing leading practices and consideration of knowledge gaps and emerging evidence.

Questions to address during the interactive workshop:

- Discuss practice domains where high quality evidence is lacking and where it is emerging

- Share strategies and challenges for implementing the guideline recommendations

Learning Objectives:

1. To understand the methodology used to develop the guideline.

2. To be aware of what constitutes the evidence underlying the guideline recommendations.

3. To apply the guideline while considering a typical primary care case.

\section{2:00 PM - SESSION 103}

\section{6}

DEVELOPING A PAIN MANAGEMENT TEAM IN PRIMARY CARE: THE CALGARY FOOTHILLS PRIMARY CARE NETWORK PAIN MANAGEMENT TEAM

Chair: Chris Spanswick

Speakers: Chris Spanswick, MB ChB; Isabel Martin, MD; Yolanda Martens-van Hilst, RN

Chris Spanswick, MB ChB, Calgary Chronic Pain Centre; Isabel Martin, MD; Yolanda Martens-van Hilst, RN; The Pain Management Team, Team Lead, Physician, Pharmacist, Behavioural Health Consultant, Physiotherapist, Kinesiologist, Dietitian, Calgary Foothills Primary Care Network, Pain Management Team, Calgary, Alberta

WORKSHOP OBJECTIVE: The aim of this workshop is to introduce the Calgary Foothills Primary Care Network (CFPCN) multidisciplinary pain management team, and discuss the challenges and successes associated with developing this team and opening a pain management clinic. The CFPCN multidisciplinary pain management team was created to support CFPCN physicians and other health care providers in the community in caring for their patients with non-complex chronic pain. The team is focused on early intervention for patients with non-complex chronic pain, to prevent deterioration and the need for such patients to utilize the Calgary Chronic Pain Centre. This is done by optimizing multidisciplinary care and use of community resources in a primary care setting.

Learning Objectives:

1. At the end of the workshop, the participant will be aware of chronic pain management, the barriers to effective treatment of patients with chronic pain, and the 
limitations in the resources currently available for the treatment of patients with non-complex chronic pain in primary care.

2. At the end of the workshop, the participant will know how to develop a multidisciplinary chronic pain team within a primary care network.

3. At the end of the workshop, the participant will know the roles of each healthcare provider in the treatment of chronic pain, and how to effectively utilize each team member to contribute to the success of the patient.

\section{A}

INTRODUCTION AND RATIONALE FOR DEVELOPMENT OF THE CALGARY FOOTHILLS PRIMARY CARE NETWORK PAIN MANAGEMENT TEAM

Chris Spanswick, MB ChB

Calgary Chronic Pain Centre, Calgary Foothills Primary Care

Network, Pain Management Team, Calgary, Alberta

BRIEF DESCRIPTION: As workshop chair, Dr. Spanswick will provide a brief overview of chronic pain management, the barriers to effective treatment of patients with chronic pain, and the limitations in the resources currently available for the treatment of patients with non-complex chronic pain in primary care. He will introduce the rationale for the development of the Calgary Foothills Primary Care Network Pain Management Team from the perspective of the Calgary Chronic Pain Centre.

\section{B}

\section{OVERVIEW OF THE CALGARY FOOTHILLS PRIMARY CARE NETWORK PAIN MANAGEMENT TEAM}

Isabel Martin, MD and Yolanda Martens-van Hilst, RN

Calgary Foothills Primary Care Network, Pain Management Team, Calgary, Alberta

BRIEF DESCRIPTION: As team lead and physician lead for the Calgary Foothills Primary Care Network (CFPCN) Pain Management Team, Yolanda and Dr. Martin will introduce the vision and mission for the Pain Management Team. The objectives for developing the pain management team were to develop a strong integrated service for patients with noncomplex chronic pain, to improve access for patients with chronic pain while offering direct support for physician and other health care providers, to optimize multi-disciplinary care for chronic pain patients, to decrease the number of non-complex patients waiting for assessment at the Calgary Chronic Pain Centre, and to develop physician and multidiscipline team chronic pain leaders throughout the CFPCN. Yolanda and Dr. Martin will also provide a description of the CFPCN Pain Management Team project and the tools for forming a multidisciplinary chronic pain team within primary care. Dr. Martin and Yolanda will also discuss the guidelines for referral to the Pain Management Team within the CFPCN.

6C

THE CALGARY FOOTHILLS PRIMARY CARE NETWORK PAIN MANAGEMENT TEAM IN ACTION

The Pain Management Team, Team Lead, Physician, Pharmacist, Behavioural Health Consultant, Physiotherapist, Kinesiologist, Dietitian

Calgary Foothills Primary Care Network, Pain Management Team,

Calgary, Alberta

BRIEF DESCRIPTION: Members of the Calgary Foothills Primary Care Network (CFPCN) Pain Management Team will introduce their roles within the team by presenting a patient case to the workshop participants. Each member will discuss their perspective in managing the patient with non-complex chronic pain, and provide examples how the team interacts to contribute to the successful management of the patient. This discussion will include information from the following team members: team lead (Yolanda), physician (Dr. Sevilla), behavioral health consultant (David), pharmacist (Lauren), physiotherapist (Tim), kinesiologist (Trevor), and dietitian (Teresa).
2:00 PM - SESSION 104

\section{7}

\section{GETTING TO THE BOTTOM OF LOW BACK AND BUTTOCK PAIN: EXAMINATION TECHNIQUES TO IMPROVE DIAGNOSTIC EVALUATION}

Chair: Pam Squire

Speakers: Pam Squire, MD, CCFP, CPE; Owen Williamson, MBBS, FRACS, FFPMANZCA

Pam Squire, MD CCFP CPE, Clinical Assistant Professor, University of British Columbia, Vancouver, British Columbia; Owen

Williamson, MBBS FRACS FFPMANZCA, Adjunct Senior Lecturer, Monash University, Melbourne, Australia

WORKSHOP OBJECTIVE: To improve examination skills in clinicians who assess patients with chronic low back and buttock pain. This session will begin with a brief didactic discussion on the reliability and validity of examination techniques for chronic back and buttock pain. This will be followed by a hands on demonstration of how to perform and interpret a time-sensitive examination. A handout will be provided as a template reminder for future exams and dictations. The examination techniques will be demonstrated by a unique interdisciplinary team consisting of an orthopedically trained spine surgeon (who also has a pain fellowship), a physical medicine and rehab specialist (who runs an interdisciplinary pain clinic), an experienced athletic therapist (who also works in the interdisciplinary pain clinic) and a family physician whose practice is restricted to chronic pain. Please dress to be examined by others in the workshop.

Learning Objectives:

1. List the differential diagnosis of a patient who presents with chronic buttock and low back pain and describe the symptoms, signs and investigations that differentiate the source of buttock and low back pain.

2. Demonstrate the surface anatomy and examination of possible sources of pain within the low back and buttock.

3. Use a pain diagram and examination techniques to determine if there is a neuropathic component to the pain.

\section{A}

\section{WHAT KIND OF PAIN IS IT?}

Pam Squire, MD, CCFP, CPE

Clinical Assistant Professor, University of British Columbia,

Vancouver, British Columbia

BRIEF DESCRIPTION: Low back and buttock pain is commonly described as non-specific when no apparent cause for the pain can be found. Traditionally non-specific pain has been conceptualised as being inflammatory or mechanical in nature, but this approach has done little to improve outcomes in patients with chronic pain. Advances in understanding the neuropathology of pain offer a new approach to the diagnosis and treatment of low back and buttock pain, with the realisation that neuropathic pain may arise locally or centrally and present in this region, or arise locally and present more distally in the lower limb. Dr Squire will discuss the diagnosis of neuropathic pain in the low back, buttock and lower limb and demonstrate examination techniques that will enable the participants to identify neuropathic components to low back and buttock pain.

\section{B}

\section{WHERE DOES IT COME FROM?}

\section{Owen Williamson, MBBS, FRACS, FFPMANZCA}

Adjunct Senior Lecturer, Monash University, Melbourne, Australia Low back and buttock pain can be difficult to treat because it is difficult to determine the source of the pain. Although low back and buttock pain is usually thought to arise from the lumbar spine, sacroiliac joints or hips, it can also arise from musculo-tendinous and neurovascular structures within the buttock itself. Dr Williamson will provide a case-based introduction to the diagnosis of buttock pain and an evidence-based approach to symptoms and signs that can differentiate causes of low back and buttock pain. He will lead a series of small group activities that will familiarise the participants with the surface anatomy of relevant low back and buttock structures and demonstrate examination techniques that will enable the participants to distinguish common causes of low back and buttock pain. 


\section{2:00 PM - SESSION 105}

8

\section{OBSERVING AND REPORTING PAIN: AN EDUCATIONAL WORKSHOP FOR FAMILY MEMBERS OF PERSONS WITH DEMENTIA}

Chair and Speaker: Cary Brown, BMR(OT), MA, PhD,

Department of Occupational Therapy, University of Alberta,

Edmonton, Alberta; Pain Awareness Award Recipient, 2010

BRIEF DESCRIPTION: This presentation will review the process of developing the Understanding Pain and Dementia workshop toolkit (a pain health literacy resource for learning about pain in persons with dementia). We will present our evaluation of the toolkit and subsequent decisions about the most appropriate knowledge translation and exchange (KTE) strategies. Findings from our review of KTE vehicles to increase awareness of the resource in relation to our target audience will also be discussed. There will be an opportunity to examine the unique learning needs of seniors (most often the caregivers of persons with dementia) and for session participants to share ideas and examples of successful KT projects with persons with dementia and their caregivers.

\section{4:15 PM - INTERPROFESSIONAL PAIN EDUCATION} AWARD PRESENTATION

\section{9}

SUBOPTIMAL PAIN EDUCATION - AN INCONVENIENT TRUTH Chair: Paul Taenzer

Speaker: Philip Peng, MBBS, FRCP(C), Director, Anesthesia Chronic Pain Program, University Health Network and Mount Sinai Hospital, Director of Research, Wasser Pain Management Center, Mount Sinai Hospital, Associate Professor, Department of Anesthesia, University of Toronto, Toronto, Ontario

\section{5:00 PM - SYMPOSIUM}

\section{0}

OPTIMIZING CHRONIC PAIN MANAGEMENT: EXPLORING EMERGING EVIDENCE ON TARGETING MULTIPLE PAIN PATHWAY AND NON-PHARMACOLOGICAL PERSPECTIVES

Chair: Ian Forster

Speakers: Perry G. Fine, MD; Roman D. Jovey, MD

Perry G. Fine, MD, Professor of Anesthesiology, Pain Research Center, School of Medicine, University of Utah, Salt Lake City, Utah, USA; Roman D. Jovey, MD, Medical Director, CPM Centre for Pain Management, Mississauga, Ontario

Learning Objectives:

Participants should be able to:

1. Understand the impact of unresolved acute pain

2. Review why moderate to severe chronic pain may be undertreated both pharmacologically and non-pharmacologically.

3. Understand that patient and physician barriers can lead to the under treatment of pain.

4. Determine if the pathophysiology of pain supports a multipathway approach.

\section{SCIENTIFIC PROGRAM DAY ONE FRIDAY MAY 14, 2010}

\author{
8:00 AM - SYMPOSIUM
}

11

MEASURING FUNCTIONALITY IN FIBROMYALGIA: WHY SHOULD WE DO IT, WHAT ARE WE MEASURING AND WHO DO WE DO IT FOR?

Chair: Pam Squire

Speakers: Pam Squire, MD, CCFP, CPE; Owen Williamson, MBBS, FRACS, FFPMANZCA; Janice Sumpton, BSc Phm; Dwight Moulin, MD Pam Squire, MD, CCFP, CPE, Clinical Assistant Professor, University of British Columbia, Vancouver, British Columbia; Owen Williamson, MBBS, FRACS, FFPMANZCA, Adjunct Senior Lecturer, Monash University, Melbourne, Australia; Janice Sumpton, BSc Phm, Pharmacist, London Health Sciences Centre, London, Ontario; Board of Directors, Canadian Pain Coalition; Fibromyalgia Patient; Dwight Moulin, Professor, Departments of Clinical Neurosciences/ Oncology, Earl Russell Chair Pain Research, University of Western Ontario; Medical Director of Pain and Symptom Management, London Regional Cancer Program, Head of the Division of Neurology, Victoria Campus, London Health Sciences Centre, London, Ontario

Learning Objectives:

At the end of this program, participants will be able to:

1. Describe why assessing a patient's function is important and how it could be done.

2. Recognize the differences between a physician and patient's perspective on the impact of Fibromyalgia on functionality and formulate explanations for when functionality reports differ between physicians and patients.

3. Implement functional assessments into the routine care of FM patients.

BRIEF DESCRIPTION: It is accepted that improved functioning is a key component of any patient with a chronic pain condition like Fibromyalgia. The challenge becomes making functional assessments a routine part of care that will optimize a patient's outcome. This symposium will address questions such as: What is functioning? Why is it important to assess functioning? What are simple, valid tools to use? How are functionality tools interpreted and how might they impact a treatment plan? A patient will also highlight the significant impact of FM on her life.

$$
\text { 9:00 AM - KEYNOTE SPEAKERS }
$$

\section{2}

\section{PAIN - CURRENT DEBATES}

Chair: Michael McGillion, RN, PhD, Assistant Professor, Lawrence S. Bloomberg Faculty of Nursing, University of Toronto, Toronto, Ontario

\section{A}

LEARNING, MEMORY AND BRAIN PLASTICITY IN CHRONIC PAIN

Herta Flor, PhD, Central Institute of Mental Health; University of Heidelberg, Mannheim, Germany

Learning Objectives:

Participants will learn that:

1. Memory and learning processes are essential for the understanding of chronic pain.

2. These memory processes lead to maladaptive plastic changes in the nervous system.

3. Treatments for chronic pain must focus on these memory and plasticity processes.

BRIEF DESCRIPTION: Recently, many similarities have been identified between chronic pain and memory processes and it has been shown that plastic alterations in the central nervous system are a frequent sequel of extended states of pain. We suggest that learning processes, specifically implicit learning such as sensitization, pavlovian and instrumental conditioning but also explicit memory processes, play a major role in the 
development and maintenance of chronic pain. A characteristic of some of these learning processes is that they occur outside the patient's awareness and are therefore difficult to detect and modify but greatly influence subsequent behavior and perception. There is convincing evidence that enhanced perceptual sensitisation as evidenced by exaggerated pain ratings is present after repetitive or longstanding painful stimulation in chronic pain patients whereas healthy controls tend to habituate. This sensitisation creates pain memory traces in the brain that upregulate the subsequent processing of both painful and non-painful stimuli. Functional magnetic resonance imaging, magnetoencephalographic recordings and multi-channel EEG recordings revealed enhanced activity in multiple brain areas that are correlated with pain ratings as well as psychological variables such as catastrophizing or affective distress. Furthermore, in neuropathic pain states such as phantom limb pain or complex regional pain syndrome alterations in the cortical map representing the pain-affected body site are closely related to pain intensity ratings. Chronic pain before nerve injury or deafferentation rather than acute pain at the time of the injury or amputation is the best predictor of later neuropathic pain confirming the notion of longlasting pain memories. Studies involving aversive pavlovian and operant conditioning paradigms revealed that central pain memories can be enhanced by these learning variables and that chronic pain patients show faster acquisition and delayed extinction of both peripheral and central pain-related responses with concurrent changes in brain areas involved in both the sensory and affective processing of pain. In this context it has been shown that the responses of and modelling by significant others have also a powerful influence on pain intensity, pain behaviours and brain-related responses to pain and that social variables must be taken into account in models of pain chronicity. These data confirm the view that learning processes may be more important for the acquisition and maintenance of chronic pain than peripheral nociceptive input. Therapeutic implications of these findings suggest that pain treatments must start early and that acute pain should be adequately controlled in order to prevent the onset of chronicity. Treatments of chronic pain should focus on the extinction of these aversive pain memories and can involve both pharmacological interventions designed to prevent or reverse maladaptive plasticity and behavioral intervention such as mirror training, imagery or sensory discrimination that behaviourally alter pain-related memory traces. The combination of substances that aid in the extinction of pain memories with extinction training might offer especially interesting new therapeutic possibilities.

\section{B}

\section{WHAT'S WRONG WITH ANIMAL MODELS OF PAIN?}

Jeffrey S. Mogil, PhD, EP, Taylor Professor of Pain Studies, Canada

Research Chair in Genetics of Pain Department of Psychology and Centre for Research on Pain, McGill University, Montreal, Quebec

Learning Objectives:

1. Appreciate the epidemiological disconnect between common human chronic pain disorders (and their symptoms) and commonly used animal models of them.

2. Learn how facial expressions of pain may be used as a new dependent measure of pain in animals.

3. Learn about recently developed animal models of migraine and vestibulodynia. BRIEF DESCRIPTION: Recent decades have seen an explosion in our understanding of the molecular and cellular underpinnings of pain, but virtually none of this knowledge has resulted in new clinical therapies. Many pain researchers believe that the problem may lie in the existing animal models of pain, which are reliable but much more complex and subtle than is commonly realized, and of questionable clinical relevance. Most basic science studies of pain continue to rely on the measurement of reflexive, evoked hypersensitivity responses after artificial neuropathic or inflammatory injuries, whereas clinical pain in humans features much spontaneous pain and an important cognitive and emotional overlay. In addition to the disconnect between clinical symptoms and animal measures, there is a disconnect between the clinical epidemiology of pain and the types of pain being modeled in animals. We have recently attempted to develop an "ethological" approach to animal models of common pain pathologies, involving systematic and rigorous analysis of videotaped spontaneous mouse behaviors. I will talk about some recent successes in our laboratory, involving migraine, vestibulodynia, and the development of a facial expression-based pain scale for the mouse.

\section{0:45 AM - PLENARY}

\section{3}

\section{UNRAVELING HUMAN COMPLEX PERSISTENT PAIN CONDITIONS}

Chair: Yoram Shir

Speaker: William Maixner, DDS, PhD

William Maixner, DDS, PhD, Kenan Distinguished Professor, Director, Centre of Neurosensory Disorders, Chapel Hill, North Carolina, USA

Learning Objectives:

1. To become knowledgeable in current concepts associated with etiological pathways associated with complex persistent pain conditions

2. To become knowledgeable in how to assess the biopsychosocial and molecular pathways that underlie heterogeneous complex persistent pain conditions.

3. To become knowledgeable of the emerging concepts and technologies that may improve the diagnosis and treatment of patients with complex persistent pain conditions.

BRIEF DESCRIPTION: Pain perception is one of the most complicated measurable traits because it is an aggregate of several phenotypes associated with peripheral and central nervous system dynamics, stress responsiveness and inflammatory state. As a complex trait, it is expected to have a polygenic nature shaped by environmental pressures. Dr. Maixner will discuss emerging concepts and knowledge of the contribution of genetic variants, including recent discoveries that emphasize a genetic contribution to human pain perception and clinical pain phenotypes $(1,2)$. He will present findings from recently completed $(3,4)$ and ongoing (see www.oppera.org) cross-sectional and prospective studies that examine the biopsychosocial and genetic factors contributing to the onset and maintenance of a common persistent pain condition that is comorbid with many other common persistent pain conditions. Finally, he will discuss emerging technologies that will prove useful in unraveling the pain genetic networks in subpopulation of patients with persistent pain conditions.

\section{REFERENCES}

1. Diatchenko, L., Nackley, A. G., Slade, G. D., Fillingim, R. B. \&

Maixner, W. Idiopathic pain disorders--pathways of vulnerability. Pain 123, 226-230 (2006).

2. Diatchenko, L., Nackley, A. G., Tchivileva, I. E., Shabalina, S. A. \& Maixner, W. Genetic architecture of human pain perception. Trends Genet. 23, 605-613 (2007).

3. Diatchenko, L. et al. Catechol-O-methyltransferase gene polymorphisms are associated with multiple pain-evoking stimuli. Pain 125, 216-224 (2006).

4. Diatchenko, L. et al. Genetic basis for individual variations in pain perception and the development of a chronic pain condition. Hum. Mol. Genet. 14, 135-143 (2005).

\section{1:30 PM - TRAINEE SESSION 201}

\section{4}

\section{SUCCESS IN SCIENTIFIC MANUSCRIPT PUBLICATION: PEARLS AND PERILS OF PUBLISHING}

Chair: Sheila O'Keefe McCarthy

Speakers: Ken Craig PhD; Christine Chambers, PhD, R Psych

Ken Craig, PhD, Editor-in-Chief, Pain Research \& Management,

Professor Emeritus, University of British Columbia, Vancouver, British Columbia, Department of Psychology, Christine Chambers, PhD R, Associate Professor of Paediatrics and Psychology, Canada Research Chair in Pain and Child Health, Dalhousie University and IWK Health Centre, Halifax, Nova Scotia

WORKSHOP OBJECTIVE: There are approximately 3000 doctoral and post doctoral students in Canada. Less than half of those are actively engaged in competitive, peer-reviewed scientific manuscript writing, a recognized benchmark of success, and still fewer who specialize in pain research. Many graduate students find it a challenge to be successful in publishing while doing course work and completing academic and scientific research. The aim of this student trainee workshop is to provide strategies how to navigate and strategize for successful manuscript publication.

\section{Learning Objectives:}

1. Provide publishing tips and strategies from a journal editor's perspective eager to see researchers' papers 
2. Discuss what mentoring a new researcher requires in order to be successful in scientific publishing

3. Provide experiental examples of successful publication from a clinical and/or basic pain scientist's perspective

4. Provide trainees a viable strategy to make writing a priority

\section{A}

Ken Craig, PhD

University of British Columbia, Vancouver, British Columbia

BRIEF DESCRIPTION: At least 50 major journals are dedicated to pain research and close to 1,000 journals publish pain-related research. They need your manuscripts and will work with you to bring scientific understanding to pain relief. But basic expectations must be met. An understanding of editors' requirements, the review process, and reviewer mandates can greatly improve the likelihood of success.

\section{B}

\section{Christine Chambers, PhD, R Psych}

IWK Health Centre and Dalhousie University, Halifax, Nova Scotia BRIEF DESCRIPTION: Dr. Chambers will provide trainees with an overview of her own experiences of navigating through the various steps of manuscript writing and publishing, and will provide strategies for how trainees can make writing a task that is often avoided and procrastinated a priority.

\section{1:30 PM - SLIDE SESSION 202}

\section{5}

\section{SLIDE SESSION}

Chair: Sandra LeFort

Speakers: Douglas Y. Shapiro, MD, PhD; Fiona A. Russell, PhD; Gregg A Tkachuk, PhD; Cory Toth, MD; Owen D Williamson, MBBS, FFPMANZCA

\section{A}

EFFICACY AND SAFETY OF TAPENTADOL PROLONGED RELEASE (PR) VERSUS OXYCODONE CONTROLLED RELEASE (CR) IN OPIOID-NAIVE AND OPIOID-EXPERIENCED PATIENTS WITH CHRONIC PAIN ASSOCIATED WITH OSTEOARTHRITIS OF THE KNEE

Mila Etropolski, MD, Johnson \& Johnson Pharmaceutical Research \& Development, L.L.C., New Jersey, USA; Bernd Lange, MD, MSc, Global Development, Grünenthal $\mathrm{GmbH}$, Aachen, Germany; Brigitte Kuperwasser, MD, MPH; Kathleen Kelly, MD, FACS, FCCM; Akiko Okamoto, ScD, Johnson \& Johnson Pharmaceutical Research \& Development, L.L.C., New Jersey, USA; Achim Steup, Dipl. Stat., Global Development, Grünenthal $\mathrm{GmbH}$, Aachen, Germany; Ilse Van Hove, MSc, Johnson \& Johnson Pharmaceutical Research \& Development, Division of Janssen Pharmaceutica, N.V., Beerse, Belgium; Horst Weber, MD, PhD, Global Development, Grünenthal $\mathrm{GmbH}$, Aachen, Germany; Jürgen Häussler, MD, Johnson \& Johnson Pharmaceutical Research \& Development, L.L.C.; Douglas Y. Shapiro, MD, PhD, Director, Neuroscience, Johnson \& Johnson Pharmaceutical Research \& Development, L.L.C., New Jersey, USA AIM: Tapentadol is a $\mu$-opioid receptor agonist and noradrenaline reuptake inhibitor. This analysis characterized the efficacy and safety of tapentadol PR by prior opioid experience in patients with moderate-to-severe chronic osteoarthritis knee pain (ClinicalTrials.gov Identifier: NCT00421928).

METHODS: Randomized patients received controlled, adjustable twicedaily doses of tapentadol PR (100-250mg), oxycodone HCl CR (20-50mg), or placebo during a 12-week maintenance period following a 3-week titration period. Patients were categorized by prior opioid use during the 3 months before screening. Change from baseline in average pain intensity was assessed (11-point NRS) over the maintenance period. Post-discontinuation pain measurements were imputed using last observation carried forward.

RESULTS: Opioid-naive patients represented $67.6 \%$ of the intent-to-treat population $(n=1,023)$. The least-squares mean difference (LSMD [SEM]) for the change from baseline in average pain intensity over the maintenance period for opioid-naive patients was statistically superior to placebo with tapentadol PR $(-0.7[0.21] ; P=0.001)$ but not with oxycodone CR $(-0.3$ [0.21]; $P=0.139$ ). Results were similar for opioid-experienced patients (tapentadol PR vs placebo: -0.8 [0.32], $P=0.014$; oxycodone $C R$ vs placebo: -0.5 [0.32], $P=0.101$ ). The incidences of overall TEAEs were lower with tapentadol PR than oxycodone $\mathrm{CR}$, regardless of previous opioid experience (opioid-naive: placebo, $61.0 \%$; tapentadol PR, $79.6 \%$; oxycodone CR, $87.2 \%$; opioidexperienced: placebo, $61.4 \%$; tapentadol PR, $67.9 \%$; oxycodone CR, $88.0 \%$ ); similar results were observed for gastrointestinal-related TEAEs (opioid-naive: placebo, 25.6\%; tapentadol PR, 47.7\%; oxycodone CR, 67.5\%; opioidexperienced: placebo, $27.2 \%$; tapentadol PR, $33.0 \%$; oxycodone CR, $66.7 \%$ ). CONCLUSIONS: Tapentadol PR (100-250mg bid) provides effective analgesia with better tolerability than oxycodone $\mathrm{HCl}$ CR (20-50 mg bid), regardless of prior opioid experience.

\section{B}

PROTEINASE ACTIVATED RECEPTOR-4 (PAR4) ACTIVATION IS PRO-NOCICEPTIVE IN RAT KNEE JOINTS VIA A MAST CELL DEPENDENT PATHWAY

Fiona A Russell, PhD; Shu Zhan, PhD; Jason J McDougall, PhD, University of Calgary, Calgary, Alberta

AIM: This study examined whether synovial mast cells are involved in proteinase activated receptor-4 (PAR4)-induced pain behaviour and primary afferent nerve sensitisation in rat knees.

METHODS: Mechanical allodynic thresholds were determined using a dynamic planter aesthesiometer and weight bearing was used as a measure of hindlimb incapacitance in male Wistar rats. Measurements were taken 0-240 minutes after i.art injection of the PAR4 activating peptide, AYPGKF-NH2, or inactive peptide, YAPGKF-NH2 (100 mg). Rats were either naive or pre-treated with the mast cell stabiliser, cromolyn $(20 \mathrm{mg} / \mathrm{kg}$ s.c around the knee joint 5 minutes pre-drug administration). In separate experiments, electrophysiological recordings were made from knee joint primary afferents in rats during normal and noxious joint rotations. Afferent firing rate was recorded during 10 second rotations for 15 minutes post close intra-arterial injection of 10-9 - 10-5 mol of AYPGKF-NH2 (100 $\mu \mathrm{l}$ bolus). Rats were either naive or pre-treated with cromolyn $(20 \mathrm{mg} / \mathrm{kg}$ via saphenous arterial cannulation 5 minutes prior to AYPGKF-NH2 administration). Results were expressed as \% change in firing rate compared to baseline and analysed using 2-way ANOVA and Bonferroni post-tests; $\mathrm{P}<0.05$ was considered significant.

RESULTS: AYPGKF-NH2 caused significant reduction in paw withdrawal threshold and ipsilateral weight bearing over 180 minutes $(\mathrm{P}<0.05) \mathrm{com}$ pared to control treatment (YAPGKF-NH2). These pain responses were inhibited by cromolyn pre-treatment. Cromolyn also attenuated AYPGKF$\mathrm{NH} 2$-induced increase in joint afferent firing rate.

CONCLUSIONS: This data reveal that in normal rat knee joints PAR4 activation leads to primary afferent sensitisation and a heightened pain behavioural response which is mast cell dependent.

\section{C}

CONFIRMATORY FACTOR ANALYTIC EVIDENCE THAT THE TAMPA SCALE FOR KINESIOPHOBIA (TSK-11) MEASURES A SINGULAR, SECOND-ORDER LATENT CONSTRUCT - FEAR OF MOVEMENT/(RE)INJURY

Gregg A Tkachuk, Ph.D., Dept. of Clinical Health Psychology, Faculty of Medicine, University of Manitoba, Winnipeg, Manitoba; Pan Am Pain Clinic; Cheryl A Harris, Ph.D., Psychosocial Oncology Program, The Ottawa Hospital Cancer Centre, Ottawa, Ontario

AIM: To demonstrate that the TSK-11 represents a singular, second-order latent construct - fear of movement/(re)injury, within a hierarchical factorial structure that includes two first-order factors. To demonstrate that the TSK-11 scales are internally consistent and valid measures of this construct. METHODS: Two hundred seventy-six individuals with chronic pain $(65 \%$ women; average age 47.76 years; average pain duration 8.50 years) completed the original English version of the TSK-13 and other study measures. Confirmatory factor analytic techniques and exploratory post-hoc model fitting were used to establish the best fitting TSK model (i.e., 13, 12, or 11-items). A second-order model was then tested. Measures of internal consistency included item-total correlations and Cronbach's $\alpha$. Construct, concurrent, and predictive validity were assessed using correlational and hierarchical regression analyses. 
RESULTS: The TSK 11-item model best supported the conceptualization of fear of movement/(re)injury as a singular latent construct, within a hierarchical factor structure consisting of two inter-related but independent first-order factors - somatic focus and activity avoidance. The TSK-11 scales are internally consistent. Expected associations between the TSK-11 scales and other measures provided evidence of validity, after controlling for pain severity, age, and gender.

CONCLUSIONS: These results provide the first evidence that it is appropriate for clinicians and researchers to compute total and/or subscales scores for the TSK-11. They also provide further evidence that this brief measure allows for more parsimony in the measurement of this construct. Further research is required to replicate and extend this finding across gender and other demographic samples.

\section{D}

\section{CANNABINOID-MEDIATED MODULATION OF NEUROPATHIC PAIN AND MICROGLIAL ACCUMULATION IN A MODEL OF MURINE TYPE I DIABETIC PERIPHERAL NEUROPATHIC PAIN}

Cory Toth, MD; Nicole Pradzinsky, N/A; Connie Ellis, N/A, University of Calgary, Calgary, Alberta; William H. Frey II, PhD, University of Minnesota

AIM: Despite the frequency of diabetes mellitus and its relationship to diabetic peripheral neuropathy (DPN) and neuropathic pain $(\mathrm{NeP})$, our understanding of underlying mechanisms leading to chronic pain in diabetes remains poor. Recent evidence has demonstated a prominent role of microglial cells in neuropathic pain states. One potential therapeutic option gaining clinical acceptance is the cannabinoids, for which cannabinoid receptors $(\mathrm{CB})$ are expressed on neurons and microglia. We sought to examine the role of $\mathrm{CB}$ receptors in the facilitation of pain.

METHODS: We studied the accumulation and activation of spinal and thalamic microglia in streptozotocin (STZ)-diabetic CD1 mice and the impact of cannabinoid receptor agonism/antagonism during the development of a chronic $\mathrm{NeP}$ state. We provided either intranasal or intraperitoneal cannabinoid agonists/antagonists at multiple doses both at the initiation of diabetes as well as after establishment of diabetes and its related $\mathrm{NeP}$ state.

RESULTS: Tactile allodynia and thermal hypersensitivity were observed over 8 months in diabetic mice without intervention. Microglial density increases were seen in the dorsal spinal cord and in thalamic nuclei and were accompanied by elevation of phosphorylated p38 MAPK, a marker of microglial activation. When initiated coincidentally with diabetes, moderate-high doses of intranasal cannabidiol (cannaboid receptor 2 agonist) and intraperitoneal cannabidiol attenuated the development of an $\mathrm{NeP}$ state, even after their discontinuation and without modification of the diabetic state. Cannabidiol was also associated with restriction in elevation of microglial density in the dorsal spinal cord and elevation in phosphorylated p38 MAPK. When initiated in an established DPN NeP state, both CB1 and CB2 agonists demonstrated an antinociceptive effect until their discontinuation. There were no pronociceptive effects demonstated for either CB1 or CB2 antagonists.

CONCLUSIONS: The prevention of microglial accumulation and activation in the dorsal spinal cord was associated with limited development of a neuropathic pain state. Cannabinoids demonstrated antinociceptive effects in this mouse model of DPN. These results suggest that such interventions may also benefit humans with DPN, and their early introduction may also modify the development of the $\mathrm{NeP}$ state.

\section{E}

\section{PSYCHOLOGICAL FACTORS ASSOCIATED WITH PAIN TRAJECTORIES FOLLOWING TRAUMA}

Owen D Williamson, MBBS FFPMANZCA, Department of Epidemiology and Preventive Medicine, Monash University; Alex Holmes, PhD FRANZCP, Department of Psychiatry, University of Melbourne; Malcolm Hogg, MBBS FFPMANZCA, Pain Service, Royal Melbourne Hospital, Parkville; Carolyn Arnold, MBBS FFPMANZCA, Caulfield Pain Management and Research Centre, Caulfield; Amy Prosser, BA (Hons), Department of Psychiatry, University of Melbourne, Parkville; Jackie Clements, BBSc, Grad Dip App Ch Psych, Department of Psychiatry, University of Melbourne, Parkville; Alex Konstantatos, MBBS FFPMANZCA, Acute Pain Service, Alfred Hospital, Melbourne; Meagan L O'Donnell, PhD, Australian Centre for Post Traumatic Mental Health, University of Melbourne, Parkville, Australia

AIM: This aim of this study was to identify time-related pain trajectories and associated psychological factors in a trauma population.

METHODS: Patients with any injury of AIS severity $\geq 2$, but no significant head injury, were recruited from Level 1 trauma centers in Melbourne, Australia. Patients were assessed within 15 days and at 3 and 12 months post-injury. Average pain over 24 hours was assessed using an 11-point scale. Pain score changes were used to categorize patients into nine trajectories (deteriorated, unchanged or improved combined with time intervals baseline to 3 months and 3 to 12 months). The Hospital Anxiety and Depression Scale, Survey of Pain Attitudes and Pain Catastrophizing Scales were administered. Factors associated with changes in pain scores were identified using logistic regression.

RESULTS: 204 patients were assessed (males $74.5 \%$, median age 40 years (range 18-67 years), major trauma (ISS $>15$ ) 27.5\%). Median (interquartile range) pain scores at baseline, 3 and 12 months respectively were 3 (2-6), $2(1-3)$ and $2(0-3)$. Although overall pain scores improved from baseline to 3 months $(\mathrm{p}<0.001)$ and did not change from 3 to 12 months $(\mathrm{p}=0.68)$, pain scores deteriorated by $\geq 2$ points in $12.3 \%$ and improved by $\geq 2$ points in $23.5 \%$ of patients from 3 to 12 months. Deterioration was associated with increased catastrophizing $(\mathrm{p}=0.003)$ and decreased pain control $(\mathrm{p}=0.022)$ but not changes in anxiety or depression.

CONCLUSIONS: Individual pain trajectories, associated with differing psychological responses to pain, can be identified within a trauma population. Further studies of individual trajectories might lead to improvements in population pain outcomes.

\section{1:30 PM - SESSION 203}

\section{6}

\section{LIKE NAILING JELL-O TO A TREE: ACUTE PAIN MANAGEMENT IN DIFFICULT CIRCUMSTANCES}

Chair: Saifee Rashiq

Speakers: Kathryn Dong, MD FRCPC; Yoanna Skrobik, MD FRCPC; Saifee Rashiq, MB MSc FRCPC

Kathryn Dong, MD FRCPC, Department of Emergency Medicine, University of Alberta, Edmonton, Alberta; Yoanna Skrobik, MD

FRCPC, Department of Medicine, Universite de Montreal, Montreal, Quebec; Saifee Rashiq, MB MSc FRCPC, Department of

Anesthesiology \& Pain Medicine, University of Alberta, Edmonton, Alberta

WORKSHOP OBJECTIVE: This interactive session is about circumstances in which the act of relieving acute pain is made difficult or impossible by factors other than a lack of technical know-how. What happens when you have to choose between being effective, correct, practical, ethical, expedient and safe? Hear front-line clinicians tell you how they do it, and how they'd like to see it done better. Bring a story and an opinion!

Learning Objectives:

1. After participating in this session, participants will better understand the principles of pain control in illegal substance users/those who appear to be "drugseeking" in the ED.

2. After participating in this session, participants will be able to assess and manage pain in a sedated ICU patient with confidence. 
3. After participating in this session, participants will be challenged to think of ways in which evidence based techniques can be deployed in their own institutions to make acute pain management better.

\section{$16 \mathrm{~A}$}

PAIN, SUSPICION AND SUBSTANCE ABUSE IN THE ED

\section{Kathryn Dong, MD FRCPC}

Department of Emergency Medicine, University of Alberta,

Edmonton, Alberta

BRIEF DESCRIPTION: "Morphine 2.5 - 5 mg IV prn \& Gravol 25-50 mg IV q4h prn" are the most commonly written emergency department orders for pain control. What happens, though, if your patient commonly injects him or herself with $100 \mathrm{mg}$ (or a "grey") of morphine at a time? Most commonly this leads to conflict between the physician or nurse and the patient who is constantly asking for more analgesia. The ultimate outcome is likely to be poor pain control for the patient, possible withdrawal, and a future reluctance to present for medical care when it is needed.

\section{B}

\section{TO SLEEP, PERCHANCE TO SCREAM...}

\section{Yoanna Skrobik, MD FRCPC}

Department of Medicine, Universite de Montreal, Montreal, Quebec BRIEF DESCRIPTION: Effective pain management in the ICU is not merely humane. In this session, evidence that adequate analgesia actually improves survivor outcome will be presented. Effective ways to assess pain in the sedated ICU patient will be described, and original Canadian research data will be used to show that simple changes in culture can yield big improvements in pain-related care.

\section{$16 \mathrm{C}$}

\section{IS THERE A BETTER WAY?}

\section{Saifee Rashiq, MB MSc FRCPC}

Department of Anesthesiology \& Pain Medicine, University of Alberta, Edmonton, Alberta

BRIEF DESCRIPTION: Shortcomings in acute pain management are not difficult to identify. While providers and patients alike all want the situation to improve, the barriers to providing universally acceptable care seem insurmountable. Can we change the way we do business to make this an achievable goal?

\section{3:00 PM - MODERATED POSTER SESSION 204}

\section{7}

\section{MODERATED POSTER SESSION}

Chair: Katherine Harman

Speakers: A. Clark, MD; Kimberley Allen, MN, PhD Student; Ruth E. Dubin, PhD, MD, FCCP

\section{A}

\section{THE CALGARY CHRONIC PAIN IN-PATIENT CONSULTATION} SERVICE: THE FIRST THREE YEARS

A Clark, MD; P Taenzer, PhD; J Boyd, MSN; C Spanswick, MB ChB; M Reyes, MN; R Hanis, MN; L Montgomery, MD; S Chary, MB BS; N Reddy, MB ChB; N Dike, MD; G Schultz, PhD; A Bezuidenhout, BA, Calgary Chronic Pain Centre, Alberta Health Services, Calgary, Alberta

AIM: To review the growth and to evaluate the impact of an in-patient consult service for patients with complex chronic pain staffed by advanced practice nurses and physicians. The service provides consultation and advice rather than direct provision of care.

METHODS: A database was established to collect information concerning the numbers of consultations performed, the frequency of follow-up visits and to capture clinical outcome measures.

RESULTS: The service was established in the first quarter of 2006 at one acute care hospital in Calgary and expanded to all three acute care hospitals by January 2007 to provide advice about the management of chronic pain. Consultations per quarter increased from 105 in 2007 to 178 in 2009, similarly visits increased from 330 to 661 per quarter. Worst pain intensity $(\mathrm{N}=213)$ before and after consultation in 2007 was $8.4 / 5.5$ and in 2009 was
8.9/6.5 (VAS Scale $0-10)$ with average pain intensity $(\mathrm{N}=212)$ being 6.7/3.9 and 6.7/4.2 respectively. Patient perception of improvement ( $\mathrm{N}=216)$ was "very much improved" in $7 \% / 10 \%$, "much improved" in $60 \% / 53 \%$, "minimally improved" in 31\%/31\% and "no change" in 2\%/7\% respectively for 2007 and 2009.

CONCLUSIONS: The chronic pain consult service has shown a steady increase in number of consultations since its inception and appears to have improved the management of the in-hospital complex chronic pain population. We conclude this consultative model has merit in this health care setting.

\section{B}

\section{A SYSTEMATIC REVIEW EVALUATING INTERVENTIONS FOR TREATING PAINFUL NIPPLES AMONG BREASTFEEDING WOMEN}

Cindy-Lee Dennis, PhD; Kimberley Allen, MN, PhD Student,

Lawrence S. Bloomberg Faculty of Nursing, University of Toronto; Felicia M McCormick, MSc; Mary J Renfrew, PhD, York University, Toronto, Ontario

AIM: There are various treatment interventions for the reduction of nipple pain associated with breastfeeding. However, it remains unclear which intervention most effectively resolves or reduces nipple pain. The aim of the systematic review was to identify the effects of all interventions used for the elimination or reduction of nipple pain, and to evaluate the impact of the interventions on breastfeeding exclusivity and duration rates.

METHODS: All randomized and quasi-randomized controlled trials were identified by searching the Cochrane Register of Controlled Trials, MEDLINE, EMBASE, CINAHL and hand searches. Participants were breastfeeding women with variously defined nipple pain. Interventions included pharmacologic and non-pharmacologic interventions (oral and topical), dressings, nipple protection, and expressed breast milk. Trials were independently reviewed by two authors. Data was extracted and entered into Review Manager software (RevMan 2008). Statistical analysis was conducted using RevMan 2008 using fixed-effect meta-analysis for combining data. Where there was significant heterogeneity or when pooling results from studies with different interventions, random-effects meta-analysis was utilized.

RESULTS: Three trials were included in the systematic review, including 469 women from three different countries. Significant heterogeneity and diverse interventions prevented pooling of review data. No significant differences in nipple pain were found for the following comparisons: glycerin gel with breastfeeding correction and education ( 1 trial, $\mathrm{n}=63$; weighted mean difference $(\mathrm{WMD})=0.22,95 \%$ confidence interval $(\mathrm{CI})-0.32$ to 0.76 ); breast shells and lanolin versus no intervention ( 1 trial, $\mathrm{n}=61$; $\mathrm{WMD}=-0.20,95 \% \mathrm{CI}-0.60$ to 0.20$)$; glycerin gel dressing versus breast shells and lanolin ( 1 trial, $\mathrm{n}=64$; WMD $=0.42,95 \% \mathrm{CI}-0.09$ to 0.93 ); expressed breast milk versus no intervention ( 1 trial, $\mathrm{n}=151$; study days $1-3, \mathrm{RR}=0.96,95 \% \mathrm{CI} 0.90$ to 1.03 ; study days $4-5, \mathrm{RR}=1.17,95 \% \mathrm{CI}$ 0.71 to 1.92 ; study days $6-7, \mathrm{RR}=0.62,95 \% \mathrm{CI} 0.11$ to 3.63 ). A significant decrease in pain scores was found for women using no intervention versus lanolin at 4 to 5 days post-treatment ( 1 trial, $\mathrm{n}=147$; $\mathrm{RR}=1.82,95 \% \mathrm{CI}$ 1.18 to 2.83 ), however, this significant difference was not seen at 1 to 3 , or 6 to 7 days post-treatment. When comparing lanolin to expressed breast milk, there were no differences in pain scores after 1 to 3 or 6 to 7 days posttreatment, yet there was a significant decrease in pain for the EBM group at 4 to 5 days post-treatment ( 1 trial, $\mathrm{n}=152, \mathrm{RR}=1.56,95 \% \mathrm{CI} 1.05$ to 2.32). Pain scores were significantly lower for women treated with an allpurpose nipple cream compared with lanolin ( 1 trial, $\mathrm{n}=150$; WMD = 2.51, 95\% CI 0.60 to 4.41) when measured with the McGill Pain Questionnaire. Significant differences were not found using two other pain measures.

CONCLUSIONS: There is insufficient evidence to support the use of any intervention for the treatment of nipple pain among breastfeeding women. There is preliminary evidence to support further research on the role of expressed breast milk on the reduction of nipple pain. To improve comparability of future research, standardized measurement of nipple pain is required. 
17C

STOP THIS RIDE I WANT TO GET OFF! THE CHRONIC PAIN ROLLER-COASTER: FUELED BY STRESS AND CONFLICT

Ruth E. Dubin, Ph.D, MD, FCCP, Kingston Family Health Team and Assistant Professor, Department of Family Medicine; Cheryl King Van Vlack, Ph.D, Department of Rehabilitation Medicine, Queen's University, Kingston, Ontario

AIM: Four case studies spanning 6-22 years in a family practice illustrate "pain" visits over the long term and common themes of mood disruption, conflict, and financial stress. Medical, insurance and legal system changes to derail this pattern are suggested.

METHODS: All visits (family MD, consultants, emergency or after-hours clinics) were tabulated to build a chronological graph of patients' healthcare utilization (1). Discussions about medication side-effects or doses, mood disruption (depression, anxiety, insomnia), financial stressors, and conflict with employers, insurers or lawyers, were graphed. Each patient reviewed their history and commented on how they had coped with their experience.

RESULTS: Healthcare utilization patterns resembled a roller-coaster ride with increased visits at times of stressful life events, financial insecurity and mood disorders. Healthcare utilization fell when major conflicts (lawsuits, acceptance of disability) were resolved and some financial stability was achieved.

CONCLUSIONS: Physicians, insurers, lawyers and employers may be contributing to patients' pain and disability by adopting a disbelieving and confrontational approach that is absent in patients suffering other more "visible" disabilities. Better training of physicians in understanding chronic pain as a valid medical condition, teaching patients how to manage stress using self-education, mind-body or psychological therapies may help. However widespread changes to insurance and legal systems might avoid this destructive ride.

FOOTNOTES/REFERENCES:

1. Dubin RE and C King-VanVlack 2009. The Trajectory of chronic pain: can a community-based exercise/educations program soften the ride.

Pain Res Manage: in press.

\section{4:00 PM - HOT TOPICS IN PAIN RESEARCH}

\section{8}

\section{STUDENT PRESENTATIONS}

Chair: Dean Tripp

Speakers: Marta Ceko, MSc; Valerie Cotton, BSc [in progress]; Samantha Fuss, BA; Adam Samosh, BMSc, Meds III; Sarah Walker, MSc

\section{A}

\section{INVESTIGATION OF CONFOUNDS IN HUMAN DNIC STUDIES}

Marta Ceko, MSc; Marissa Lapedis; M Catherine Bushnell, PhD; Petra Schweinhardt, MD PhD, The Alan Edwards Centre for Research on Pain, McGill University, Montreal, Quebec

AIM: Diffuse noxious inhibitory control (DNIC), i.e. pain inhibits pain, is a well described phenomenon in animals. DNIC is commonly tested in humans by applying a test stimulus before (TS1) and during or after (TS2) a painful conditioning stimulus (CS). If TS2 is perceived as less painful than TS1, DNIC is thought to have occurred. Testing DNIC during the CS, however, is problematic because TS2 might be perceived as less painful due to distraction caused by the painful CS. Therefore, TS2 is sometimes applied after the CS, but none of these studies employed a control condition with a non-painful CS. We aimed at comparing DNIC in an experimental and a control condition.

METHODS: Subjects: 13 women (age 21-63, mean+/-SD: 43+/-13.6).

Design: Within-subject, counter-balanced crossover. TS1: 9 short stimuli (44, 46, $48^{\circ} \mathrm{C}$; $3 \mathrm{x}$ each) on the forearm (3 loci, pseudorandomized). CS: Immersion of contralateral arm in $10^{\circ} \mathrm{C}$ (experimental condition) or $32^{\circ} \mathrm{C}$ water (control condition). TS2: Applied $1 \mathrm{~min}$ after the CS. Pain ratings: $0-200$.

RESULTS: Compared to TS1, TS2 was rated as significantly less painful in the experimental $\left(46^{\circ} \mathrm{C}: \mathrm{p}=0.04 ; 48^{\circ} \mathrm{C}: \mathrm{p}=0.04\right)$ as well as in the control condition $\left(46^{\circ} \mathrm{C}: \mathrm{p}=0.02 ; 48^{\circ} \mathrm{C}: \mathrm{p}=0.02\right)$. Importantly, the change in pain ratings did not differ between conditions $\left(46^{\circ} \mathrm{C}\right.$ : $\left.\mathrm{p}=0.97 ; 48^{\circ} \mathrm{C}: \mathrm{p}=0.69\right)$. CONCLUSIONS: While replicating several human DNIC studies, i.e. painful CS reduces subsequent pain, we found a similar pain reduction after a non-painful CS. This raises the question whether the observed reduction is driven by DNIC. Novel, well-controlled paradigms are needed to demonstrate DNIC in humans.

\section{B}

\section{THE IMPACT OF LONG-TERM YOGA PRACTICE ON EXPERIMENTAL PAIN PERCEPTION}

Valerie Cotton, BSc [in progress], McGill University; Chantal Villemure, Ph.D.; M.C. Bushnell, Ph.D., Alan Edwards Centre for Research on Pain, McGill University, Montreal, Quebec

AIM: Yoga practice integrates physical discipline, mental training and moral principles to encourage a healthy and holistic way of living. The emotional and cognitive tools developed in yoga practice could potentially alter a person's relationship with pain, particularly their affective reaction to pain. In this study, we test the hypothesis that regular yoga practice alters the affective reaction to pain.

METHODS: We evaluated the pain perception of nine yoga practitioners, who had been practicing regularly for at least six years, and eight sedentary control subjects. Subjects were matched for Body Mass Index, exercise hours per week, education, age and sex. Cool and warm detection thresholds and cold and heat pain thresholds were evaluated using a TSA Medoc contact thermode and the method of limits ( 3 trials per measure). Pain tolerance was tested twice by asking subjects to submerge their hand in a cold circulating water bath $\left(\sim 5^{\circ} \mathrm{C}\right)$ for as long as they could, up to a maximum of two minutes. The geometric means of each variable were calculated for each group and submitted to ANOVAs.

RESULTS: The yoga and control group significantly differed only in terms of their tolerance to pain (for thresholds all p's $>0.16$ ). The yoga group kept their hand in the cold water more than three times as long as the controls $($ Mean \pm SE: Yoga $=87 \mathrm{~s} \pm 10$; Control $=25 \mathrm{~s} \pm 11 ; \mathrm{F}(1,15)=17.4 ; \mathrm{p}<0.0009)$.

CONCLUSIONS: The equivalent thresholds and increased pain tolerance found in yoga practitioners confirms that regular yoga practice influences affective reaction to pain.

\section{$18 \mathrm{C}$}

\section{PREVALENCE AND FREQUENCY CHARACTERISTICS OF PAIN IN A COMMUNITY SAMPLE OF CHILDREN AND ADOLESCENTS}

Samantha Fuss, BA; Gabrielle Pagé, MA; Andrea Martin, MA; Sarah Ritvo, BA; Suzy Malakhi, BSW; Joel Katz, Ph D., York University, Toronto, Ontario

AIM: Previous epidemiological research conducted in Europe has demonstrated that approximately $25-30 \%$ of children and adolescents have experienced persistent pain $[1,2]$. Very little is known about the incidence of persistent pain among Canadian youth.

The purpose of this study was to ascertain the prevalence and frequency characteristics of pain in a Canadian community sample of children and adolescents between the ages of 8-18.

METHODS: English-speaking individuals were recruited to participate in this study which took place at the Ontario Science Centre (Toronto, Canada). Participants completed a pain history questionnaire created for this project that assessed chronicity and frequency of pain experiences.

RESULTS: Of 1006 participants (54\% female) with a mean age of 11.2 years $(\mathrm{SD}=2.69), 27.6 \%$ reported having pain that lasted for longer than three months. In terms of frequency of reported pain, $18.6 \%$ experienced no pain, $29.1 \%$ experienced pain less often than once a month, $27.4 \%$ experienced pain once or twice a month, $19 \%$ experienced pain once or twice a week and $5.8 \%$ experienced pain everyday.

CONCLUSIONS: The prevalence of persistent pain in the present sample is consistent with previous research. A sizeable proportion of children and adolescents report experiencing pain on a weekly basis.

FOOTNOTES/REFERENCES:

1. Perquin, C.W., et al., Pain in children and adolescents: a common experience. Pain, 2000. 87(1): p. 51-58.

2. Roth-Isigkeit, A., et al., Pain Among Children and Adolescents: Restrictions in Daily Living and Triggering Factors. Pediatrics, 2005. 115(2): p. e152-162. 
18D

\section{SAFETY OF INTRAVENOUS LIDOCAINE INFUSIONS FOR TREATMENT OF CHRONIC NEUROPATHIC PAIN}

Adam Samosh, BMSc, Meds III, Schulich School of Medicine;

Patricia K. Morley-Forster, MD, FRCPC, Department of

Anesthesiology \& Perioperative Medicine; Dwight E. Moulin, MD,

FRCPC, Department of Neurology; Katherine Ower, MD, FRCPC,

Department of Anesthesiology \& Perioperative Medicine; James T.

Watson, MD, FRCPC, Department of Anesthesiology \& Perioperative

Medicine, University of Western Ontario, London, Ontario

AIM: The purpose of this study was to determine the frequency of side effects in adult outpatients receiving an intravenous infusion of lidocaine for treatment of chronic neuropathic pain. This is the first prospective examination of hemodynamic and central nervous system (CNS) side effects.

METHODS: All ambulatory patients scheduled for a lidocaine infusion between June 15 and August 21, 2009 at the St. Joseph's Outpatient Pain Clinic were included in this prospective study $(n=46)$. The dose used was $5 \mathrm{mg}$ per $\mathrm{kg}$ of lean body weight determined from their height and weight using the James formula infused over 45 minutes. The infusion was controlled by Alaris Medical system. Monitoring included oximetry, non-invasive blood pressure, and ECG recorded at baseline and Q 5 minutes until 30 minutes post-infusion. Sedation, nausea and dizziness were solicited and measured by VAS from 0-100 mm Q 15 minutes. All other reported side effects were measured Q 15 minutes. Cardiac, CNS, and hemodynamic adverse events were defined and recorded. Observation was continued for 30 minutes postinfusion including presence of postural hypotension. Patients were asked to record in a diary any side effects up to 7 days following infusion.

RESULTS: Mean dose of lidocaine administered was $268 \pm 59 \mathrm{mg}$; mean age was $51.5 \pm 13.6 \mathrm{yrs}$. Most common side effects during the infusion were sedation $(72 \%)$, nausea $(22 \%)$, mild to moderate dizziness $(39 \%)$ and dry mouth $(28 \%)$. Intensity of sedation increased significantly as the infusion progressed. No significant adverse events occurred. Fatigue was experienced during post-infusion week in $22 \%$ of subjects.

CONCLUSIONS: Lidocaine infusions of $5 \mathrm{mg} / \mathrm{kg}$ are safe and well tolerated in this outpatient population.

FOOTNOTES/REFERENCES:

1. http://www.halls.md/body-mass-index/leanbody.htm.

$18 \mathrm{E}$

THE ASSOCIATION BETWEEN PSYCHOLOGICAL CHARACTERISTICS AND PAIN IN WOMEN WAITING FOR GYNAECOLOGICAL SURGERY

Sarah Walker, MSc, Queen's University; Wilma M. Hopman, MA, Faculty, Department of Community Health and Epidemiology; Margaret B. Harrison, RN, PhD, Professor, School of Nursing; Elizabeth G. VanDenkerkhof, RN, DrPH, Associate Professor School of Nursing \& Department of Anesthesiology, Queen's University, Kingston, Ontario

AIM: Pain prior to surgical management is frequently a problem for women with gynaecological conditions. Psychological factors also influence an individual's experience of pain. Minimal research was found that examined pain and psychological symptoms in this population. The primary objective was to examine levels of pain intensity and pain interference in women awaiting gynaecological surgery, and secondarily to examine psychological factors associated with pain, specifically anxiety, depression, somatization and catastrophizing.

METHODS: Participants included 429 women in a tertiary care centre in southeastern Ontario. Anxiety was measured using the State Trait Anxiety Inventory (STAI), depression with the Centre for Epidemiologic Studies Depression Scale (CES-D), somatization using the Seven Symptom Screening Test (SSST) and catastrophizing was measured using an abbreviated coping strategies questionnaire (CSQ). Pain was assessed using the Brief Pain Inventory (BPI).

RESULTS: Eighteen percent of women had a high anxiety score, $37.1 \%$ demonstrated a risk of depression needing treatment, $46.6 \%$ of women had $\geq 2$ symptoms of somatization and $40.1 \%$ of women were high catastrophizers. A moderate to severe pain intensity score occurred in $30.5 \%$ of participants and $31.5 \%$ had a moderate to severe pain interference score. Of the women that experienced pain in the last week, $81.4 \%$ believed their pain was due to their primary condition. In multivariable analysis, depression, somatization and catastrophizing were all associated with elevated levels of pain intensity and interference; younger age was associated with interference but not intensity.

CONCLUSIONS: This study supports the need for appropriate preoperative assessment of physical and psychological symptoms that present while waiting for surgery. This assessment will benefit the patient through reducing complications and improve patient outcomes.

\section{4:00 PM - SESSION 205}

\section{9}

\section{THE IMPACT OF STEREOTYPES AND STIGMA ON THE} ASSESSMENT AND TREATMENT OF PATIENTS WITH PAIN

Chair: Diane LaChapelle

Speakers: Susan Lavoie, BA, PhD Candidate; Bruce Dick, PhD

Susan Lavoie, BA, PhD Candidate, Dept of Psychology, University of

New Brunswick, Fredericton, New Brunswick; Bruce Dick, PhD,

Associate Professor, Dept of Anesthesiology and Pain Medicine, University of Alberta; Pediatric Chronic Pain Program, Stollery

Children's Hospital, Edmonton, Alberta

WORKSHOP OBJECTIVE: To present data from laboratory and clinical studies relating to how stereotypes and stigma influence perceptions of patients with pain and, in turn, how these perceptions influence the assessment and treatment of patients. The goal is to increase awareness of how unconscious biases may influence clinical practice and to provide strategies for reducing the impact of stereotypes and stigma.

Learning Objectives:

Participants will be able to identify:

1. The most commonly held stereotypes about patients with pain

2. How stereotypes influence assessment and treatment decisions

3. Strategies to reduce the potential impact of stereotypes and stigma in clinical practice

\section{A}

\section{COMMONLY HELD STEREOTYPES ABOUT ADULTS WITH} PAIN: EVIDENCE FROM THE LAB AND CLINIC

\section{Susan Lavoie, BA, PhD Candidate}

Dept of Psychology, University of New Brunswick, Fredericton, New Brunswick

BRIEF DESCRIPTION: The multidimensional and subjective nature of pain can cause even the most highly trained professional, well-intentioned family member, or lay observer to be influenced by a variety of factors that are either unrelated to the patient's pain condition or are inadequate indicators of the patient's level of pain and disability. The existing stereotype literature related to the influence of patient (attractiveness and perceived personal responsibility for onset and offset of pain condition), illness (presence or absence of visible cues to disability and the degree to which there is supporting objective medical evidence) and observer (attributional style and experience with pain) characteristics on perceptions of patients with pain will be presented. Data from laboratory- and clinically-based studies will be presented in relation to how these stereotypes influence the judgements made by both the general public and health professionals about men and women with chronic pain. Research findings will be discussed in the context of a unifying theoretical model. Lastly, the practical impact that stereotypes and stigma exert on patients' lives will be explored.

\section{B}

\section{STIGMA IN CHILDREN AND ADOLESCENTS WITH CHRONIC PAIN}

Bruce Dick, PhD

Associate Professor, Dept of Anesthesiology and Pain Medicine, University of Alberta, Pediatric Chronic Pain Program, Stollery Children's Hospital, Edmonton, Alberta

BRIEF DESCRIPTION: Stigma is an important problem faced by many individuals with chronic pain. In the adult chronic pain literature, stigma has been found to be associated with increased depression, decreased selfesteem, strained interpersonal relationships, and lower quality of life. Unfortunately, the presence of stigma is often ignored and sometimes even 
denied in this population. While there is increasing interest in stigma in the adult literature, there is a true dearth of research on stigma in pediatric and adolescent chronic pain populations. Studies of stigma in pediatric and adolescent medical populations affected by HIV/Aids, epilepsy, obesity, depression and other forms of mental illness, have found that stigma affects a child's self-concept and increases the risk of depression. Many individuals receiving health care services in our Pediatric Chronic Pain Program at the Stollery Children's Hospital have reported the presence and negative impact of stigma in their lives. As a result, we have adapted an adult scale assessing stigma in chronic pain for children and teens with chronic pain. The Children's Chronic Pain Stigma Scale (CCPSS) assesses perceived stigma levels from physicians, teachers, family members, and the general public. Data collected using the CCPSS will be presented with a discussion of differences in perceived stigma between target groups. Associations between stigma and age, diagnosis, pain chronicity, disability, and mental health will be presented along with a statistical model of how these factors interact. Clinical methods aimed at decreasing stigma and its effects on children and adolescents will also be presented.

\section{4:00 PM - SESSION 206}

\section{0}

\section{PROTEINASE ACTIVATED RECEPTORS AND PAIN}

Chair: Fiona Russell

Speakers: Zsuzsanna Helyes, PhD; Nicolas Cenac, PhD, INSERM

$\underline{\mathrm{U} 563}$

Zsuzsanna Helyes, PhD, University of Pecs, Faculty of Medicine,

Department of Pharmacology and Pharmacotherapy, Hungary;

Nicolas Cenac, PhD, INSERM U563, Department of Immunology and Infectious Diseases and Universite Toulouse III, Paul Sabatier, France

Learning Objectives:

1. To review how the different proteinase activated receptors (PARs) are involved in different types of pain.

2. To show the intricate links between PARs, TRP channels and kinin receptors on sensory nerves.

3. To explore the different PAR-induced mechanisms involved in visceral pain and joint inflammatory pain.

\section{A}

INVOLVEMENT OF CAPSAICIN-SENSITIVE FIBRES, TRPV1 RECEPTORS AND TACHYKININS IN PAR 2-INDUCED JOINT INFLAMMATION AND NOCICEPTION

\section{Zsuzsanna Helyes, PhD}

University of Pecs, Faculty of Medicine, Department of

Pharmacology and Pharmacotherapy, Hungary

\section{B}

REGULATION OF TRPV4 FUNCTIONS BY PROTEASES: IMPLICATION IN VISCERAL PAIN

Nicolas Cenac, PhD, INSERM U563

Department of Immunology and Infectious Diseases and Universite Toulouse III, Paul Sabatier, France

\section{4:00 PM - SESSION 207}

\section{1}

\section{ULTRASOUND IN PAIN MEDICINE}

Chair: Philip Peng

Speakers: Philip Peng, MBBS FRCPC; Peter Cheng, DO

Philip Peng, MBBS FRCPC, Toronto Western Hospital, Toronto,

Ontario; Peter Cheng, DO, Kaiser Permenente, Riverside, California WORKSHOP OBJECTIVE: To give the audience an overview of the application of ultrasound to guide injections in pain management. The anatomy, sonoanatomy, injection techniques and the literature published relevant to some selected ultrasound guided injections in axial, peripheral and musculoskeletal structures will be reviewed.

Learning Objectives:

1. To provide an basic understanding of the application of ultrasound in injections in pain medicine.
2. To review the anatomy, sonoanatomy relevant to some selected ultrasound guided injections.

3. To summarize the injection techniques and the literature published relevant to some selected ultrasound guided injections.

\section{A}

ULTRASOUND IN PAIN MANAGEMENT - PERIPHERAL AND AXIAL STRUCTURES

Philip Peng, MBBS FRCPC

Toronto Western Hospital, Toronto, Ontario

BRIEF DESCRIPTION: The speaker will give an overview of the application of ultrasound to guide injections in pain management. Furthermore, the anatomy, sonoanatomy, injection techniques and the literature published relevant to some selected ultrasound guided injections will be reviewed.

\section{B}

\section{ULTRASOUND FOR PAIN MANAGEMENT - JOINT INJECTIONS}

\section{Peter Cheng, DO}

Kaiser Permenente, Riverside, California

BRIEF DESCRIPTION: The speaker will review the anatomy, sonoanatomy, injection techniques and the literature published relevant to some selected ultrasound guided musculoskeletal injections will be reviewed.

\section{SCIENTIFIC PROGRAM DAY TWO SATURDAY MAY 15, 2010}

\section{7:30 AM - SYMPOSIUM}

\section{2}

\section{TRANSDERMAL BUPRENORPHINE: A NEW TREATMENT MODALITY FOR MODERATE PAIN}

Chair: Pam Squire

Speaker: Malcolm Hogg, MBBS, Grad Dip in Med (Pain Management), FANZCA, FFPMANZCA

Malcolm Hogg, MBBS, Grad Dip in Med (Pain Management),

FANZCA, FFPMANZCA, Department of Anaesthesia and Pain

Management, Royal Melbourne Hospital, Australia

Learning Objectives:

At the end of this presentation attendees will be able to:

1. Describe the unique parameters of moderate pain and the pharmacology of buprenorphine.

2. Summarize the clinical research supporting the use of transdermal buprenorphine for the treatment of moderate pain.

3. Give examples of the clinical application of this analgesic including indications, contraindications, risks and benefits.

BRIEF DESCRIPTION: Managing pain has challenged experts for many years, including Canadian healthcare professionals. As the population ages and patients become more involved in their healthcare, physicians and other health care workers are learning to individualize treatment management strategies with the assistance of multiple different treatment options. Typically the focus revolves around treating severe pain but moderate pain also impacts the lives of many Canadians. The Nanos Research looked at the impact that moderate to severe pain has on patient's ability to work and found that $47 \%$ of Canadian pain sufferers had their job responsibilities reduced due to their pain. This session will review the scope of moderate pain and introduce a new 7-day transdermal buprenorphine patch indicated for patients with moderate pain. 


\section{8:35 AM - KEYNOTE SPEAKERS}

\section{3}

\section{PATIENT EDUCATION FOR CHRONIC PAIN: WHERE HAVE} WE BEEN, WHERE ARE WE GOING?

Chair: Jason J. McDougall

Speaker: Sandra LeFort, PhD, MN, BN, BA, RN

Sandra M. LeFort, PhD, MN, BN, BA, RN, Professor, School of

Nursing, Memorial University of Newfoundland, St. John's,

Newfoundland

Learning Objectives:

1. To gain an understanding of past approaches to chronic pain patient education.

2. To learn about new models of patient education and how these might be incorporated into programs for chronic pain patients.

BRIEF DESCRIPTION: This presentation will briefly review standard patient education approaches that have been described in the literature and discuss how new emerging education trends and technologies might be used in future to improve accessibility and acceptability by chronic pain patients and their families.

\section{A}

HOW BRAIN IMAGING CAN HELP TO UNDERSTAND

\section{CLINICAL PAIN}

\section{Chair: Jason J. McDougall}

Speaker: Petra Schweinhardt, MD, PhD

Petra Schweinhardt, MD PhD, Assistant Professor, Alan Edwards Centre for Research on Pain, McGill University, Montreal, Quebec

Learning Objectives:

1. Gain an understanding of the mismatch between objective sign and pain severity in chronic pain conditions.

2. Learn about different imaging techniques that can be used to investigate brain structure, function, and biochemistry.

3. Learn about brain alterations in chronic pain and their potential functional significance

BRIEF DESCRIPTION: The prevalence of chronic pain is estimated to be around $20 \%$ (1). In only a minority of the patients, an obvious origin of the pain can be determined such as nerve or tissue injury. A large proportion of the patients with chronic pain are assigned to the diagnostic category of functional pain syndromes, for which per definition no underlying organic cause can be determined. But also in patients suffering from neuropathic or nociceptive pain mismatches between quantifiable signs such as extent of tissue injury and amount of pain are frequently observed. Moreover, patients with seemingly very similar types of injury might report hugely varying degrees of pain. Several reasons are likely to contribute to those findings, including genetic variability and aspects of the injury/disease that cannot be easily quantified. In addition, it has become increasingly clear in recent years that the brain plays an important role in modifying pain experiences, either by augmentation or attenuation. Pre-existing differences in endogenous pain modulating systems might contribute to the probability of an individual developing chronic pain as well as to the severity of the pain. But evidence is also accumulating that pain itself can alter the brain. In vivo imaging techniques, such as functional and structural magnetic resonance imaging, spectroscopy and positron emission tomography, have provided substantial evidence in recent years that chronic pain patients have an altered function, biochemistry and even structure of the brain. Such brain alterations are predominantly observed in areas involved in pain processing and pain modulation. In several instances, they have been shown to be related to the amount of time for which the patient has been suffering from pain. It appears therefore likely that at least some of the brain alterations observed represent maladaptive plastic processes that contribute to the generation and maintenance of pain. It will be of paramount importance in the next years to determine the causes of such maladaptive plasticity, which might occur due to prolonged nociceptive input, stress, or maybe even "spontaneously". REFERENCES:

1. O. Gureje, M. Von Korff, G. E. Simon, R. Gater, Jama 280, 147 (Jul 8, 1998)
9:30 AM - MODERATED POSTER SESSION

\section{4}

MODERATED POSTER SESSION

Chair: Judy Watt-Watson

Speakers: Peter MacDougall, PhD, MD, FRCPC; Christine Popovich, BSc; Erica Weinberg, BSc, MSc, MPhil, MD

\section{A}

THE NOVA SCOTIA CHRONIC PAIN COLLABORATIVE CARE NETWORK (NSCPCCN) MENTOR AND MENTEE WORKSHOP ASSESSMENT DATA

Peter MacDougall, PhD MD FRCPC; Sara Whynot, MLT(ASCP), Dalhousie University, Department of Anesthesia; Michele Chapell, RN, Dalhousie University, Halifax, Nova Scotia; Michael Cord, HBSc MD, University of Toronto, Toronto; Spencer Tighe, MD FRCPC, University of Ottawa, Ottawa, Ontario

AIM: The NSCPCCN is a mentor - mentee network designed to provide clinical support, continuing professional development (CPD) and knowledge translation (KT) to primary care practitioners (PCP's) in the community. The network was initially launched as a pilot project in one health care district in Nova Scotia. The goal of this study was to determine the baseline characteristics of mentors and PCP mentees at the inauguration of the NSCPCCN through a two day workshop.

METHODS: A two day workshop was held to launch the NSCPCCN. The first day of the workshop consisted of training for mentor physicians. A questionnaire was provided to the mentors at the end of the session to determine the mentors understanding of the concept of mentoring in this framework. The second day of the workshop was devoted to matching mentor - mentee groups. Data was collected from the mentee physicians to determine the impact of chronic pain on their practice, initial satisfaction with chronic pain management, opioid prescribing and the rate of aberrant opioid behavior screening.

RESULTS: Mentorship data was expressed in Likert scales from 0 (strongly disagree) to 5 (strongly agree). Of the 7 mentors responding, $6 \mathrm{had}$ no previous similar mentoring experience. Confidence in mentoring, understanding the values of the NSCPCCN and the expectations of the NSCPCCN averaged $3.9 / 5,3.4 / 5$ and $3.1 / 5$ respectively. The ability to describe mentoring models, know when to chose the most approrpiate mentor role and confidence in functioning as a mentor in this setting averaged 3.1/5, 2.3/5 and 3.4/5.

The average number of visits for chronic pain was $43 /$ month with a range of 2 - 125. Visit duration ranged from 15 to 400 minutes. The average time without the 400 minute outlier was 22 minutes. Average non-compensated time was 13 minutes. Satisfaction with chronic pain management and opioid prescribing averaged $3.4 / 5$ and 3.7, respectively. The average number of patients screened for aberrant opioid behavior and suspected of same are 22.6 and 5 respectively.

CONCLUSIONS: Mentors entering the NSCPCCN were unlikely to have acted as mentors in the past. However, the mentors had a reasonable grasp of the concepts of mentoring. Mentee practices demonstrate a wide variation in visits for chronic pain. Non-compensated time was similar to that reported previously (1). Aberrant opioid screening and suspicion of this behavior was much higher than in previous groups (1).

FOOTNOTES/REFERENCES:

1. Chappell et. al. Canadian Pain Society Annual Meeting 2009.

Abstract.

\section{B}

SEX DIFFERENCES IN THE EFFECTS OF ATTENTION ON THE NEURAL RESPONSE TO NON-PAINFUL SENSORY STIMULI

Christine Popovich, BSc, University of Toronto; Colleen Dockstader, PhD; Douglas Cheyne, PhD; Rosemary Tannock, PhD, The Hospital for Sick Children, Toronto, Ontario

AIM: To determine whether males and females differ in attention modulation of sensorimotor mu rhythms in response to non-painful somatosensory information. Sex-related differences have been found in cortical oscillations (specifically, the $8-12 \mathrm{~Hz}$ mu frequency band) in response to painful stimuli, but it is unclear whether differences also occur in response to non-painful stimuli and whether there are sex differences in attention to sensory stimuli. 
METHODS: We used magnetoencephalography to capture mu oscillation in the primary somatosensory cortex in response to non-painful transcutaneous median nerve stimulation (MNS) in 10 female and 10 male healthy adults, aged 21-36 years. Stimuli were presented in trains of four (ISI: $2 \mathrm{~s}$ ) followed by a $4-\sec$ gap for a total of 83 trains over 14 minutes. Participants completed two counterbalanced conditions: attend to a videoclip while ignoring MNS; attend to MNS and ignore the videoclip.

RESULTS: Females showed strong and prolonged mu suppression when attending to MNS stimuli, whereas males showed brief mu suppression followed by mu enhancement. Since mu suppression reflects stimulus processing and mu enhancement reflects cortical inhibition of that region, our findings indicate that females engage in intensive and extensive processing of the sensory stimuli, when directing attention to the stimuli, whereas males engage in brief sensory processing, then inhibit further processing CONCLUSIONS: Sex-related differences in attentional processing of sensory stimuli might account in part for the well-documented greater pain sensitivity in females and their decreased response to pain-therapies involving redirection of attention away from nociceptive information.

\section{C \\ KNOWLEDGE TRANSLATION IN PAIN EDUCATION: IS THE MESSAGE BEING UNDERSTOOD?}

Erica Weinberg, BSc, MSc, MPhil, MD, Rouge Valley Health System, Scarborough, Ontario; Philip A Baer, MDCM, FRCPC, FACR,

Canadian Rheumatology Association

AIM: To assess whether new clinical and scientific information potentially impacting pain management is being translated into daily clinical practice at the primary care level in Canada.

METHODS: Over 190 health care professionals, mostly primary care physicians, were surveyed at a number of CME events in 2009 for current knowledge in pain management. Multiple choice questions regarding prevalence of chronic pain, screening for opioid misuse risk, acetaminophen dosing, risk factors for NSAID-induced GI events, and codeine metabolism were posed.

RESULTS: In 2009, the majority of respondents were aware of the prevalence of chronic pain in Canadian adults. However, clinicians are still not fully aware of issues surrounding codeine metabolism, maximum safe acetaminophen dosing in chronic usage, and the increased GI risk of SSRIs used concomitantly with NSAIDs. Only $18.1 \%$ of clinicians used validated tools for screening opioid misuse risk prior to initiating opioids, and $20.3 \%$ still do not routinely screen their patients at all.

CONCLUSIONS: Continuing medical education in proper pain management and risk stratification is still required.

REFERENCES:

1. Food and Drug Administration; Organ-Specific Warnings; Internal Analgesic, Antipyretic, and Antirheumatic Drug Products for Over theCounter Human Use; Final Monograph. Federal Register / Vol. 74, No. 81 / Wednesday, April 29, 2009.

2. Chou R. et al. Clinical Guidelines for the Use of Chronic Opioid Therapy in Chronic Noncancer Pain. The Journal of Pain, Vol 10, No 2 (February), 2009: pp 113-130.

3. Macfarlane GJ et al. Managing low back pain presenting to primary care: Where do we go from here? Pain 122 (2006) 219-222.

\section{0:30 AM - SESSION 301}

\section{5}

DO BLOCKS HAVE A ROLE IN CHRONIC PAIN

\section{MANAGEMENT?}

Chair: Paul Taenzer

Speakers: A John Clark, MD FRCPC; Ian Beauprie, MD FRCPC A John Clark, MD FRCPC, Calgary Chronic Pain Centre, Alberta Health Services and University of Calgary, Calgary, Alberta; Ian Beauprie, MD FRCPC, Pain Management Unit, Department of Anesthesia, CDHA and Dalhousie University, Halifax, Nova Scotia WORKSHOP OBJECTIVE: This workshop will consist of an opening debate of the evidence for and against the use of blocks (interventions) in the management of chronic pain. This will be followed by small group round tables to discuss controversial issues about the provision of interventions. Each small group will report their conclusions back to all workshop participants to allow for discussion and debate amongst all participants.
Learning Objectives:

1. To review the evidence for and against the use of blocks (interventions) in the management of chronic pain.

2. To determine if there is an optimum frequency interventions should be provided and whether there should be a maximum number.

3. To discuss the role ultrasound and/or fluoroscopy should play when interventions are performed and to debate whether Bier blocks should be de-listed from provincial payment plans.

\section{A}

CON: BLOCKS HAVE LITTLE ROLE IN THE MANAGEMENT OF CHRONIC PAIN

A John Clark, MD, FRCPC

Calgary Chronic Pain Centre, Alberta Health Services and University of Calgary, Calgary, Alberta

BRIEF DESCRIPTION: Evidence for lack of efficacy of most blocks used in chronic pain managenment will be presented.

\section{B}

\section{PRO: BLOCKS ARE IMPORTANT MODALITIES IN THE MANAGEMENT OF CHRONIC PAIN}

lan Beauprie, MD, FRCPC

Pain Management Unit, Department of Anesthesia, CDHA and Dalhousie University, Halifax, Nova Scotia

BRIEF DESCRIPTION: Blocks for chronic pain management have been used for decades with benefit for many patients, current evidence to support their use will be reviewed.

\section{0:30 AM - SESSION 302}

\section{6}

PUDENDAL NEURALGIA: A COMPREHENSIVE APPROACH

Chair: Allan S Gordon

Speakers: Allan S Gordon, MD, FRCP(C); Philip Peng, MBBS,

FRCP(C); Stanley \ Antolak, MD

Allan S Gordon MD, FRCP(C), Neurologist and Director, Wasser Pain Management Centre, Mount Sinai Hospital; Philip Peng, MBBS, FRCP(C), Director, Anesthesia Chronic Pain Program, University Health Network and Mount Sinai Hospital, Director of Research, Wasser Pain Management Center, Mount Sinai Hospital, Associate Professor, Department of Anesthesia, University of Toronto, Toronto, Ontario; Stanley J Antolak, MD, Centre for Urologic and Pelvic Pain, Lake Elmo, Minnesota, USA

WORKSHOP OBJECTIVE: To familiarize the audience with modern diagnosis and management of pudendal neuralgia and to identify a major unmet need in Canada.

Learning Objectives:

1. To be able to diagnose pudendal neuralgia in patients with pelvic pain

2. To understand the role of diagnostic blocks

3. To look and surgical and non-surgical management techniques.

\section{A}

\section{PUDENDAL NEURALGIA: CLINICAL DIAGNOSIS AND MANAGEMENT}

Allan S Gordon, MD, FRCP(C)

Wasser Pain Management Centre, Mount Sinai Hospital, Toronto, Ontario

BRIEF DESCRIPTION: Pudendal neuralgia is a chronic pelvic pain involving the sensory distribution of the course of the pudendal nerve. The symptoms of pain and sensory disturbance can be very disturbing. Diagnosis is mainly based on clinical presentation although neurophysiological tests and nerve block aid in diagnosis. Management involves a multimodal approach: modification of activities, pharmacologic treatment, physical therapy, pudendal nerve block, and, in refractory cases, surgery. 
26B

THE ROLE OF NERVE BLOCKS IN PUDENDAL NEURALGIA Philip Peng, MBBS, FRCP(C)

University Health Network and Wasser Pain Management Centre, Mount Sinai Hospital, University of Toronto, Toronto, Ontario

BRIEF DESCRIPTION: In this presentation, we will discuss the neuroanatomical basis for the pudendal neuralgia and the role of interventional procedure in the diagnosis and management of pudendal neuralgia. Various guided imaging techniques will be discussed as well as the likelihood of clinical benefits.

\section{C}

\section{SURGICAL CARE IN PUDENDAL NEURALGIA}

Stanley J Antolak, MD

Centre for Urologic and Pelvic Pain, Lake Elmo, Minnesota, USA

BRIEF DESCRIPTION: Surgical decompression of the pudendal nerve is needed in approximately $30 \%$ of patients who fail pudendal nerve blocks. These patients have pudendal nerve entrapment. Transgluteal and transperineal approaches are used. Surgery may be either unilateral or bilateral depending on patients' problems. RCT and case series reports indicate 50\% to $70 \%$ response rates of pain cure or control. Pain relief may require 9 to 24 months. There is negligible morbidity. Return to employment depends chiefly on the degree of impairment prior to surgery. Canadian patients presently undergo surgery in USA or France. Development of a comprehensive nation-wide pudendal treatment program should include a centre for surgical treatment.

10:30 AM - SESSION 303

\section{7}

\section{UPDATE ON UROGENITAL CHRONIC PELVIC PAIN SYNDROME (UCPPS) IN MEN AND WOMEN: NEW AVENUES OF EMPIRICAL AND CLINICAL PURSUIT}

Chair: Dean A. Tripp

Speakers: Dean A. Tripp, PhD; Laura Katz, MSc Candidate; Jessica

Ginting, PhD Candidate

Dean A. Tripp, PhD, Associate Professor, Departments of

Psychology, Anesthesiology \& Urology; Laura Katz, MSc Candidate,

Department of Psychology; Jessica Ginting, PhD Candidate,

Department of Psychology, Queen's University, Kingston, Ontario

Learning Objectives:

1. To understand the differences and similarities between UCPPS diseases and the modern burden they place on health care services

2. To differentiate pertinent psychosocial and supportive predictors of disability and poorer QoL in both IC/PBS and CP/CPPS and be familiar with clinical treatment suggestions

3. To recognize the expanded role of catastrophizing in the UCPPS literature as well as clinical suggestions for its management

\section{A}

\section{INTRODUCTION TO UROGENITAL CHRONIC PELVIC PAIN SYNDROME IN MEN AND WOMEN}

\section{Dean A. Tripp, PhD}

Associate Professor, Departments of Psychology, Anesthesiology \& Urology, Queen's University, Kingston, Ontario

BRIEF DESCRIPTION: The National Institute of Diabetes and Digestive and Kidney Diseases (NIDDK) have adopted the umbrella term "Urologic Chronic Pelvic Pain Syndrome", or UCPPS, to refer to pain syndromes associated with the male and female pelvises staring in 2007. Previous to this date, the female version was named interstitial cystitis/painful bladder syndrome (IC/PBS), and the male version was called chronic prostatitis/ chronic pelvic pain syndrome (CP/CPPS). Researchers today are attempting to disentangle the separate and common factors that are associated with these painful chronic conditions because many believe there may be a similar underlying pathology or etiology, primarily based on current symptom presentation. IC/PBS is a chronic, painful disorder characterized by chronic pelvic pain, urinary urgency, and frequency. Although this disease previously was believed to be a condition of menopausal women, growing numbers of men and women are being diagnosed in their twenties and younger, affecting all cultures, socioeconomic backgrounds, and ages. IC/ PBS is far more common in females than in men, with prevalence ranging from 1 in 100,000 to 5.1 in 1,000 in the general population. Up to $12 \%$ of women may have early symptoms of IC/PBS. The treatment options are suboptimal, and patients with IC/PBS have reported significant negative effects on their physical and mental functioning quality of life (QOL). Prostatitis is a common and costly medical condition, with CP/CPPS the most frequent subtype encountered by family physicians, internists, and urologists. Men with CP/CPPS have chronic genitourinary pain, the hallmark symptom of this syndrome, but also report urinary and sexual dysfunction, both of which have a negative effect on the quality of life. The prevalence rate of physician-diagnosed prostatitis in one U.S. community was $9 \%$; population-based surveys of symptoms estimate the prevalence of prostatitis-like symptoms to be between 6 and 12\% and recent survey of adolescent males raise the possibility of similar prevalence in much younger males. With little evidence of a cure for either disease, an improved understanding of the predictive factors most closely associated with poorer QOL is essential for directing medical and psychosocial interventions for enhanced patient adjustment in UCPPS. Novel research will be reviewed, highlighting up-to-the-minute findings in UCPPS studies along with clinical implications for the general treatment of patients.

\section{B}

\section{UNDERSTANDING DISABILITY AND QUALITY OF LIFE IN WOMEN WITH IC/PBS}

Laura Katz, MSc Candidate

Department of Psychology, Queen's University, Kingston, Ontario

BRIEF DESCRIPTION: Interstitial Cystitis / Painful Bladder Syndrome (IC/PBS) is a painful and refractory medical condition that affects $3-20 \%$ of women in North America. Results of a new study suggest that pain-related disability is a significant issue in women with IC/PBS but has received little empirical attention. Previous research suggests that psychosocial variables are important predictors of disability in women diagnosed with IC/PBS. The literature has evaluated disability as a general factor and has failed to investigate various aspects of how IC/PBS symptoms may affect specific domains of women's lives. This discussion will explore various facets of disability (such as family home responsibilities, recreation, social activity, occupation, sexual behavior, self-care and life-support activities) as reported by women with IC/PBS. Demographic (e.g., age, duration of symptoms), medical (e.g., urinary frequency and urgency, pain type, pain severity), psychological (e.g., catastrophizing, depression, anxiety) and social (e.g., social support) variables will be reviewed as predictors of disability. Furthermore, various aspects of disability will be used to predict Quality of Life (QoL) in women with IC/PBS, in a more complex model. Concluding remarks will discuss future clinical research as well as possible psychosocial interventions to decrease specific domains of pain-related disability and improve QoL in women with IC/PBS.

\section{C}

DOES SUPPORT MAKE A DIFFERENCE IN COUPLES SUFFERING UROGENITAL CHRONIC PELVIC PAIN SYNDROME?

\section{Jessica Ginting, PhD Candidate}

Department of Psychology, Queen's University, Kingston, Ontario BRIEF DESCRIPTION: The general pain research shows that spousal responses (support or no-support) to chronic pain influence patient adjustment. Recently, our group has examined spousal responses for its potential role in impacting the association between pain and Quality of Life (QoL), depressive symptoms and disability in men with chronic prostatitis/chronic pelvic pain syndrome (CP/CPPS) and women with interstitial cystitis/painful bladder syndrome (IC/PBS). Various types of spousal support behaviours have been examined in pain previously but none have examined UCPPS samples or have they examined a stress-buffering model of such effect. New data shows a stress-buffering effect of distracting responses (trying to help keep patient's mind off pain) observed in both men and women, but only influenced the association between pain and mental QoL in women, and between pain and disability in men. Distracting spouse responses moderated the relationship between pain and mental QoL (or disability), such that the association between pain and mental QoL (or disability) was stronger at lower levels of distracting spouse responses to pain behaviour than it was at 
higher levels of distracting spouse responses to pain behavior. Interestingly, in men with CP/CPPS, solicitous spouse responses (doing more for spouse) also influenced the relationship between pain and disability, such that when female spouses were solicitously responding (doing more for male patients), the association between pain and disability was stronger than when women did less for their spouses. The results of such research indicate that distracting spouse responses is associated with improved mental $\mathrm{QoL}$ in women with IC/PBS and diminished disability in men with CP/CPPS, and that solicitous responding may be detrimental for men with CP/CPPS. This talk will take the research one step further and discuss spousal psycho-education treatment options for IC/PBS and CP/CPPS management that may be considered for outpatient services.

\section{D}

\section{CATASTROPHIZING AND UROGENITAL CHRONIC PELVIC PAIN SYNDROME: WHAT DO WE NOW KNOW?}

\section{Dean A. Tripp, PhD}

Associate Professor, Departments of Psychology, Anesthesiology \& Urology, Queen's University, Kingston, Ontario

BRIEF DESCRIPTION: Pain Catastrophizing has been identified as a pervasive set of dysfunctional beliefs or appraisals of one's ability to manage or tolerate pain and is widely reported as key in understanding differences in pain experience. Pain catastrophizing has been consistently identified as a major individual difference factor in pain research, associated with greater acute pain report in clinical populations and in healthy individuals undergoing laboratory-based pain induction tasks. Catastrophizing is also predictive of greater pain report in chronic pain conditions and greater pain behaviors, such as visits to health care professionals, analgesic use, and disability. This session will highlight and discuss our recent research examining Pain Catastrophizing in UCPPS. In particular, data from several new studies will be detailed showing that catastrophizing continues to be one of the most robust predictors of poorer outcomes in both men and women who are suffering pelvic pain. New data that assessed the association of sexual dysfunction with quality of life (QOL) while simultaneously examining the shared influence of empirically supported variables that are also associated with diminished interstitial cystitis/painful bladder syndrome (IC/PBS) QOL (i.e., pain, catastrophizing, depression) will be reviewed. Indeed, previous research has indicated that sexual dysfunction is prevalent, bothersome, and an important predictor of diminished QOL in patients with IC/ PBS. However, the deleterious association between sexual dysfunction and QOL has not been investigated in more inclusive models that use validated measures. As well, longitudinal data suggesting that catastrophizing is a stable variable in men will be reviewed. Finally, the potential mediating effects that catastrophizing and social support may exert on the relationship between pain and depression will be discussed. All of these findings will be summarized and treatment models that attack catastrophizing will be briefly presented.

10:30 AM - SESSION 304

\section{8}

\section{MODULATING THE BODY'S NATURAL CANNABINOID SYSTEM - A PROMISING APPROACH FOR THE TREATMENT OF PAIN}

Chair: Niklas Schuelert

Speakers: Niklas Schuelert, Postdoctoral fellow; Devi Sagar, Postdoctoral fellow; Mark A. Ware, MBBS, MRCP, MSc

Niklas Schuelert, Postdoctoral fellow, Joint Inflammation \& Pain Laboratory, Department of Physiology and Pharmacology, University of Calgary, Calgary, Alberta; Devi Sagar, Postdoctoral fellow, Arthritis Research Campaign Research Fellow; School of Biomedical Sciences; University of Nottingham, United Kingdom; Mark A. Ware, MBBS, MRCP, MSc, Department of Family Medicine and Anesthesia, McGill University, Montreal, Quebec

WORKSHOP OBJECTIVE: The objective of this workshop is to provide an update of the latest research on the involvement of endogenous cannabinoids throughout the pain pathway. Advantages and limitations of endocannabinoid modulation in clinical pain management will be also discussed.
Learning Objectives:

1. To gain an understanding about what endocannabinoids are, where they can be found and how they are involved in pain transmission

2. To learn, how animal models can be used to investigate the endocannabinoid system as a novel target for the treatment of pain.

3. To get an update on recent approaches to modulate the endocannabinoid system in clinical pain management. Advantages and potential limitations will be discussed.

\section{A}

\section{MODULATING THE ENDOCANNABINOID SYSTEM CAN} REDUCE PAIN TRANSMISSION

Niklas Schuelert, Postdoctoral fellow

Joint Inflammation \& Pain Laboratory, Department of Physiology and Pharmacology, University of Calgary, Calgary, Alberta

BRIEF DESCRIPTION: A major limitation of cannabinoids as therapeutic agents for the treatment of pain is the side effects resulting from nonselective activation of central cannabinoid (CB) receptors. Cannabinoids that occur naturally in the human body (Endocannabinoids) seem to be involved in pain transmission. We examined whether inhibition of endocannabinoid metabolism by peripheral and systemic administration of the hydrolase inhibitor URB597 could modulate joint nociception in two rodent models of osteoarthritis (OA). OA-like changes were induced in male Wistar rats by an intra-articular injection of MIA, while DunkinHartley guinea pigs develop OA naturally and were used as a model of spontaneous OA. Joint nociception was measured by recording electrophysiologically from knee joint primary afferents in response to noxious rotation of the joint both before and following close intra-arterial injection of URB597 and the CB1 receptor antagonist AM252. The effect of systemic URB597 administration on joint pain perception in the MIA model was determined by hindlimb incapacitance. Peripheral URB597 application significantly reduced nociception in both models of OA but had no effect in control rat joints. Systemic co-administration of AM251 abolished the antinociceptive effect of URB597. Systemic URB597 administration significantly reduced hindlimb incapacitance in the MIA joint and co-administration of the CB1 antagonist abolished this effect. In summary, URB597 reduces mechanonociception and pain in OA models and this response is mediated by CB1 receptors. Therefore, targeting endocannabinoid metabolizing enzymes in the peripheral nervous system could offer novel therapeutic approaches for an efficient treatment of OA pain, minimizing centrally mediated side effects.

\section{B}

\section{ENDOCANNABINOID MODULATION OF SPINAL EXCITABILITY IN OSTEOARTHRITIC PAIN}

\section{Devi Sagar, Postdoctoral fellow}

Arthritis Research Campaign Research Fellow; School of Biomedical Sciences; University of Nottingham, United Kingdom

BRIEF DESCRIPTION: Anedotal evidence for the analgesic effects of Cannabis Sativa in the treatment of joint pain has been recognised for decades. More recently, the role of the endocannabinoid system in rheumatic disease has been demonstrated by elevated levels of the endocannabinoids anandamide (AEA) and related n-acylethanolamines (NAEs) in the synovial fluid of arthritis patients. Endocannabinoid levels are altered in animal models of chronic pain, pharmacological studies have further implicated this system in the control of peripheral neuronal excitability in animal models of joint pain. Intra-articular injection of monosodium iododacetate (MIA) in rats produces a robust model of osteoarthritic (OA) pain, in which we have demonstrated alterations in spinal excitability following joint damage. We have also shown that these changes are associated with elevated levels of AEA and the endocannabinoid-2-arachidonyl glycerol $(2-A G)$ in the spinal cord. Here we report the modulation of spinal neuronal responses by elevated levels of endocannabinoids in the spinal cord via the activation of $\mathrm{CB} 1$ and or $\mathrm{CB} 2$ receptors in MIA-treated rats. Furthermore, we show alterations in the spinal levels of synthetic enzymes for AEA and 2-AG in these rats. These findings support the hypothesis that the endocannabinoid system is altered in osteoarthritis, with elements of this system providing potential therapeutic targets for the associated pain. 
28C

HARNESSING THE ENDOCANNABINOID SYSTEM IN CLINICAL PAIN MANAGEMENT

Mark A. Ware, MBBS, MRCP, MSC

Department of Family Medicine and Anesthesia, McGill University, Quebec, Canada

BRIEF DESCRIPTION: Increasing basic science awareness of the role of the endogenous cannabinoid system (ECS) in pain modulation leads to a crucial clinical question: how can we utilize this knowledge and understanding in providing better pain management for patients with pain? This session will review some therapeutic options that utilize the ECS and that have been found to have cannabinomimetic effects. This includes pharmaceutical agents such as nabilone and tetrahydrocannabinol (THC), the primary psychoactive ingredient in Cannabis. Additional modalities that maybe less well known cannabinoid modulators include exercise and osteopathy. Challenges and opportunities in elucidating and validating the role of the ECS in these and other approaches will be discussed. Future developments that may harness the ECS will also be presented, including peripherally restricted CB1 agonists and FAAH inhibitors. Attendees will gain an appreciation of the role of the ECS in pain management, knowledge of the existing strategies to utilize the ECS, and awareness of the future of clinical approaches to the role of the ECS in clinical pain management.

$$
\text { 10:30 AM - SESSION } 305
$$

\section{9}

FROM VISION TO REALITY - LEADERSHIP \& INTEGRATION OF ACUTE AND INTER-PROFESSIONAL CARE MODELS TO PROVIDE FAIR EQUITABLE ACCESS TO PROVINCIAL CHRONIC PAIN SERVICES IN NOVA SCOTIA

Chair: Mary E. Lynch

Speakers: Mary E. Lynch, MD, FRCPC; Rachelle O'Sullivan, BSc, MBA; Gail Sloane, RN, BScN, MHSc (Bioethics); Peter MacDougall, MD, FRCPC

Mary E. Lynch, MD, FRCPC, Director, Pain Management Unit, Capital District Health, Nova Scotia; Rachelle O'Sullivan, BSc, MBA, Director of Acute and Tertiary Care, Nova Scotia Department of Health; Gail Sloane, RN, BScN, MHSc (Bioethics), Nova Scotia and Capital Health Chronic Pain Waitlist Project Coordinator; Peter MacDougall, MD, FRCPC, Director, Nova Scotia Chronic Pain Collaborative Care Network

WORKSHOP OBJECTIVE: After attending this workshop the participant:

1. Will develop an appreciation of the need for multiple and sustained approaches to chronic pain service delivery through a provincial chronic pain initiative.

2. Will appreciate the various roles required to develop a sustainable provincial chronic pain network.

3. Will understand the need to ensure involvement and process development in the coordination and implementation of a provincial chronic pain network.

4. The importance of developing an ongoing accountability or quality improvement component as part of any provincial program.

Learning Objectives:

1. Awareness of the multi-pronged strategy developed in Nova Scotia to bring evidence based approaches to provincial community based chronic pain clinics.

2. Broader understanding of the advantages of partnerships between the Provincial Department of Health, academic pain specialists, District Health Authorities, and the community practitioners initiating and sustaining a province wide strategy for improved management of inter-professional chronic pain management.

3. Broader understanding of the advantages of partnerships between the Provincial Department of Health, academic pain specialists, District Health Authorities, and the community practitioners initiating and sustaining a province wide strategy for improved management of inter-professional chronic pain management.

\section{A}

FROM VISION TO REALITY - LEADERSHIP \& INTEGRATION OF ACUTE AND INTER-PROFESSIONAL CARE MODELS TO PROVIDE FAIR EQUITABLE ACCESS TO PROVINCIAL CHRONIC PAIN SERVICES IN NOVA SCOTIA

\section{Mary E. Lynch, MD, FRCPC}

Director, Pain Management Unit, Capital District Health, Nova

Scotia

BRIEF DESCRIPTION: Overall Aim of Workshop: This workshop will provide participants an overview of the road-map used to develop a Provincial Chronic Pain Initiative and development of a parallel mentormentee network for community Primary Care Practitioners. The challenges and successes of going from vision to service delivery will be presented through a variety of stakeholder perspectives. This will include: priority setting, human resource development and recruitment, development of standardized model of care and evaluation. This will also include evaluation data findings and a framework for ongoing quality improvement and network support.

Overarching this discussion will be identifying the importance of trust and relationship building between and among all stakeholders. Given the challenges of operating a provincial network, teamwork, creativity and communication are key components. This will provide a strong foundation to develop research informed practices and guidelines.

\section{B}

\section{THE PERSPECTIVE OF THE NS DEPARTMENT OF HEALTH}

Rachelle O'Sullivan, BSc, MBA

Director of Acute and Tertiary Care, Nova Scotia Department of Health

BRIEF DESCRIPTION: In the present climate of limited resources and escalating health care costs it is a constant challenge for provincial health representatives to find solutions. This requires re-allocation of resources in new and creative ways while assuring these solutions are evidence based and congruent with the needs of the community. A review of the implementation of the Action Plan for Chronic Pain Services with an update on progress to date, including challenges met and solutions identified, and the processes being put into place to support the second phase, including the creation of a Provincial Advisory Committee on Chronic Pain will be provided. In addition, suggestions for effectively working with provincial governments on initiatives will be discussed.

\section{C}

PROGRESS WITH THE NUTS AND BOLTS OF KEEPING THE NETWORK MOVING FORWARD IN A COORDINATED WAY

Gail Sloane, RN, BScN, MHSc (Bioethics)

Nova Scotia and Capital Health Chronic Pain Waitlist Project

Coordinator

BRIEF DESCRIPTION: In order to assure that provincial pain services function in a coordinated way numerous issues have had to be addressed. These issues will be reviewed including development of standardized and coordinated referral, development and revision of triage criteria, the application of uniform triage criteria across the network, development of a consistent data set including clinical outcome measures to be used at all sites allowing ongoing evaluation in the areas of demographics, clinical outcomes, healthcare utilization, satisfaction and wait times, implementation of consistent resources based on the level of service to be provided at each of the sites, and ongoing support and education of the interdisciplinary teams delivering the service.

\section{D}

UPDATE THE NOVA SCOTIA CHRONIC PAIN COLLABORATIVE CARE NETWORK (NSCPCCN)

Peter MacDougall, MD, FRCPC

Director, Nova Scotia Chronic Pain Collaborative Care Network

BRIEF DESCRIPTION: An update regarding the NSCPCCN will be presented. This mentor-mentee network designed to increase capacity for pain management through close communication between primary care providers (PCP's) and pain specialists has been up and running for 18 months. The NSCPCCN was expanded to Capital District Health 
Authority in 2009 and to five additional districts in 2010. A website, www. communitypainnetwork.com has been added to facilitate knowledge translation. Knowledge translation activities include ongoing dialogue between the network members, links to key literature and podcasts of rounds relevant to practitioners.

\section{2:30 PM - SYMPOSIUM}

\section{0}

\section{INTERRELATIONSHIPS BETWEEN PAIN AND SLEEP}

Chair: Jonathan Fleming

Speaker: Pam Squire, MD, CCFP, CPE

Pam Squire, MD, CCFP, CPE, Clinical Assistant Professor, University of British Columbia, Vancouver, British Columbia

Learning Objectives:

1. Sleep physiology: the basic principles of sleep physiology and neurobiology will be discussed as well as new emerging polysomnographic measures used to evaluate sleep quality.

2. Interrelationship between pain and sleep: this part of the symposium will focus on the prevalence of sleep disturbances in painful conditions and present study data highlighting the impact of sleep deprivation/disturbances on pain reporting as well as subjective and objective measures of sleep quality in patients suffering from chronic pain conditions.

3. Impact of pain medication on sleep difficulties: This section is intended to present data on sleep quality in pain patients for medications used to manage chronic neuropathic pain.

BRIEF DESCRIPTION: This symposium will address the basic principle of sleep physiology, address interrelationships between pain and sleep and what is the impact of pain medication on sleep difficulties.

\section{2:00 PM - SESSION 306}

\section{1}

\section{INTERDISCIPLINARY PEDIATRIC CHRONIC PAIN MANAGEMENT: A TEAM APPROACH USING INNOVATIVE METHODS TO REACH OUT TO CHILDREN AND TEENS}

Chair: Bruce D. Dick

Speakers: Mark K. Simmonds, MB, FRCA, FRCPC, FFPMRCA;

Kathy L. Reid, RN, MN; Bruce D. Dick, PhD

Mark K. Simmonds, MB, FRCA, FRCPC, FFPMRCA, University of

Alberta \& Stollery Children's Hospital; Kathy L. Reid, RN, MN,

Stollery Children's Hospital; Bruce D. Dick, PhD, University of Alberta \& Stollery Children's Hospital, Edmonton, Alberta WORKSHOP OBJECTIVES:

1. To help participants understand how straightforward explanations to communicate with a child about their chronic pain validates their pain experience including research results upon which this method is based.

2. Participants will learn about the professional and ethical standards related to using telehealth to replace the face-to-face visit and outcome data from our pediatric chronic pain program using this technology.

3. To understand and discuss the rationale, benefits and shortcomings of distance treatment programs for children and adolescents with chronic pain along with qualitative and quantitative findings from our local pediatric cancer pain distance treatment program.

Learning Objectives:

1. To help participants understand how straightforward explanations to communicate with and validate a child's chronic pain including data generated from research in this area in our pediatric chronic pain clinic.

2. Participants will learn about the professional and ethical standards related to using telehealth to replace the face-to-face visit and will understand research results from our pediatric pain management program that incorporates this treatment technology.

3. To understand and discuss the rationale, benefits and shortcomings of distance treatment programs for children and adolescents with chronic pain and findings from our local pediatric oncology distance treatment program.

\section{A}

REACHING OUT TO CHILDREN WITH CHRONIC PAIN TELLING THEM IT'S REAL

Mark K. Simmonds, MB, FRCA, FRCPC, FFPMRCA

University of Alberta \& Stollery Children's Hospital, Edmonton,

Alberta

BRIEF DESCRIPTION: While it is accepted that multidisciplinary programs are the optimum way of managing pediatric chronic pain, there are only a handful of dedicated pediatric multidisciplinary chronic pain treatment facilities across Canada $(1,2)$. This woeful shortfall is likely to take many years to address. In the interim there will be a generation of children with untreated chronic pain who will continue to feel isolated, be disbelieved and under-treated (3). A cognitive-behavioural approach to treating chronic pain in children has been found to be empirically supported (4). Discussing the nature and origin of chronic pain is a key part of this treatment.

In our pediatric chronic pain clinic, a needs study was conducted to examine key factors identified by families as important when first attending our clinic. Parents $(n=29)$ were surveyed prior to their initial visit regarding their needs for information concerning chronic pain and its treatment. Information about the causes of their child's pain was important or very important to $97 \%$. Irrespective of the diagnosis, validation of a child's pain as a "real" sensory experience is a vital first step in the management of chronic pain $(5,6)$. At our pediatric pain centre this is the primary goal of the initial interdisciplinary consultation.

Our clinic research also found that parents $(n=27)$ reported seeing an average of 4 (range $1-9$ ) health care professionals regarding their child's pain prior to their pain clinic appointment. In the context of our needs assessment research results, we propose that improved health service provision can be achieved through validation and interdisciplinary care of a child's chronic pain experience. This can be accomplished using straightforward explanations in the primary care setting by interested healthcare professionals, long before the child comes to the attention of an interdisciplinary pain centre. REFERENCES

1. Berde CB, Solodiuk J. Multidisciplinary programs for management of acute and chronic pain in children. In: Schechter NL, Berde CB, Yaster M (Eds). Pain in Infants, Children and Adolescents.

Philadelphia: Lippincott Williams \& Wilkins, 2003: 471-86.

2. Dedicated multidisciplinary pain management centres for children in Canada: the current status. Can J Anaesth. 2007 Dec; 54(12):985-91.

3. Dell'api M, Rennick JE, Rosmus C. Childhood chronic pain and health care professional interactions: shaping the chronic pain experiences of children. J Child Health Care. 2007 Dec;11(4):269-86.

4. Eccleston C, Yorke L, Morley S, Williams AC, Mastroyannopoulou K. Psychological therapies for the management of chronic and recurrent pain in children and adolescents. Cochrane Database Syst Rev. 2003;(1):CD003968. Review.

5. Carter B. Chronic pain in childhood and the medical encounter: professional ventriloquism and hidden voices. Qual Health Res. 2002 Jan;12(1):28-41.

6. Clemente I, Lee SH, Heritage J. Children in chronic pain: promoting pediatric patients' symptom accounts in tertiary care. Soc Sci Med. 2008 Mar;66(6):1418-28.

\section{B}

USING TECHNOLOGY TO REPLACE A FACE-TO-FACE VISIT: USING TELEHEALTH IN A PEDIATRIC CHRONIC PAIN CLINIC Kathy L. Reid, RN, MN

Stollery Children's Hospital, Edmonton, Alberta

BRIEF DESCRIPTION: The use of technologies such as telehealth allows pediatric institutions to assess and manage the health care needs of children and their families who are geographically disadvantaged when seeking health services (1). Telehealth equipment is available in many health units, hospitals and schools across Canada. The Canadian Nurses Association and the Canadian Medical Association both recognize the importance of using telehealth (2,3). Advantages of using telehealth include increased access to care, decreased travel costs for families, and the ability for children and adolescents to participate from their home town and even from their school. Barriers to the use of telehealth include concerns regarding privacy, security breaches, and the resistance of users, including both health care professionals and clients $(4,5)$. Research has shown that the use of telehealth is an effective method of teaching pediatric diabetes (6), as well as an effective 
delivery method of a mindfulness program for adults with chronic pain (7). Parents and adolescents report satisfaction with telehealth for child psychiatry assessments (8).

This workshop will address how telehealth has been used to implement our Pain 101 pain management course for children over the age of 10 years. This 10-week course teaches cognitive-behavioural strategies to manage pain, including relaxation, pacing, sleep hygiene, changing thoughts and setback planning. We also offer a 2-hour pain management session for parents of children attending Pain 101. Offering these sessions via telehealth improves access to care, dramatically decreases costs to families, allows patients to remain in school and reduces repeat visits to the city for treatment. To date, a large and growing number of children have attended Pain 101. Approximately 30\% have attended via telehealth. Pain 101 outcome data will be presented with comparisons between children enrolled in Pain 101 via telehealth vs. those who attend in person. These outcomes target functional disability, school attendance, sleep, and mood.

\section{REFERENCES}

1. Spooner, S., Gotlieb, E., \& the Steering Committee on Clinical Information Technology and Committee on Medical Liability (2004). Pediatrics, 113, e639 - e643.

2. Canadian Nurses Association (2007). Telehealth: the role of the Nurse (Position Statement). Ottawa.

3. Canadian Medical Association $(1998,2008)$. Telehealth policies. Retrieved from http://policybase.cma.ca/dbtw-wpd/exec/dbtwpub.dll October 12, 2008

4. Kaplan, B. \& Litewka, S. (2008). Ethical challenges of telemedicine and telehealth. Cambridge Quarterly of Health Care Ethics, 17, $401-416$

5. Drotar, D., Greenley, R., Hoff, A., Johnson, C., Lewandowski, A., Moore, M., Spilsbury, J., Witherspoon, D., \& Zebracki, K. (2006). Summary of issues and challenges in the use of new technologies in clinical care and with children and adolescents with chronic illness. Children's Health Care, 35, 91 - 102.

6. Anderson, B., Svorent, B., \& Laffel, L. (2007). Initiatives to promote effective self-care skills in children and adolescents with Diabetes Mellitus. Disease Management and Health Outcomes, 15, 101 - 108.

7. Gardner-Nix, J., Backman, S., Barbati, J., \& Grummitt, J. (2008). Evaluating distance education of a mindfulness-based meditation program for chronic pain management. Journal of Telemedicine and Telecare, $14,88-92$.

8. Elford, D., St. John, K., Ghandi, M., \& Bowering, R. (2001). A prospective satisfaction study and cost analysis of a pilot child telepsychiatry service in Newfoundland. Journal of Telemedicine and Telecare, $7,73-81$

\section{$31 \mathrm{C}$}

\section{REACHING OUT TO CHILDREN WITH CHRONIC PAIN - DISTANCE TREATMENT PROGRAMS}

\section{Bruce D. Dick, PhD}

University of Alberta \& Stollery Children's Hospital, Edmonton,

\section{Alberta}

BRIEF DESCRIPTION: Multidisciplinary treatment programs have been found to be effective in treating children and adolescents with chronic pain (1). Unfortunately, such programs are relatively rare in Canada. Even when families of these children live within program catchment areas, many families requiring services live at a considerable distance from the hospital (2). Consequently, innovative treatment modalities are increasingly being developed and investigated in order to provide families with needed services in a timely and cost-effective way.

Information technology, including web-based delivery, has the potential to provide a medium whereby children with chronic pain and their families can obtain valuable educational materials and interact with skilled service providers from a distance $(3,4)$. There is mounting evidence that these services are effective at providing needed information and treatment strategies, thereby helping children and families take an active role in treatment $(5,6)$. Distance treatment programs have the potential to meet unmet needs, improve mental health and quality of life, reduce travel and operating costs and provide flexibility in services to geographically isolated families while maintaining therapeutic alliance $(6,7,8)$.

\section{REFERENCES}

1. Eccleston C, Yorke L, Morley S, Williams AC, Mastroyannopoulou K. Psychological therapies for the management of chronic and recurrent pain in children and adolescents. Cochrane Database Syst Rev. 2003;(1):CD003968. Review.

2. Dedicated multidisciplinary pain management centres for children in Canada: the current status. Can J Anaesth. 2007 Dec; 54(12):985-91.

3. Hicks C, von Baeyer C, McGrath PJ. Online psychological treatment for pediatric recurrent pain: A randomized evaluation. Journal of Pediatric Psychology. 2005;1-13.

4. Schulpen TW. The burden of nocturnal enuresis. Acta Paediatrica, 86, 981-984.

5. Scogin, F., Bynum, J. Stephens, G., \& Calhoon, S. Efficacy of selfadministered treatment programs: A meta- analytic review. Professional Psychology: Research and Practice. 1990; 21: 42-47.

6. Elgar F, McGrath PJ. Self-administered psychosocial treatments for children and families. Canadian Journal of Clinical Psychology. 2003;59(3):321-339.

7. Lingley-Pottie P, McGrath PJ. A paediatric therapeutic alliance occurs with distance intervention. Journal of Telemedicine and Telecare. 2008; $14: 236-240$

8. Lingley-Pottie P, McGrath PJ. Telehealth: A child and family-friendly approach to mental health-care reform. Journal of Telemedicine and Telecare. 2008;14:225-226

\section{2:00 PM - SESSION 307}

\section{2}

\section{UNRAVELLING CHRONIC PAIN REHABILITATION, AN EXAMINATION OF THE EFFECTIVENESS OF INDIVIDUAL INTERVENTIONS}

Chair: Katherine Harman

Speakers: Maureen Simmonds, PT, PhD; Katherine Harman, PT, PhD; Douglas Cane, PhD

Maureen Simmonds, PT, PhD, McGill University, Montreal, Quebec; Katherine Harman, PT, PhD, Dalhousie University; Douglas Cane, PhD, QEII Health Sciences Centre, Halifax, Nova Scotia

WORKSHOP OBJECTIVE: Rehabilitation for chronic pain is generally offered in multidisciplinary environments with several interventions offered together. Although there are many strategies used, two related rehabilitation strategies - activity pacing and exercise/activity are among the most frequently employed. A review of evidence will be presented covering the combined interventions and these two approaches.

Learning Objectives:

1. To understand the specific and non-specific effects of commonly used and novel interventions in chronic pain rehabilitation.

2. To become familiar with research findings that evaluate the psychosocial outcomes associated with pacing and examine the relationship of pacing to other activity patterns observed in the chronic pain population.

3. To understand the approach to prescribing therapeutic exercise for specific purposes in chronic pain rehabilitation.

\section{A}

\section{WHAT INTERVENTIONS ARE WORKING, WHY AND HOW DO WE KNOW?}

Maureen Simmonds, PT, PhD

McGill University, Montreal, Quebec

BRIEF DESCRIPTION: Rehabilitation for chronic pain generally includes a range of interventions. The rationale used for many such interventions is frequently based on the traditional biomedical model, is often clinically untested, and rarely reappraised and conceptually updated. The purpose of this presentation is to test and challenge the assumptions used to support the use of specific passive and active interventions; evaluate the evidence of efficacy and effectiveness; and where applicable, propose alternative updated explanations that support the perceived or actual efficacy and effectiveness of specific interventions in rehabilitation.

\section{B}

AN EXAMINATION OF EXERCISE INTERVENTIONS AND THE PRESCRIPTION FOR SPECIFIC BENEFIT

Katherine Harman, PT, PhD

Dalhousie University, Halifax, Nova Scotia

BRIEF DESCRIPTION: Exercise is a common rehabilitation intervention for chronic pain patients. Performed in combination 
with other therapies, it can be difficult to separate out effects of individual interventions. When prescribing exercise it is important to attend to the specific benefit being sought, apply principles of therapeutic exercise prescription and test its effectiveness. Exercise approaches for strengthening, stretching and endurance will be discussed. In addition to impairmentbased exercise, other approaches such as graded (quota-based) activity and group exercise programs offer other benefits. Goal-setting and education contribute to the context in which exercise is performed and may enhance the benefits.

\section{$32 \mathrm{C}$ \\ EXAMINING THE EVIDENCE FOR AND AGAINST THE USE OF PACING AS A PAIN MANAGEMENT STRATEGY}

Douglas Cane, PhD

QEII Health Sciences Centre, Halifax, Nova Scotia

BRIEF DESCRIPTION: Instruction in some form of pacing is frequently included as a pain management intervention in both individual and group treatment. However, the effectiveness of pacing as a pain management intervention and the relationship of pacing to psychosocial functioning has seldom been evaluated. Recently a small literature has emerged which has begun to examine the relationship between pacing and psychosocial outcomes such as perceived disability, depression, and activity. Findings to date have been inconsistent with studies reporting both positive and negative associations between pacing and various measures of psychosocial functioning. This presentation reviews the research literature with respect to pacing and its relationship to functioning, and examines factors which may contribute to the discrepant outcomes reported by various studies. Particular attention is paid to the relationship between pacing and avoidance and the manner in which this relationship may mediate the observed relationship between pacing and functioning. Finally, some tentative suggestions are made with respect to enhancing the effectiveness of interventions designed to increase the use of pacing while minimizing the potential that the use of pacing will result in undesirable psychosocial outcomes.

\section{2:00 PM - SESSION 308}

\section{3}

\section{THE BIOPSYCHOSOCIAL-SPIRITUAL MODEL OF PAIN - EVIDENCE AND ETHICS}

Chair: Sharon Habermann

Speakers: Sharon Habermann, PhD, RPsych

Sharon Habermann, PhD, RPsych, Alberta Health Services Chronic

Pain Centre, Calgary, Alberta; Providence Theological Seminary,

Otterburne, Manitoba

WORKSHOP OBJECTIVE: Participants will:

1. Become familiar with empirical research related to spirituality and chronic pain

2. Be introduced to a proposed framework for understanding the potential direct and indirect pathways between spirituality, coping, and chronic pain 3. Become familiar with the ethical issues and guidelines relevant for those who are interested in integrating spirituality and treatment for chronic pain

\section{Learning Objectives:}

1. Become familiar with the empirical research related to spirituality and chronic pain - Spirituality has been linked to many positive mental and physical health outcomes, but relatively little empirical research has been conducted on the importance of spirituality among those with chronic pain, particularly as it pertains to coping and self-management. During the workshop, the pertinent empirical studies will be reviewed, including the efficacy of spiritually-based interventions for chronic pain.

2. Be introduced to a proposed framework for understanding the potential direct and indirect pathways between spirituality, coping, and chronic pain. A framework describing the potential relationship between spirituality, coping, and chronic pain has recently been proposed by Wachholtz et al, 2007. This framework will be presented, with a description of how it relates to previous empirical research.

3. Become familiar with the ethical issues and guidelines relevant for those who are interested in integrating spirituality and treatment for chronic pain. Ethical issues related to applying spiritual interventions with patients will be discussed, along with guidelines for those who wish to address the spiritual domain with patients.

\section{2:00 PM - SESSION 309}

\section{4}

UNDERSTANDING SLEEP AND ITS RELATIONSHIP TO PAIN: AN INTRODUCTION FOR ALLIED HEALTH PROFESSIONS

Chair: Cary Brown

Speakers: Cary Brown, BMR(OT), MA, PhD

Cary Brown, BMR(OT), MA, PhD, Dept of Occupational Therapy,

University of Alberta, Edmonton, Alberta

WORKSHOP OBJECTIVE: Provide an introductory background for allied health professionals to the relationship between disordered sleep and chronic pain.

Learning Objectives:

1. Develop an understanding of basic sleep architecture and its relationship to chronic pain.

2. Explore the Model of Human Occupational (MOHO) as a theoretical construct to better understand the complexity of pain, sleep and function from an allied health professional perspective.

3. Provide participants an opportunity to practice evaluating a patient in an illustrative case-study within the $\mathrm{MOHO}$ systems components of habituation, volition and performance.

\section{A}

UNDERSTANDING SLEEP AND ITS RELATIONSHIP TO PAIN: AN INTRODUCTION FOR ALLIED HEALTH PROFESSIONS

\section{Cary Brown, BMR(OT), MA, PhD}

Dept of Occupational Therapy, University of Alberta, Edmonton,

Alberta

BRIEF DESCRIPTION: We know that there is a relationship between disordered sleep and chronic pain that spans all age groups between children to those elderly persons living in residential care facilities [1-5]. Traditionally healthcare providers have seen disordered sleep (for example insomnia) as a consequence of chronic pain and have assumed that, as pain becomes better managed, restorative sleep patterns will return. However, current research is beginning to support a bi-directional relationship between pain and sleep where the sleep problem may actually have preceded the development of chronic pain [6]. This is an exciting proposal because it highlights the importance of addressing sleep problems early in the intervention process.

There are a range of non-pharmacological interventions for disordered sleep that allied healthcare professionals (AHPs) can implement with their clients who have chronic pain. However, to make the best match between intervention, patient and the socio-cultural context of the treatment environment, AHPs need to understand basic sleep architecture. This workshop will introduce AHP to the basics of sleep, outline how the Model of Human Occupation (MOHO) [7] used by rehabilitation therapists can be applied to better guide evidence -based practice, and offer an illustrative case study. Participants in the workshop will have the opportunity to practice evaluating a patient in an illustrative case-study within the MOHO systems components of habituation, volition and performance. We will provide a resource list of non-pharmacological interventions for AHPs, and there will be an opportunity for participants to share other resources and stories of successful intervention.

\section{REFERENCES:}

1. Hossain, J.L. and C.M. Shapiro, Sleep Breath, 2002. 6(2): p. 85-102.

2. Ireland, J.L. and V. Culpin, J Adolesc Health, 2006. 38(6): p. 649-55.

3. Knutson, K.L., et al., Arch Intern Med, 2006. 166(16): p. 1768-74.

4. Koch, S., et al., J Clin Nurs, 2006. 15(10): p. 1267-75.

5. Palermo, T.M., Pain Res Manag, 2009. 14(1): p. 21-6.

6. Tang, N.K., K.J. Wright, and P.M. Salkovskis, J Sleep Res, 2007. 16(1): p. 85-95.

7. Kielhofner, G., Model of human occupation: Theory and application. 4th ed. 2008, Philadelphia: Lippincott Williams \& Wilkins. 


\section{POSTERS FRIDAY MAY 14 AND SATURDAY MAY 15, 2010}

\section{P1}

\section{CHILDREN'S PAIN COPING STRATEGIES: A COMPARISON BASED ON PARENTAL CHRONIC PAIN STATUS}

Sara Ahola Kohut, MA, York University; Rebecca Pillai Riddell, PhD, CPsych, York University, Hospital for Sick Children; Jennifer Stinson, RN, PhD, CPNP, Hospital for Sick Children, Toronto, Ontario

AIM: To compare children with chronic pain conditions on their self identified coping techniques based on their parent's chronic pain status.

METHODS: A sample of 64 children (Mean age $=13.82$, S.D. $=2.67$ ) with chronic pain was recruited from a Rheumatology Clinic in a university affiliated hospital. Children were required to have experienced a significant pain episode within the past three months. Children and their parents were asked to complete a demographic and general health questionnaire as well as the Pain Coping Questionnaire (Reid, Gilbert \& McGrath, 1998).

RESULTS: From a total sample of 64 parent-child dyads, 34\% of parents reported experiencing chronic pain $(n=22)$. Children with parents coping with chronic pain reported significantly higher rates of internalizing $(p=.00)$. There was also a trend for these children to report higher rates of externalizing $(\mathrm{p}=.06)$ and lower rates of problem solving $(\mathrm{p}=.06)$. A comparison of parent-child consistency found that parents with chronic pain did not differ significantly from their children on their reports of their child's coping strategies except information seeking $(p=.01)$. In contrast, parents without pain had significantly different ratings from their children on internalizing, externalizing, behavioural distraction and information seeking (all $\mathrm{p}<.05$ ).

CONCLUSIONS: Rheumatology patients who have parents who also suffer from chronic pain report using significantly more maladaptive coping strategies, most notably internalizing thoughts and behaviours (e.g. catastrophizing). Results also suggest that parents who suffer from chronic pain may be more in tune with their child's coping strategies.

\section{P2}

KANGAROO CARE: HOW FATHERS AND MOTHERS FEEL ABOUT IT AS AN INTERVENTION TO MANAGE PAIN IN THEIR PRETERM INFANTS

Marsha Campbell-Yeo, MN, PhD c, IWK Health Centre, Halifax, Nova Scotia, and McGill University; Celeste Johnston, PhD, McGill University; Françoise Filion, MN, McGill University; Anne-Monique Nuyt, MD, Ste. Justine Hospital; Patricia Bourgault, MD, Sherbrooke University; Lucie LaFond, BScN, Ste. Justine Hospital; Suzanne Whissel, BScN, Sherbrooke Universty, Montreal, Quebec; Kim Caddell, BScN, IWK Health Centre, Halifax, Nova Scotia

AIM: Maternal skin-to-skin or kangaroo care $(\mathrm{KC})$ has been consistently shown to diminish procedural pain and improve physiological recovery in preterm infants. To date, studies examining Kangaroo Care (KC) as an intervention for pain management has focused primarily on mothers. There have been no reports of others' experience providing $\mathrm{KC}$ during heelstick. The purpose of this study was to understand father's attitudes in comparison to mothers after they have provided $\mathrm{KC}$ to their preterm infant during a heel lance.

METHODS: Fathers and Mothers of infants participating in a multicentered randomized cross-over trial of $\mathrm{KC}$ to reduce pain during heel lance were asked to complete a questionnaire following the procedure.

RESULTS: 69 mothers and 36 fathers completed the questionnaire. The average age was similar for the fathers and mothers, 31 and 29.7 years respectively. All except four were Caucasian. $23 \%$ of mothers and $27 \%$ of fathers had provided $\mathrm{KC}$ at least once in the past for a non pain condition. Mothers were likely to have a higher number of prior exposures. For mothers, number of prior exposures ranged from 0 to 17 and for fathers from 0 to 5 times. Father and mother's expressed similar feelings after KC. Responses fell within four primary themes: being a parent; anxiety, ambivalence, and empathy. When asked if $\mathrm{KC}$ was doing anything beyond helping the infant, fathers and mothers reported only positive feelings.

CONCLUSIONS: Both fathers and mothers almost unanimously supported Kangaroo care during heel lance, the most commonly occurring painful event in the NICU.

\section{P3}

\section{CORRELATION BETWEEN BLOOD PRESSURE AND PAIN INTENSITY DURING HOT AND COLD IMMERSION OF THE ARM}

Philippe Chalaye, MSc, Université de Sherbrooke, Sherbrooke, Quebec; Laurent Devoize, DDS, Université Clermont; Serge Marchand, PhD, Université de Sherbrooke, Sherbrooke, Quebec AIM: Pain activates the sympathetic nervous system, thus generating increases in heart rate and blood pressure. However, such autonomic responses are not always well correlated with the intensity of pain. A better understanding of the autonomic responses to pain could help in the evaluation of pain in the context of patients not able to communicate their pain. METHODS: We measured heart rate and continuous blood pressure in 18 healthy subjects. Each participant verbally evaluated pain every $15 \mathrm{sec}$ onds during a 5 minute immersion of the arm in painfully hot $\left(47.5^{\circ} \mathrm{C}\right)$ and cold $\left(7.0^{\circ} \mathrm{C}\right)$ water done in a randomized order.

RESULTS: Results show that the cold immersion was perceived as significantly more painful than the hot immersion $(\mathrm{p}=0.03)$. Relative mean blood pressure increased significantly more in the cold immersion in comparison to the hot immersion $(\mathrm{p}<0.001)$. Relative heart rate tended to increase more in the hot immersion compared to the cold immersion $(\mathrm{p}=0.06)$. A significant positive correlation was found between the relative change in mean blood pressure and pain intensity during the cold immersion $(\mathrm{R}=0.985, \mathrm{p}<0.001)$ and during the hot immersion $(\mathrm{R}=0.787, \mathrm{p}<0.001)$. On the other hand, heart rate positively correlated with pain intensity during the hot immersion $(\mathrm{R}=0.756, \mathrm{p}<0.001)$ and negatively during the cold immersion $(R=-0.624, p=0.03)$.

CONCLUSIONS: Painful hot and cold immersions seem to have different effects on heart rate possibly due to thermoregulatory mechanisms. Relative mean blood pressure appears to be a better predictor of pain intensity than relative heart rate.

\section{P4}

\section{N-OF-1 TRIALS: NEW RESEARCH TOOL FOR CHRONIC PAIN MEDICINE?}

Alexis M. Codrington, PhD, McGill University Health Centre Pain Centre, Montreal General Hospital; Department of Anesthesia, McGill University; Stéphanie Chevalier, PhD, Department of Medicine, McGill University; McGill Nutrition \& Food Science Centre; Mark A. Ware, MD, McGill University Health Centre Pain Centre, Montreal General Hospital; Departments of Anesthesia and Family Medicine, McGill University; Yoram Shir, MD, McGill University Health Centre Pain Centre, Montreal General Hospital; Department of Anesthesia, McGill University, Montreal, Quebec AIM: Determine a way to optimize treatment given the great heterogeneity within chronic pain patient populations and consequent variability exhibited in response to analgesic medications. The $\mathrm{N}$-of-1 or single-subject trial methodology allows for immediate measurement of treatment efficacy in individual patients.

METHODS: N-of-1 trials are useful for chronic, stable conditions. Proposed treatments have a rapid onset of action and pain should return soon after treatment withdrawal. Patients serve as their own control in blinded treatment comparisons, during multiple randomly allocated crossover pairs. Outcome measures are assessed during each treatment period. RESULTS: In addition to evaluating treatment effectiveness, by running a series of $\mathrm{N}$-of- 1 trials, individual patient assessments can be used to obtain an overall population estimate of treatment efficacy and provide details of patientresponse heterogeneity. The greatest benefit of this study design is, if proven to be effective, the possibility of immediate and continued medical benefit.

CONCLUSIONS: This is an experimental approach particularly valuable for chronic pain management with the potential for immediate impact on patient clinical care and clinical research. Our research unit is using this approach set within the growing field of complementary and alternative medicine research; the effect of soy protein on neuropathic facial pain, a chronic disorder lacking effective pharmacotherapy, will be investigated. The implementation of this study will serve as the lead project to the creation of an $\mathrm{N}$-of-1 program. This endeavor would provide assistance to other physicians in developing and assessing tailored treatments within their practice.

Supported by the Louise $\mathcal{E}$ Alan Edwards Foundation. 
P5

\section{DEVELOPMENT OF TACTILE HYPERSENSITIVITY IN A RAT MODEL OF PERIPHERAL NEUROPATHY IS REDUCED BY PROGESTERONE ADMINISTRATION}

Liliane Dableh, MSc, McMaster University; James L. Henry, PhD, McMaster University, Hamilton, Ontario

AIM: The purpose of this study was to determine if single or repetitive progesterone administration would alter the development of tactile hypersensitivity in a rat model of neuropathic pain, and to determine if early versus late initiation of treatment has an effect on outcome.

METHODS: Rats were implanted with a polyethylene cuff around one sciatic nerve, and withdrawal thresholds of the paw from von Frey filament stimulation were measured on approximately days $2,4,6,8,10,15,20,25$, 35,45 and 85 .

RESULTS: Rats were given progesterone or vehicle starting $1 \mathrm{~h}$ after cuff implantation and then daily until day 4; progesterone-treated rats showed a trend towards recovery compared to vehicle-treated rats. When treatment was started $1 \mathrm{~h}$ after cuff implantation and given daily until day 10 , progesterone-treated rats showed significant recovery in the later part of the study. When treatment was initiated 20 days after cuff implantation and given until day 23 or day 30 , no changes in withdrawal thresholds were observed compared to controls. In this paradigm progesterone did not have an acute effect on withdrawal threshold at 30,60 or 90 min after administration. CONCLUSIONS: These results indicate that progesterone, when administered immediately after nerve injury, and for a sufficient period of time, can attenuate the development of neuropathic pain, and may offer new strategies for the treatment of this highly debilitating type of pain.

\section{P6}

\section{INFANT EMOTIONAL AVAILABILITY AND PAIN REACTIVITY DURING ROUTINE IMMUNIZATIONS}

Laila Din Osmun, MA; Jessica Hillgrove Stuart, MA, York University; Rebecca Pillai Riddell, PhD, York University, The Hospital for Sick Children, Toronto, Ontario

AIM: The goals of this study were to explore the relationships between infant emotional availability towards caregivers and infant pain reactivity during routine infant immunizations.

METHODS: Fifty-nine infants $(M=9.14$ months old, $S D=4.16$ months; range 3 to 18 months) were recruited from three pediatrician clinics from the same neighbourhood in Northwest Toronto and videotaped during routine infant immunizations. Infant emotional availability was coded using the Emotional Availability Scales (EAS; Biringen, 2000), which included two dimensions of infant interactive behaviours, infant responsiveness and infant involvement, and a composite infant emotional availability score. Infant pain reactivity was coded immediately (pain distress reactivity) and 1 minute (pain distress regulation) after needle using the Neonatal Facial Coding Scale (NFCS; Grunau and Craig, 1987).

RESULTS: Exploratory correlations controlling for infant age revealed that the composite infant emotional availability score, as well as the individual infant responsiveness and involvement dimensions, were significantly related to lower facials expressions of pain post immunization, both immediately and 1 minute after needle.

CONCLUSIONS: The results suggest that the quality of infant interactive behaviours towards their caregivers (i.e. emotionally availability) is significantly related to lower infant pain reactivity and better immediate pain reactivity regulation after a needle. It is possible that infants who are more emotionally available towards their caregivers express less pain because they are better able to use their parents to regulate their pain related distress or that perhaps these infants are more available to parents because they express less pain.

\section{P7}

\section{SEX-RELATED DIFFERENCES IN THE ADOLESCENT SOMATOSENSORY CORTEX TO REPEATED ELECTRICAL STIMULATION}

Colleen Dockstader, PhD, Departments of Anesthesia and Pain Medicine; Rosemary Tannock, PhD; Douglas Cheyne, PhD, Program in Neuroscience and Mental Health, The Hospital for Sick Children; Karen D. Davis, PhD, Brain, Imaging and Behaviour-Systems Neuroscience, Toronto Western Research Institute, The University of Toronto; Patricia A. McGrath, PhD, Departments of Anesthesia and Pain Medicine, The Hospital for Sick Children, Toronto, Ontario AIM: Sex-related differences in tactile sensitivities emerge around puberty. However, while studies confirm that there are sex differences in behavioural and neural responses to repeated somatosensory stimuli in adults, no studies have evaluated sex differences to repeated somatosensory stimuli in adolescents. We wished to evaluate sex-related differences in the modulation of cortical rhythms to repeated electrical stimuli in adolescents.

METHODS: We used magnetoencephalography to capture changes in cortical oscillations of the primary somatosensory cortex (SI) in response to non-painful, transcutaneous, median nerve stimulation in a group of healthy boys and girls $(5 \mathrm{M}$, mean age $=14.8$ years $+/-1.5 \mathrm{SD}$; $5 \mathrm{~F}$, mean age $=15.6$ years $+/-2.3 \mathrm{SD}$ ). Over 11 minutes, stimuli were presented every $670 \mathrm{~ms}$ in trains of four followed by a $1.3 \mathrm{~s}$ gap.

RESULTS: Male and female adolescents showed a similar response to the first 50 trains of stimuli, with a broad-spectrum $(1-200 \mathrm{~Hz})$ burst of activity at $\sim 20 \mathrm{~ms}$ followed by suppression of mu $(8-12 \mathrm{~Hz})$ and beta $(13-29 \mathrm{~Hz})$ rhythmic activity and a subsequent beta overshoot (rebound), although males showed higher overall power. Over repeated presentations, males showed consistent mu suppression but decreased beta suppression and increased beta rebound. To the contrary, over time females showed substantially less mu response and reduced beta rebound.

CONCLUSIONS: Since sensorimotor beta rebound is observed during states of cortical inhibition (when domain-specific processing is suppressed), sex differences in beta activity suggest that adolescent males increase inhibition of somatosensory processing to persistent stimuli whereas adolescent females decrease inhibition of repeated stimulation.

\section{P8}

\section{GENDER DIFFERENCES IN CANCER PAIN: THE TAIWANESE EXPERIENCE}

Guo S.L., RN. PhD student, Lawrence S. Bloomberg Faculty of Nursing, University of Toronto, Toronto, Ontario; Lai Y.H., RN, PhD., Department of Nursing, College of Medicine, National Taiwan University, Taipei, Taiwan; Howell D., RN. PhD.; Watt-Watson J., RN. PhD., Lawrence S. Bloomberg Faculty of Nursing, University of Toronto, Toronto, Ontario

AIM: Differences in pain experience were examined between male and female Taiwanese cancer patients for pain-related outcomes.

METHODS: A descriptive, inferential cross-sectional method was used. Patients were recruited from inpatient oncology wards in Taiwan. Participants: Eligible patients were, 1) adults (>18 years), and 2 ) reported cancer-related pain. Measures: Pain experiences were measured using the Brief Pain Inventory-Short Form. Pain and analgesic beliefs were measured with the Pain and Opioid Analgesic Beliefs Scale-(Cancer). Catastrophizing was measured using Catastrophizing subscale, and the Profile of Mood States measured anxiety and depression.

RESULTS: A total of 160 inpatients participated, the mean age was $49.9(\mathrm{SD}=10.4)$ years, and $51.2 \%$ were men. Women reported higher scores on pain intensity and interference, misconceptions about opioids use, pain catastrophizing, mood states than men $(\mathrm{p}<.05)$. For women, pain intensity was moderately associated with pain interference, belief about pain endurance, anxiety, and depression. However, depression was not correlated to pain intensity for men. Regression analysis revealed that pain intensity, depression, and belief about pain endurance were significant predictors for pain interference for women $(\beta=.40, \beta=.32, \beta=-.25, p<.05$, respectively). For men, the significant predictors for pain interference were pain intensity, anxiety, catastrophizing, and physical status $(\beta=.33, \beta=.23, \beta=-.31, \beta=.21, p<.05$, respectively).

CONCLUSIONS: Pain intensity is a predictor of pain interference for both women and men. Women presented higher levels of pain intensity, anxiety and depression than men. Attention to patient self-reports of pain 
and early, effective pain management is critical if clinicians are to relieve the suffering caused by cancer-related pain.

\section{P9}

CHANGES IN MATERNAL FACIAL EXPRESSION OF FEAR AND PAIN AND INFANT FACIAL EXPRESSION OF PAIN DURING PAEDIATRIC IMMUNIZATION

Rachel Horton, MA, York University; Rebecca Pillai Riddell, Ph.D., C. Psych., York University, The Hospital for Sick Children, Toronto, Ontario

AIM: Guided by the Sociocommunication Model, the aim of the current study was to examine how mothers' facial expressions of pain and fear and infants' facial expressions of pain change over the course of paediatric immunization.

METHODS: Thirty-two mother-infant dyads were videotaped during a routine paediatric immunization procedure. Mothers' facial expressions of pain and fear were coded using the Facial Action Coding System (FACS) and infant facial expressions of pain were coded using the Neonatal Facial Coding System (NFCS). Facial expressions for both mothers and infants were coded at four 10-second time periods: 1 minute pre-needle, immediately before needle, immediately after needle, and 1-minute post-needle.

RESULTS: Infants' facial expressions of pain were significantly different at each of the four time periods. Similarly, mothers' facial expressions of pain and fear were significantly different across time periods. Post-hoc pairedsamples t-tests revealed that mothers and infants demonstrated significantly less pain pre-needle versus post-needle. Mothers expressed significantly more fear pre-needle versus post-needle.

CONCLUSIONS: The finding that mothers expressed the highest levels of pain during the period when infants expressed the highest levels of pain is indicative of mothers' empathic connection with their infants. Mothers' expressions of fear indicate the apprehensive anticipation of infant pain. The relationship between maternal and infant facial expressions underscores the interconnectedness and emotional synchrony between caregivers and infants during events that cause pain. Our results highlight how the caregiver-infant relationship is intimately connected to infant pain, as proposed by the Sociocommunication Model.

\section{P10}

\section{THE EFFICACY OF PSYCHOLOGICAL TREATMENTS FOR HEADACHE BASED ON A SYSTEMATIC REVIEW OF META- ANALYSIS OF CONTROLLED TRIALS}

Anna Huguet, Ph.D.; Patrick J McGrath, Ph.D., Centre for Pediatric Pain Research, IWK Health Centre, Halifax, Nova Scotia; Jennifer Stinson, Ph.D., Hospital for Sick Children, Toronto, Ontario; Sander van Zanten, Ph.D., Division of Gastroenterology, University of Alberta, Edmonton, Alberta; Jordi Miró, Ph.D., Pain Research Unit, Rovira i Virgili University, Tarragona, Catalonia, Spain; Carolyn Watters, Ph.D., Faculty of Computer Science, Dalhousie University, Halifax, Nova Scotia; Cathy MacLean, MD, Department of Family Medicine, University of Calgary, Calgary, Alberta; Bonnie MacKay, Ph.D., Faculty of Computer Science, Dalhousie University; Michelle Tougas, BA, Centre for Pediatric Pain Research, IWK Health Centre, Halifax, Nova Scotia

AIM: Recurrent headaches are frequent in the general population. Psychological therapies are commonly used for individuals suffering recurrent headache, because there is substantial evidence from clinical trials that they are effective interventions for the management of pain and its disabling consequences. However, we do not know what the essential components of these psychological therapies are. Ours goals are to search, assess, and synthesize published meta-analyses of controlled trials of psychological treatment for recurrent headaches.

METHODS: The search strategy used to search in the following databases: DARE, Cochrane Database, Medline, EMBASE, and ISI Web of Knowledge was derived from suggestions by Boynton et al. (1998) and White et al. (2001). Two researchers are independently assessing each report derived from our search strategy for eligibility for inclusion in the systematic review (number of abstracts initially identified by our search strategy: 16,749), extracting the information for the review, and assessing the quality of the meta-analyses following the PRISMA's statement checklist (Liberati et al., in press).
RESULTS: We will present our preliminary results that appear to indicate that despite the efficacy of the psychological treatments for recurrent headaches proven by controlled trials, several variables related with both headache population and psychological treatment may effect on how well a psychological intervention works.

CONCLUSIONS: Suggestions for improving research in psychological treatment for recurrent headaches are discussed, as are directions for improving the efficacy of treatments in the clinical setting.

\section{REFERENCES:}

1. Boynton J, Glanville J, McDaid D, Lefebvre C. Identifying systematic reviews in MEDLINE: developing an objective approach to search strategy. Journal of Information Science, 1998:24(3):137-157.

2. Liberati A, Altman DG, Tetzlaff J, Mulrow C, Gøtzsche PC, Ioannidis JP, Clarke M, Devereaux PJ, Kleijnen J, Moher D. The PRISMA statement for reporting systematic reviews and meta-analyses of studies that evaluate health care interventions: explanation and elaboration. Journal of Clinical Epidemiology, in press.

3. White VJ, Glanville JM, Lefebvre C, Sheldon TA. A statistical approach to designing search filters to find systematic reviews: objectivity enhances accuracy. Journal of Information Science, 2001;27(6):357-370.

\section{P11}

\section{THE PREVALENCE OF PSYCHIATRIC FEATURES WITHIN A CHRONIC PAIN POPULATION}

Christina lorio, B.A. (Hons.), Lakehead University, Thunder Bay, Ontario; Constantina Tsirgielis, B.Sc. (Hons.); Elizabeth Pawluk, B.A. (Hons.); Monica Vermani, B.Sc., M.A., Psy.D.; Martin A. Katzman, B.Sc., M.D., F.R.C.P.C., The START Clinic for Mood and Anxiety Disorders, Toronto, Ontario

AIM: The reported prevalence rate of chronic pain within Canada ranges from 20\% to 44\% (Birse, \& Lander, 1998; Smith, Hopton, \& Chambers, 1999). Along with the high prevalence rate of chronic pain comes a high cost to society, including loss of productivity, increased utilization of health care, and a substantial amount of health care expenditures (Turk, Loeser, \& Monarch, 2002). In response to the high cost to the individual as well as to society, examination of this population is imperative to advance treatment options. As coexisting psychiatric disorders are associated with poorer treatment outcomes and greater levels of disability in chronic pain patients (Burns, Johnson, Mahoney, Devine, \& Pawl, 1998; Holzberg, Robinson, \& Geisser, 1996), investigation of these factors is essential.

METHODS: The present study gathered data from 200 chronic pain patients receiving treatment from various pain clinics within the Greater Toronto Area (GTA).

RESULTS: Results revealed the following prevalence rates for current psychiatric presentations within the sample: major depressive episode $(38 \%)$, major depressive episode with melancholic features (28.5\%), dysthymia $(22.5 \%)$, risk of suicidality $(42.5 \%)$, generalized anxiety disorder (37\%), bipolar mood disorder $(2.5 \%)$, panic disorder $(10.5 \%)$, agoraphobia $(33.5 \%)$, social phobia $(19.5 \%)$, specific phobia (18\%), obsessive compulsive disorder $(11 \%)$, post-traumatic stress disorder $(14 \%)$, alcohol dependence $(6 \%)$, alcohol abuse (12\%), substance dependence $(9.5 \%)$, substance abuse (2\%), bulimia (2.5\%), and hypochondriasis (7.5\%).

CONCLUSIONS: These prevalence rates suggest greater attention be given to psychiatric features within this population.

REFERENCES:

1. Birse, T.M., \& Lander, J. (1998). Prevalence of chronic pain. Canadian Journal of Public Health, 89, 129-131.

2. Burns, J., Johnson, B., Mahoney, N., Devine, J., \& Pawl, R. (1998). Cognitive and physical capacity process variables predict long-term outcome after treatment of chronic pain. Journal of Consulting and Clinical Psychology, 66, 434-439.

3. Holzberg, A.D., Robinson, M.E., \& Geisser, M.E. (1996). The effects of depression and chronic pain on psychosocial and physical functioning. The Clinical Journal of Pain, 12, 118-125.

3. Smith, B.H., Hopton, J.L., \& Chambers, W.A. (1999). Chronic pain in primary care. Family Practice, 16, 475-482.

4. Turk, D.C., Loeser, J.D., \& Monarch, E.S. (2002). Chronic pain: Purposes and costs of interdisciplinary pain rehabilitation programs. TEN, 4, 64-69. 


\section{P12}

DEVELOPMENT OF A NOVEL WEB-BASED TOOL FOR THE VISUAL ASSESSMENT OF CHRONIC PAIN

Chitra Lalloo, BHSc, MSc Candidate, McMaster University, Medical Sciences (MSc) Program, Faculty of Health Sciences; James L. Henry, PhD, McMaster University, Department of Psychiatry and Behavioural Neuroscience, Faculty of Health Sciences, Hamilton, Ontario

AIM: The Iconic Pain Assessment Tool (IPAT) is a novel, web-based scale that allows patients to visually document the quality, intensity and location of their pain. Formal and informal pilot testing is intended to facilitate a "bottom-up", patient-directed process of tool development and refinement. METHODS: Direct consumer feedback was collected through the McMaster Pain Institute Open House, monthly pain support group meetings and an educated consumer panel. Informal interviews with a range of health professionals $(n=10)$ were also carried out. Lastly, a formal pilot test of the IPAT was conducted in $n=23$ individuals with chronic pain. Outcome measures were: (i) a written questionnaire, (ii) informal discussion between participant and investigator and (iii) observation of participants as they navigated the tool.

RESULTS: The data indicate that the IPAT is a user-friendly tool that relates well to people with chronic pain. Advice from health professionals suggests that the tool may be helpful for initial pain assessment, monitoring treatment effects, and self-management. Prototype has been modified to reflect the feedback of patients; thus, IPAT-2 features an expanded bank of pain quality icons and a more comprehensive means of recording pain intensity.

CONCLUSIONS: We conclude that the IPAT has potential to significantly enhance the tools available for management of chronic pain. This potential will be explored through future studies involving a larger sample of patients and comparison with existing pain assessment protocols.

\section{P13}

\section{DO CASE MANAGERS AGREE WITH THEIR PATIENTS ON MEASURES OF OUTCOME AT THE END OF A 4-WEEK CHRONIC PAIN MANAGEMENT PROGRAM?}

Wenting Li, BHSc, McMaster University; Eleni G. Hapidou, Ph.D., C. Psych, Hamilton Health Sciences, McMaster University, Hamilton, Ontario

AIM: The Chronic Pain Management Unit at Chedoke Hospital offers an interdisciplinary, multimodal, 4-week program with a cognitive-behavioural orientation. Patients in the program meet regularly with their case manager to review goals, discuss progress, and develop plans for goal accomplishment. Because case managers play a key role in the patients' experience of the program, we want to know whether case managers agree with their patients on measures of program outcome.

METHODS: The study population is a convenience sample of 107 individuals who were admitted to the 4-week pain program from Aug 2008 to July 2009. Patients and their case managers completed two measures of program outcome: a global goal accomplishment questionnaire (scale of 1 to 5), and a program helpfulness questionnaire with 3 subscales, physical, emotional/mental, and social (scale of 0 to 10 for each subscale). A repeated measures analysis of variance procedure was used to compute the magnitude of mean differences between patient and case manager ratings for each scale. Intraclass correlation (ICC) was used to determine the extent of variability between patient and case manager ratings.

RESULTS: For the global goal accomplishment questionnaire, $\mathrm{n}=103$, mean difference $=0.19$, ICC $=0.35$. For the physical subscale of the program helpfulness questionnaire, $\mathrm{n}=107$, mean difference $=0.91$, ICC $=$ 0.25 ; for the emotional sub-scale, $\mathrm{n}=107$, mean difference $=0.14$, ICC $=$ 0.37 ; and for the social sub-scale, $\mathrm{n}=107$, mean difference $=0.76, \mathrm{ICC}=$ 0.02 .

CONCLUSIONS: The low to moderate agreement between patients and case managers suggest that they had different specific criteria for assessing goal accomplishment and program helpfulness. Further research is needed to investigate how patients and their case managers differ in their criteria for assessment of patient progress and program helpfulness.

\section{P14}

\section{PSYCHOMETRIC PROPERTIES AND VALIDITY OF TWO VERSIONS OF THE PAIN ASSESSMENT CHECKLIST FOR SENIORS WITH LIMITED ABILITY TO COMMUNICATE (PACSLAC)}

Amanda Lints-Martindale, M.A., University of Regina; Thomas Hadjistavropoulos, Ph.D., Centre on Aging and Health, University of Regina, Regina, Saskatchewan

AIM: The utility of the Pain Assessment Checklist for Seniors with Limited Ability to Communicate (PACSLAC; Fuchs-Lacelle \& Hadjistavropoulos, 2004) as a pain assessment tool for seniors with advanced dementia has been well documented. Although the full PACSLAC takes less than five minutes to complete, a shorter version has been proposed in the Dutch language (Zwahalen, Hamers \& Berger, 2007). A direct comparison of the two versions has not been conducted. Our goal was to directly compare the psychometric properties of the original PACSLAC with the items that comprise the shorter version.

METHODS: Following all appropriate ethical clearances, patients with severe dementia were filmed during potentially painful routine care procedures (i.e., a flu vaccination, and routine discomforting movements such those involved in some physiotherapy sessions) as well as at rest. Participants' reactions were carefully coded using the PACSLAC.

RESULTS: Analyses involved comparisons of the items that comprise the shorter version with the full set of items comprising the original PACSLAC. While both sets of items could differentiate painful from non-painful states, the effect sizes tended to be higher for the full version. Similarly, internal consistency and inter-rater reliability were somewhat more favourable for the original PACSLAC compared to the items that comprise the shorter version.

CONCLUSIONS: The results suggest that the set of items that comprises the shorter Dutch version of the PACSLAC has satisfactory psychometric properties although effect sizes (pertaining to validity) and reliability coefficients tended to be somewhat higher for the full version.

\section{P15}

\section{DEVELOPMENT OF AN ELECTRONIC DATABASE FOR AN} ACUTE PAIN SERVICE

\section{Brandy Love, BScN, University of Alberta, Edmonton, Alberta}

AIM: An electronic database was developed for the Acute Pain Service, University of Alberta Hospital to record patient characteristics, identify at-risk populations, compare treatment efficacies, and guide practice decisions.

METHODS: Steps in the development involved consideration of the goals for use, relevant variables to include, and a plan for data collection, entry, and analysis. Protocols were also created for data collection, data entry, and quality control. Lastly, the electronic database was evaluated for performance as a data storage and research tool.

RESULTS: The selected variables are supported by current evidence and were approved by the Acute Pain Service. Time required for data collection and the volume of missing data presented as areas for improvement. Protocols were developed to assist with this problem. When assessed as a research tool, the database provided retrospective analysis to support further prospective study for pain management in a selected population.

CONCLUSIONS: The electronic database met the intended goals of data storage and analysis. With continued refinement, the database will help promote quality assurance and evidence-based practice for the Acute Pain Service.

FOOTNOTES/REFERENCES:

1. Dokholyan, R. M., L.H., Falletta, J.M., Jacobs, J.P., Shahain, D., Haan, C.K., \& Peterson, E.D. (2009). Regulatory and ethical considerations for linking clinical and administrative databases. American Heart Journal, 157(6), 971-982

2. Dunwoody, C. J., Krenzischek, D. A., Pasero, C., Rathmell, J. P., \& Polomano, R. C. (2008). Assessment, physiological monitoring, and consequences of inadequately treated acute pain. Journal of

PeriAnesthesia Nursing, 23(1 Suppl), S15-27.

3. Gordon, D. B., Dahl, J. L., Miaskowski, C., McCarberg, B., Todd, K. H., Paice, J. A., et al. (2005). American Pain Society recommendations for improving the quality of acute and cancer pain management: American Pain Society Quality of Care Task Force. Archives of Internal Medicine, 165(14), 1574-1580. 
4. McClellan, M. B., McGinnis, M., Nabel, E.G. \& Olsen, L.M. (2008). Evidence-based medicine and the changing nature of healthcare: Workshop summary: Institute of Medicine.

5. Agency for Healthcare Research and Quality. (2007). Registries for evaluating patient outcomes: A user's guide: Agency for Healthcare Research and Quality.

6. Wittink, H., \& Carr, D. B. (2008). Pain management: Evidence, outcomes, and quality of life: Elsevier.

\section{P16}

\section{EXPERIENCE OF AN INTERDISCIPLINARY CLINIC WITH SPINAL STIMULATION}

Terry McCarvill, BSc, Dalhousie Medical School; Dr. Ian Beauprie, MD FRCPC, Pain Management Unit, QEII Health Sciences Centre; Dr. Rob Brownstone, MD, PhD, FRCSC, Division of Neurosurgery, QEII Health Sciences Centre; Paula Chiasson, OT, QEII Health Sciences Centre, Halifax, Nova Scotia

AIM: To review the practice of our team approach to neurostimulation with respect to need for trials, indications, and infection rates.

METHODS: Our centre assesses neurostimulation candidates in a joint clinic with pain medicine, neurosurgery, and an OT/coordinator. Candidates are reviewed in interdisciplinary conferences attended by physical medicine, and psychology as needed. Qualified candidates are then put forward for trial neurostimulation. We reviewed all candidates, examining the diagnosis, success of trial, and complications.

RESULTS: 74 patient charts were reviewed, consisting of 55 implants, 15 failed trials, and 4 patients awaiting surgery. Roughly 50\% of patients treated had failed back syndrome (FBSS). $87 \%$ of FBSS trials went on to receive permanent systems. Failed trials were most common in the nonoperative sciatica group (50\%).

Two minor infections were seen at trials $(2.7 \%)$, and one minor infection was noted in a permanent implant $(1.8 \%)$. Two serious infections (requiring removal of the device) were noted in the permanent systems (3.6\%). An additional 57 maintenance procedures (battery and hardware replacements or adjustments) were performed without complication.

CONCLUSIONS: Assessment of candidates for invasive and expensive pain management modalities requires careful assessment. Our interdisciplinary care model allows patients to be screened by two specialists at their initial visit. One in five candidates fails to respond to a percutaneous trial. Our most common indication was failed back syndrome. Our serious infection rate of is lower than our centre's previous but is still higher than optimal. Further analysis of these cases may reveal more specific outcome measures.

\section{P17}

THE IMPACT OF PARENT AND CHILD SEX DIFFERENCES ON PARENT-CHILD INTERACTIONS DURING AN EXPERIMENTAL CHILD PAIN TASK

Erin C. Moon, B.A., Dalhousie University; Christine T. Chambers, Ph.D., Dalhousie University \& IWK Health Centre; Patrick J.

McGrath, Ph.D., Dalhousie University \& IWK Health Centre, Halifax, Nova Scotia

AIM: Parent behaviour has a significant effect on children's pain experiences. Child pain reports increase when parents attend to the pain and decrease when parents distract them from the pain. Few studies have addressed how parent and child sex differences affect the interaction between parents and children when children are experiencing pain. This was the aim of the current study.

METHODS: Participants were 40 healthy children (20 M; 20 F) aged $8-12$ years $(M=9.66, S D=1.16)$ and their mothers $(n=40$; age: $M=$ 40.65 years, $S D=5.27)$ and fathers $(n=40$; age: $M=42.22$ years, $S D=$ 4.84) Children completed the cold pressor pain task twice; once with each parent. Parent-child interactions were coded and parent talk was classified as either "attending" or "distracting."

RESULTS: Fathers did not differ in their use of attending and distracting talk with their sons and daughters; however, mothers used significantly more distracting talk with their daughters $(F(1,35)=6.94, p<0.05)$. Child pain complaints were positively correlated with attending talk for both mothers $(\mathrm{r}=0.76, \mathrm{p}<0.001)$ and fathers $(\mathrm{r}=0.77, \mathrm{p}<0.001)$ and negatively correlated with distracting talk for both mothers $(r=-0.64, p<0.001)$ and fathers $(\mathrm{r}=-0.56, \mathrm{p}<0.001)$.
CONCLUSIONS: These findings suggest that while mothers may behave differently when their sons versus daughters experience pain, the impact of maternal and paternal behaviour on child pain is similar.

\section{P18}

\section{EFFECT OF EARLY EXPERIENCES DURING HOSPITALISATION ON PAIN MODULATORY MECHANISM IN PRETERM CHILDREN AND ADOLESCENTS}

Melanie Morin, BSc; Sylvie Lafrenaye, MD, MSc; Louis Couturier, MD student; Serge Marchand, PhD, Université de Sherbrooke, Sherbrooke, Quebec

AIM: Preterm infants undergo several painful procedures in the neonatal intensive care unit, which in the long-term can have undesirable consequences. They may alter the development of endogenous pain control mechanisms (DNIC) and lead to differences in the modulation of pain perception.

METHODS: We measured heat pain threshold, heat pain sensitivity and the strength of DNIC in subjects between 7-17 years old born preterm. Pain threshold was measured with a thermode; pain sensitivity was measured using a temporal summation paradigm ( 2 min. stimulation at constant temperature). The sensitivity was evaluated before and after recruiting the DNIC (by the immersion of the arm in cold water: $10^{\circ} \mathrm{C}$ ). Participants were divided into 2 groups, according to their stages of development: 7-11 years old (before puberty, $n=12$ ), 12-17 years old (during puberty, $n=25$ ).

RESULTS: Results showed that children had lower pain threshold than adolescents $(p<0,05)$. In our children and adolescents groups, what happened during their hospitalisation seems to have an impact on their DNIC efficacy. Preterm children and adolescents who had a longer hospital stay, were exposed to numerous painful procedures and needed more intensive care had a weaker pain inhibition (both ps $>0,05$ ).

CONCLUSIONS: These findings suggest that the pain modulatory mechanism of subjects born preterm is impaired before and during puberty. It would be interesting to see if it improves after puberty.

\section{P19}

\section{THE ROLE OF PSYCHOSOCIAL FACTORS IN PROSPECTIVELY PREDICTING PAIN AND PAIN-RELATED FUNCTIONAL DISABILITY AMONG CHILDREN AND ADOLESCENTS WITH RECURRENT PAIN}

Melanie Noel, M.Sc.; Sara King, Ph.D.; Christine T. Chambers, Ph.D., Dalhousie University and IWK Health Centre; Kelly Hayton, B.Sc., IWK Health Centre; Patrick J. McGrath, Ph.D., Dalhousie University and IWK Health Centre, Halifax, Nova Scotia

AIM: Recurrent pains in children (e.g., headaches and stomachaches) are often associated with social, academic, and emotional difficulties. This study examined the role of child and parent psychosocial factors in predicting pain and disability among children and adolescents experiencing recurrent pain.

METHODS: Participants were 119 children (70 girls) with recurrent headaches and/or abdominal pain aged $8-15$ years $(M=10.84, S D=2.17)$ and their parents. Participants completed baseline questionnaires assessing psychosocial variables such as children's behavioural and emotional functioning, parent's mental health, and family functioning. Four months later, children completed a daily diary over 2 weeks documenting daily pain and associated disability.

RESULTS: There was no relation between the number of days with pain reported in the diary and children's ratings of pain-related disability $(r=.06$, $\mathrm{p}=.63$ ). Children who reported more days with pain in the diary reported lower levels of self esteem $(r=-.23, p<.05)$ and a higher sense of inadequacy $(\mathrm{r}=.22, \mathrm{p}<.05)$. Their parents also had higher scores on obsessive compulsiveness $(\mathrm{r}=.33, \mathrm{p}<.05)$ and depression $(\mathrm{r}=.29, \mathrm{p}<.05)$. Children reporting increased anxiety $(\mathrm{r}=.24, \mathrm{p}<.05)$ had more functional disability. However, after controlling for child sex, age, and initial pain-related disability, the majority of psychosocial variables no longer predicted pain and disability.

CONCLUSIONS: Results suggest that while psychosocial variables are clearly related to pain and disability in children and adolescents with recurrent pain, the relationship is complex. 


\section{P20}

\section{CARDIOVASCULAR FUNCTION DURING PAIN: COMPARING HEMODYNAMIC CHANGE IN HEALTHY ADULTS VERSUS ADULTS WITH CORONARY ARTERY DISEASE}

Sheila O'Keefe-McCarthy, RN BScN MN CNCC(C) PhD student, University of Toronto, Lawrence S. Bloomberg Faculty of Nursing, Toronto, Ontario; Judith McFetridge-Durdle, RN PhD, Director and Professor, Memorial University School of Nursing, Memorial University, St John's, Newfoundland and Labrador

AIM: Cardiovascular deterioration is an adverse outcome of myocardial ischemia. The hemodynamic changes that underlie ischemic pain remain poorly understood. This systematic review examined hemodynamics during pain in healthy adults compared to those with coronary artery disease (CAD).

METHODS: Selection Criteria: Studies. Studies that measured hemodynamics during pain in healthy adults versus adults with CAD. Outcomes: Pain was measured via subjective response to noxious stimuli such as induced coronary occlusion and the cold pressor test. Hemodynamic response was measured via changes in heart rate variability (HRV), blood pressure (BP), cardiac output (CO), stroke volume (SV) and systemic vascular resistance (SVR). Electronic searches in the Cochrane Library, MEDLINE, and CINAHL data bases from 1988-2008 were conducted using $\mathrm{MeSH}$ terms including: pain, hemodynamic parameters, BP, HR, SVR, ischemic cascade, neurochemical cascade, acute myocardial infarction, cardiac nociception, and impedance cardiography. Abstracts, relevant journals, key authors and reference lists were reviewed.

RESULTS: Twelve studies examined hemodynamics during pain, 660 healthy adults and 369 with CAD. All studies reported HR and BP during pain. Five studies documented SV, CO and SVR. Over all, HR, BP, $\mathrm{CO}, \mathrm{SV}$, SVR increased during pain, exercise, and stress. CAD individuals responded to stress or pain with higher SVR compared to healthy individuals. Women reported greater severity in pain intensity. Normotensive persons reported greater pain compared to those with hypertension. Women with CAD experience greater symptomatic bradycardia and hypotension during ischemia compared to men. Inconsistencies in sampling methods, hemodynamic parameter measurement, intervention and noxious stimuli protocols, precludes generalization.

CONCLUSIONS: Hemodynamic consequences on cardiovascular function during ischemic pain are inconclusive. Studies employing robust methods are warranted to examine this problem. A greater understanding of hemodynamic change underlying ischemic pain is critical to improving CAD pain-related assessment and management practices.

\section{P21}

\section{TREATMENT OF REFRACTORY POST HERPETIC NEURALGIA IN TWO ELDERLY PATIENTS WITH SYNTHETIC \\ CANNABINOID \\ Ong, Dr. May Ching, RCPSC - Internal Medicine, St. Paul's Hospital} Vancouver, British Columbia; Snezana Basic, Medical Doctor (Yugoslavia), Valeant Canada, Montreal, Quebec

AIM: To present findings of our retrospective review of using an oral synthetic cannabinoid in the refractory post herpetic neuralgia in elderly patients.

METHODS: Two ladies, 84 and 85 years old presented with post herpetic neuralgia affecting the left $\mathrm{C} 5$-C6 dermatome and right mid thoracic region below the breast and extending to right lower extremity. One developed Herpes Zoster eruption in October 2004 affecting the left shoulder in the C5, C6 dermatome. The second one had the outbreak of chicken pox at age 32 , followed by post herpetic neuralgia involving the right T8-10 dermatome. They had constant aching, burning, and stabbing pain with allodynia to touch. They were treated with: Zovirax, Lyrica $600 \mathrm{mg} /$ day, but experienced drowsiness and weight gain. Intercostals nerve block resulted in severe pain. No benefit from opiates and TCA trial. Lidocaine infusion and Spinal Cord Stimulator (SCS), without benefit. Gabapentin $1800 \mathrm{mg}$ a day with Pregabalin $75 \mathrm{mg}$ twice a day up to $150 \mathrm{mg}$ twice a day with minimal effect. A trial of TENS and acupuncture treatment had no effect. Pain level was 10/10. Also, placed on Wellbutrin and Olanzapine for depression and anxiety secondary to chronic pain.
RESULTS: In 2007 they were placed on trial of nabilone $0.5 \mathrm{mg}$ at HS. The dose was gradually titrated up to $4.0 \mathrm{mg}$ at $\mathrm{HS}$ over one year period. Pain levels decreased significantly to $4 / 10$, and are off opiate.

CONCLUSIONS: Synthetic cannabinoid may be useful as an adjunct in the management of severe post herpetic neuralgia in elderly patients.

\section{P22}

\section{OPIATE SPARING EFFECTS OF CANNABINOID IN TEN REFRACTORY CRPS PATIENTS}

May C. Ong - Lam, RCPSC - Internal Medicine, St. Paul's Hospital Vancouver, British Columbia; Snezana Basic, Medical Doctor (Yugoslavia), Valeant Canada, Montreal, Quebec

AIM: To demonstrate the efficacy and opiate sparing effect of cannabinoid in the management of severe CRPS patients requiring high dose opiates. METHODS: Retrospective analysis conducted. Ten refractory CRPS patients requiring high dose opiate, received cannabinoid resulted in reduction of pain.

RESULTS: Patients analyzed were between 21 years and 49 years old. They were diagnosed with: CRPS II following L5S1 discectomy, CRPS II following left arm brachial plexus injury, CRPS I in all extremities following MVA, CRPS II in all extremities following MVA, CRPS I post soft tissue injury of the right knee, CRPS I post right tibia, fibula fracture secondary to MVA, CRPS I affecting both legs and arms etc. All patients were unable to function and the pain level was 10/10. Patients had burning pain, mottling coldness, and nail and hair changes, and allodynia. Pain was increased by walking, standing or prolonged sitting. The swelling in the extremities was severe. Patients were unable to weight bear on injured extremity.

Patients were treated with different analgesics, opioids, antidepressants, anticonvulsants, sedatives, sympathetic blocks and stellate ganglion blocks with no improvement in pain level or functionality.

Addition of cannabinoid medication resulted in pain level decrease and improved activities of daily living improved. Two patients went to working full time, one is back to part time work and two are in full rehabilitation program.

CONCLUSIONS: Cannabinoid seems efficacious in the management of severe CRPS patients, resulted in significant reduction of pain intensity (40\%-60\%), near complete opiate elimination and functional improvement.

\section{FOOTNOTES/REFERENCES:}

1. Backonja MM . Defining neuropathic pain. Anesth Analg. 2003; 97: 785-790.

2. Merskey, H. 1994. Classification of chronic pain: descriptions of chronic pain syndromes and definitions of pain terms. IASP Press, Seattle.

3. Matzner O, Devor M. Hyperexcitability at sites of nerve injury depends on voltage-sensitive $\mathrm{Na}+$ channels. J Neurophysiol. 1994; 72: 349-359.

4. Suzuki R, Dickenson AH . Neuropathic pain: nerves bursting with excitement. Neuroreport. 2000; 11: R17-R21.

5. Devor M, Wall PD, Catalan N. Systemic lidocaine silences ectopic neuroma and DRG discharge without blocking nerve conduction. Pain. 1992; 48: 261-268.

6. Devor M, Govrin-Lippmann R, Angelides K. Na+ channel immunolocalization in peripheral mammalian axons and changes following nerve injury and neuroma formation. J Neurosci. 1993; 13: 1976-1992.

7. England JD, Gamboni F, Ferguson MA, Levinson SR. Sodium channels accumulate at the tips of injured axons. Muscle Nerve. 1994; 17: 593 598.

8. Gracely RH, Lynch SA, Bennett GJ. Painful neuropathy: altered central processing maintained dynamically by peripheral input. Pain. 1992; 51: 175-194.

9. Obata K, Yamanaka H, Fukuoka T, Yi D, Tokunaga A, Hashimoto N, Yoshikawa H, Noguchi K. Contribution of injured and uninjured dorsal root ganglion neurons. 


\section{P23}

\section{ACUTE POSTOPERATIVE PAIN ANXIETY PREDICTS CHILD AND PARENT OUTCOMES TWO WEEKS AFTER PEDIATRIC SURGERY: A PILOT STUDY}

Gabrielle Pagé, MA, Department of Psychology, York University; Fiona Campbell, MD, Department of Anaesthesia and Pain Medicine, Hospital for Sick Children; Jennifer Stinson, Ph.D.; Lisa Isaac, MD, Department of Anaesthesia and Pain Medicine, Hospital for Sick Children; Andrea L. Martin, MA; Joel Katz, Ph.D., Department of Psychology, York University, Toronto, Ontario AIM: Pain anxiety refers to the thoughts, feelings, bodily sensations, and behavioural responses associated with the anticipation and experience of pain. In children with chronic pain, pain anxiety has been associated with pain-related disability. The goal of the present pilot study was to examine whether pain anxiety in children and parents is associated with levels of postoperative pain and disability, and parents' perceptions of their children's pain, respectively.

METHODS: 57 children undergoing major surgery (male $=22$ ) between the ages of 8 and 18 years (Mean=13.75, SD=2.46) completed the Child Pain Anxiety Symptoms Scale (CPASS), and Numerical Rating Scales for pain intensity at rest (NRSI-R) two days after surgery, and the Functional Disability Index (FDI) two weeks after surgery. One of their parents completed the Pain Anxiety Symptoms Scale (PASS) and a 29-item behavioural measure of their children's pain (Postoperative Pain Measure for Parents; PPMP) two days after surgery.

RESULTS: Multiple linear regression analysis revealed that after controlling for the child's age and gender, CPASS scores significantly predicted NRSI-R two days after surgery $\left(F=4.88, d f=3,52, R^{\wedge} 2=0.220, \beta=.440\right.$, $\mathrm{p}=0.005)$ and total score on the FDI two weeks after surgery $(\mathrm{F}=8.74$, $\mathrm{df}=3,37, \mathrm{R}^{\wedge} 2=0.415, \beta=.577, \mathrm{p}<0.001$ ). After controlling for age and gender of parents, PASS scores significantly predicted total score on the PPMP two days after surgery $\left(F=8.74, d f=3,37, R^{\wedge} 2=0.415, \beta=.577, p<0.001\right)$.

CONCLUSIONS: Pain anxiety is an important construct in the postoperative experience of pain in children and their parents. Future studies should investigate the role of pain anxiety as part of pain prevention and management strategies.

\section{P24 \\ INTERDISCIPLINARY COLLABORATION TO IMPROVE ACCESS AND MAXIMIZE OUTCOMES FOR TOTAL JOINT ARTHROPLASTY PATIENTS}

Patti Kastanias, RN(EC), MSc(A); Arlene Buzon, RN(EC), BScN, MN; Natasha Briggs, RN, BScN, MN-ACNP; Agnes Silaj, BSc(PT); Julie Byrne, RN, BScN, MN, University Health Network, Toronto, Ontario AIM: This purpose of this presentation is to highlight a successful interdisciplinary initiative designed to improve access to care by decreasing length of stay (LOS) and maximizing patient outcomes, including pain control, after total joint replacement (TJR).

METHODS: In 2006, an Ontario Ministry of Health policy mandate was announced to improve access to care by reducing wait times for TJR surgery. Our tri-site hospital center is one of the largest in Canada and houses an internationally renowned Musculoskeletal Health and Arthritis (MHA) program. The APN/NPs in Pain Service and Orthopedics collaborated with Allied Health and the MHA interdisciplinary team to create a "Fast Track Task Force" focused on improving patient outcomes and decreasing LOS. Over a two year period, the Fast Track Task Force integrated current research evidence in multimodal pain management and fast track surgery to create cost effective, short cycle, interdisciplinary quality improvement change strategies to maximize outcomes. This presentation will outline: a) the dynamic interdisciplinary change process, b) relevant recent pain, anesthesia, nursing, and orthopedic research evidence informing the changes, and c) interdisciplinary education and innovative practice changes implemented.

RESULTS: Outcome measures tracked include numerical pain ratings, LOS, descriptive physical performance and activity measures, sedation levels, and frequency of serious adverse events. Sequential improvement cycles were tailored to balance pain control with functional improvements while minimizing adverse events.

CONCLUSIONS: This inspired interdisciplinary effort has been successful in contributing to improvements in access to care, specifically by reducing length of stay, minimizing the frequency of adverse events, and improving functional ability while maintaining optimal pain control.

\section{P25}

DOES PARENTAL VIEWING OF A PREVIOUS

IMMUNIZATION VIDEO IMPACT PARENTAL PAIN RATINGS OR INFANT PAIN EXPRESSIVITY AT THE 4-MONTH IMMUNIZATION?

Nicole Racine, BSc, York University; Rebecca Pillai Riddell, PhD, C.Psych, York University, Hospital for Sick Children; Saul

Greenberg, MD, FRCPC, University of Toronto, Hospital for Sick Children; Hartley Garfield, MD, FAAP, FRCPC, University of Toronto, Hospital for Sick Children, Toronto, Ontario

AIMS: This study served to explore parental resources that impact infant pain reactivity. The objectives of the study were three-fold: 1) To examine the types and frequency of parental resources used by parents of infants at 2 and 4 month of age, 2) To investigate whether the number of parenting resources used by parents was related to infant pain reactivity or parental pain ratings, 3) To investigate if watching a video of their infant's 2 -month immunization impacted parental pain ratings or infant pain reactivity at the 4 month immunization.

METHODS: An analysis was conducted using 138 parent-infant dyads who were selected from a larger longitudinal study of parents who accompanied their infants in a routine immunization at 2 and 4-months of age.

RESULTS: Parents reported using a variety of parenting resources. Parenting books were the most frequently used resource at 2 and 4 months of age. Correlation analyses revealed that there was no significant relationship between the number of parenting resources used and infant pain reactivity or parental pain ratings. There was also no difference in infant pain reactivity or parental pain rating at 4 months of age between infants whose parents had or had not watched a video of a previous immunization.

CONCLUSIONS: Although parents reported using a variety of different parenting resources, these do not appear to directly impact infant pain reactivity. Additionally, viewing a previous immunization video does not appear to impact parental perceptions of infant pain. More research is needed to investigate factors that may impact parental pain judgments.

\section{P26}

A RANDOMIZED, DOUBLE-BLINDED, PLACEBOCONTROLLED STUDY EVALUATING THE EFFICACY AND SAFETY OF NABILONE AS AN ADJUNCTIVE TO GABAPENTIN IN MANAGING MULTIPLE SCLEROSISINDUCED NEUROPATHIC PAIN: AN INTERIM ANALYSIS

Dana A. Turcotte, B. Sc Pharm, PhD candidate; Micheal P. Namaka, B.Sc Pharm, M.Sc. Pharm, PhD, Faculty of Pharmacy, University of Manitoba; Andrew J. Gomori, MD, Department of Neurology, Health Sciences Centre; Farid Esfahani, MD, Department of Neurology, Health Sciences Centre, Winnipeg, Manitoba AIM: To determine if nabilone is effective in alleviating symptoms associated with multiple sclerosis (MS) - induced neuropathic pain (NPP) when used as adjunctive treatment to gabapentin.

METHODS: A randomized, double-blind, parallel, placebo-controlled study involving 25 patients diagnosed with MS-induced NPP was initiated using nabilone as an adjunctive therapy to gabapentin. Eligible participants previously stabilized on $>1800 \mathrm{mg} /$ day of gabapentin received an oral upward titration of nabilone or matched placebo over 4 weeks, to a target dose of $1 \mathrm{mg}$ twice daily which they continued for 5 additional weeks. Baseline pain evaluations prior to nabilone initiation were comparatively assessed to those at weeks 4 and 9 post-nabilone treatment. Outcome measures include the visual analogue scale (VAS), the Short-Form McGill Pain Questionnaire, Short-Form 36 Health Survey, and the Patient-Rated Global Impression of Change.

RESULTS: Nabilone treatment resulted in an average VAS point reduction of -4.25 at target dose. An average of 2.75 adverse events were noted in the nabilone group. Dizziness \& dry mouth were the most frequently reported $(75 \%)$, followed by drowsiness $(50 \%)$ and nausea $(25 \%)$. No patients discontinued treatment due to adverse events.

CONCLUSIONS: Interim results suggest nabilone as an effective, tolerable adjunctive treatment for MS-induced NPP. 


\section{P27}

\section{CHANGES IN FUNCTIONAL PROPERTIES OF DRG NEURONES IN A RAT MODEL OF PERIPHERAL NEUROPATHIC PAIN}

Yong Fang Zhu, MSC; James L Henry, PhD, McMaster University, Hamilton, Ontario

AIM: The aim of this study was to determine changes in properties of action potentials evoked in primary sensory neurones by dorsal root stimulation in a rat model of sciatic neuropathy.

METHODS: Intracellular recordings were made from the somata of DRG neurons in vivo using the Mosconi and Kruger model of sciatic neuropathy. Sham operated animals served as controls.

RESULTS: Pain scores by von Frey testing confirmed tactile hypersensitivity in model animals only. Changes in C-fibre afferents were not observed. Adelta afferents exhibited minor increases in membrane potential, AP duration and AP fall time. Abeta neurones exhibited the greatest changes, particularly proprioceptive neurones, and included lower peripheral receptive field activation threshold, slower axonal conduction velocity, and increased membrane potential, AP duration, AP rise time, AP fall time, and maximum rising and falling rates.

CONCLUSIONS: The induced peripheral neuropathy is accompanied by changes in functional properties of primary sensory neurones, particularly the large diameter Abeta afferents.

\section{P28}

THE CALGARY CHRONIC PAIN IN-PATIENT CONSULTATION SERVICE: THE FIRST THREE YEARS

A Clark, MD; P Taenzer, PhD; J Boyd, MSN; C Spanswick, MB ChB; M Reyes, MN; R Hanis, MN; L Montgomery, MD; S Chary, MB BS; N Reddy, MB ChB; N Dike, MD; G Schultz, PhD; A Bezuidenhout, BA, Calgary Chronic Pain Centre, Alberta Health Services, Calgary, Alberta

AIM: To review the growth and to evaluate the impact of an in-patient consult service for patients with complex chronic pain staffed by advanced practice nurses and physicians. The service provides consultation and advice rather than direct provision of care.

METHODS: A database was established to collect information concerning the numbers of consultations performed, the frequency of follow-up visits and to capture clinical outcome measures.

RESULTS: The service was established in the first quarter of 2006 at one acute care hospital in Calgary and expanded to all three acute care hospitals by January 2007 to provide advice about the management of chronic pain. Consultations per quarter increased from 105 in 2007 to 178 in 2009, similarly visits increased from 330 to 661 per quarter. Worst pain intensity $(\mathrm{N}=213)$ before and after consultation in 2007 was $8.4 / 5.5$ and in 2009 was 8.9/6.5 (VAS Scale $0-10)$ with average pain intensity $(\mathrm{N}=212)$ being $6.7 / 3.9$ and 6.7/4.2 respectively. Patient perception of improvement $(\mathrm{N}=216)$ was "very much improved" in $7 \% / 10 \%$, "much improved" in $60 \% / 53 \%$, "minimally improved" in 31\%/31\% and "no change" in 2\%/7\% respectively for 2007 and 2009.

CONCLUSIONS: The chronic pain consult service has shown a steady increase in number of consultations since its inception and appears to have improved the management of the in-hospital complex chronic pain population. We conclude this consultative model has merit in this health care setting.

\section{P29}

\section{A SYSTEMATIC REVIEW EVALUATING INTERVENTIONS FOR TREATING PAINFUL NIPPLES AMONG BREASTFEEDING WOMEN}

Cindy-Lee Dennis, PhD; Kimberley Allen, MN, PhD Student, Lawrence S. Bloomberg Faculty of Nursing, University of Toronto; Felicia M McCormick, MSc; Mary J Renfrew, PhD, York University, Toronto, Ontario

AIM: There are various treatment interventions for the reduction of nipple pain associated with breastfeeding. However, it remains unclear which intervention most effectively resolves or reduces nipple pain. The aim of the systematic review was to identify the effects of all interventions used for the elimination or reduction of nipple pain, and to evaluate the impact of the interventions on breastfeeding exclusivity and duration rates.
METHODS: All randomized and quasi-randomized controlled trials were identified by searching the Cochrane Register of Controlled Trials, MEDLINE, EMBASE, CINAHL and hand searches. Participants were breastfeeding women with variously defined nipple pain. Interventions included pharmacologic and non-pharmacologic interventions (oral and topical), dressings, nipple protection, and expressed breast milk. Trials were independently reviewed by two authors. Data was extracted and entered into Review Manager software (RevMan 2008). Statistical analysis was conducted using RevMan 2008 using fixed-effect meta-analysis for combining data. Where there was significant heterogeneity or when pooling results from studies with different interventions, random-effects meta-analysis was utilized.

RESULTS: Three trials were included in the systematic review, including 469 women from three different countries. Significant heterogeneity and diverse interventions prevented pooling of review data. No significant differences in nipple pain were found for the following comparisons: glycerin gel with breastfeeding correction and education ( 1 trial, $\mathrm{n}=63$; weighted mean difference $(\mathrm{WMD})=0.22,95 \%$ confidence interval $(\mathrm{CI})-0.32$ to 0.76 ); breast shells and lanolin versus no intervention ( 1 trial, $\mathrm{n}=61$; WMD $=$ $-0.20,95 \% \mathrm{CI}-0.60$ to 0.20$)$; glycerin gel dressing versus breast shells and lanolin ( 1 trial, $\mathrm{n}=64$; WMD $=0.42,95 \% \mathrm{CI}-0.09$ to 0.93 ); expressed breast milk versus no intervention ( 1 trial, $\mathrm{n}=151$; study days $1-3, \mathrm{RR}=$ $0.96,95 \%$ CI 0.90 to 1.03 ; study days $4-5, \mathrm{RR}=1.17,95 \% \mathrm{CI} 0.71$ to 1.92 ; study days $6-7, \mathrm{RR}=0.62,95 \% \mathrm{CI} 0.11$ to 3.63 ). A significant decrease in pain scores was found for women using no intervention versus lanolin at 4 to 5 days post-treatment ( 1 trial, $\mathrm{n}=147$; $\mathrm{RR}=1.82,95 \% \mathrm{CI} 1.18$ to 2.83 ), however, this significant difference was not seen at 1 to 3 , or 6 to 7 days posttreatment. When comparing lanolin to expressed breast milk, there were no differences in pain scores after 1 to 3 or 6 to 7 days post-treatment, yet there was a significant decrease in pain for the EBM group at 4 to 5 days posttreatment ( 1 trial, $\mathrm{n}=152, \mathrm{RR}=1.56,95 \%$ CI 1.05 to 2.32 ). Pain scores were significantly lower for women treated with an all-purpose nipple cream compared with lanolin ( 1 trial, $\mathrm{n}=150 ; \mathrm{WMD}=2.51,95 \% \mathrm{CI} 0.60$ to 4.41 ) when measured with the McGill Pain Questionnaire. Significant differences were not found using two other pain measures.

CONCLUSIONS: There is insufficient evidence to support the use of any intervention for the treatment of nipple pain among breastfeeding women. There is preliminary evidence to support further research on the role of expressed breast milk on the reduction of nipple pain. To improve comparability of future research, standardized measurement of nipple pain is required.

\section{P30}

\section{STOP THIS RIDE I WANT TO GET OFF! THE CHRONIC PAIN ROLLER-COASTER: FUELED BY STRESS AND CONFLICT}

Ruth E. Dubin, Ph.D, MD, FCCP, Kingston Family Health Team and Assistant Professor, Department of Family Medicine; Cheryl King Van Vlack, Ph.D, Department of Rehabilitation Medicine, Queen's University, Kingston, Ontario

AIM: Four case studies spanning 6-22 years in a family practice illustrate "pain" visits over the long term and common themes of mood disruption, conflict, and financial stress. Medical, insurance and legal system changes to derail this pattern are suggested.

METHODS: All visits (family MD, consultants, emergency or after-hours clinics) were tabulated to build a chronological graph of patients' healthcare utilization (1). Discussions about medication side-effects or doses, mood disruption (depression, anxiety, insomnia), financial stressors, and conflict with employers, insurers or lawyers, were graphed. Each patient reviewed their history and commented on how they had coped with their experience.

RESULTS: Healthcare utilization patterns resembled a roller-coaster ride with increased visits at times of stressful life events, financial insecurity and mood disorders. Healthcare utilization fell when major conflicts (lawsuits, acceptance of disability) were resolved and some financial stability was achieved.

CONCLUSIONS: Physicians, insurers, lawyers and employers may be contributing to patients' pain and disability by adopting a disbelieving and confrontational approach that is absent in patients suffering other more "visible" disabilities. Better training of physicians in understanding chronic pain as a valid medical condition, teaching patients how to manage stress 
using self-education, mind-body or psychological therapies may help. However widespread changes to insurance and legal systems might avoid this destructive ride.

\section{FOOTNOTES/REFERENCES:}

1. Dubin RE and C King-VanVlack 2009. The Trajectory of chronic pain: can a community-based exercise/educations program soften the ride.

Pain Res Manage: in press.

\section{P31}

\section{VALIDATION OF THE 0-10 NUMERICAL RATING SCALE FOR} CHILDREN WITH CHRONIC PAIN

Khushnuma Amaria, PhD; Erika Kewley, B.A., Department of Anesthesia and Pain Medicine, The Hospital for Sick Children; Stephen Brown, MD, FRCPC; Fiona Campbell, MD, Divisional Centre of Pain Management and Pain Research, Department of Anesthesia and Pain Medicine, The Hospital for Sick Children; Michael Jeavons, MB, ChB, FRCPC, Department of Psychiatry, The Hospital for Sick Children; Jennifer Stinson, RN(EC), PhD, CPNP, Department of Anesthesia and Pain Medicine, The Hospital for Sick Children; Patricia A. McGrath, PhD, Divisional Centre of Pain Management and Pain Research, Department of Anesthesia and Pain Medicine, The Hospital for Sick Children, Toronto, Ontario AIM: In clinical practice, children are often asked to rate the strength of their pain on a simple 0-10 Numerical Rating Scale (NRS). However, the validity of the NRS for children has not yet been determined. Our aim was to determine the concurrent validity of the NRS for assessing the intensity of children's chronic pain in clinical practice and to explore differences in validity by age and sex.

METHODS: During their first consultation at an interdisciplinary pain clinic, 145 children (mean age $=14.1 \pm 2.4,90$ females; 55 males) with chronic pain rated the intensity of their pain at four levels (current, usual, least and strongest) using a verbally-administered 0-10 NRS scale. In a separate session either before or after this appointment, children also rated their pain levels using a validated 0-10 Coloured Analog Scale (CAS).

RESULTS: NRS pain ratings were significantly correlated with CAS ratings for all four levels $(r=.52$ to .66 , all $\mathrm{p}<.001)$ while controlling for age. NRS and CAS mean pain scores were similar for usual $(5.79 \pm 2.41$ and $5.88 \pm 2.21$, respectively), current $(4.55 \pm 2.96$ and $4.71 \pm 2.63$, respectively) and strongest $(8.52 \pm 2.03$ and $8.55 \pm 1.89$, respectively) pains. The absolute differences between children's NRS and CAS pain scores were small (range $=.98 \pm 1.4$ to $1.76 \pm 1.9$ ) and did not differ by sex (all $\mathrm{t}<1.17, \mathrm{p}>.05$ ).

CONCLUSIONS: Numerical rating scales provide valid indices of pain intensity for children 8 years of age and older with chronic pain. NRS are efficient pain scales for clinical practice.

\section{P32}

FUNCTIONAL OUTCOMES OF A BRIEF REHABILITATION ORIENTED SELF MANAGEMENT EDUCATION CLASS

Chris Applewhaite, MScPT; Martha Butler, BHScOT; Cliona Corbett, MScPT, Chronic Pain Centre, Calgary Pain Program, Alberta Health Services, Calgary, Alberta

AIM: To determine functional outcomes of a four week pain education group focussed on topics related to physical rehabilitation.

METHODS: 'SMART Moves' is comprised of four 90 minute sessions, led by a physical therapist, occupational therapist, or kinesiologist. It teaches clients and facilitates application of some basic skills needed to achieve their functional goals. Using the Patient Specific Functional Scale (PSFS), clients select at least three important activities that they are having difficulty with as a result of their chronic pain, and grade their performance. The PSFS is administered before and at the conclusion of the group. RESULTS: Pre and post data was available for 77 clients who completed SMART Moves between June 2008 and Sept 2009. The average change for all clients was 1.4 points. $36 \%$ of the clients reported a detectable change of 2 points or more, and $26 \%$ reported a clinically important change.

CONCLUSIONS: On average clients did not show a significant improvement in their perceived performance of activities using the PSFS over the four weeks. Approximately one third of clients reported a detectable change in their performance, however, $26 \%$ of clients reported a clinically significant change in their performance of activities. It is possible that the PSFS is not sensitive enough to measure change over the four week time frame, or that there is a large disparity between the perceived and actual benefits of the group. Further research to analyse functional changes in the weeks and months following the group is needed. Factors that restricted improvement of client scores also need to be determined. Subsequently, strategies to improve the effectiveness of the group can be developed.

\section{P33}

\section{SEX-RELATED DIFFERENCES IN NMDA RECEPTOR EXPRESSION BY MASTICATORY MUSCLE NERVE FIBRES}

Sammy Au, BSc(Pharm) candidate; Xudong Dong, BDS, PhD; Ujendra Kumar, PhD; Brian E. Cairns, PhD, Faculty of Pharmaceutical Sciences, University of British Columbia, Vancouver, British Columbia

AIM: Injection of glutamate into the masseter muscle is a model of myofascial temporomandibular disorders (TMD). TMD has an increased prevalence in young women, and glutamate-evoked pain is more intense in women than in men. Glutamate injections evoke muscle pain by acting on peripheral NMDA receptors. The present study examined the hypothesis that the sex-related difference in response to intramuscular glutamate injection results from a greater expression of peripheral NMDA receptors by masticatory muscle nerve fibres in females.

METHODS: Nine Sprague-Dawley rats were used to examine masseter ( 3 male, 3 female) and temporalis ( 3 female) muscle expression of peripheral NMDA receptors. Muscle tissue was sliced with a cryostat microtome into 10 -mm thick sections. Immunohistochemistry was performed to examine the expression of PGP9.5, a marker for nerve fibres, and NR2B, a subunit of the NMDA receptors, in the muscle tissue. Tissue slices were observed under a Leica fluorescent microscope. The mean percentage of PGP9.5 positive nerve fibres expressing NR2B subunits was calculated and significant differences between the 3 groups determined with an ANOVA test.

RESULTS: The mean expression of NR2B subunits by nerve fibres in the masseter muscle of females $(85 \pm 5 \%)$ was significantly higher than in males $(56 \pm 3 \%)$. In female rats, the mean expression of NR2B subunits in the temporalis muscle $(66 \pm 1 \%)$ was significantly less than in the masseter muscle. CONCLUSIONS: Differences in muscle nerve fibre expression of NMDA receptors may explain sex and muscle related differences in nociceptor discharge and pain evoked by intramuscular injection of glutamate.

\section{P34}

PATTERNS AND TRENDS IN THE MANAGEMENT OF PAIN IN PRIMARY CARE: A PRACTICE AUDIT

Philip Baer, MDCM FRCPC, Canadian Rheumatology Association; Joseph Kozak, MD CCFP FCFP, West Park Hospital, Etobicoke, Ontario; Gaylord Wardell, BSc MD FRCPC, Wardell Pain Centre, Medicine Hat, Alberta; Roman Jovey, MD, CPM Centres for Pain Management, Mississauga, Ontario

AIM: To understand treatment patterns and trends in chronic pain management in the primary care setting and to identify educational opportunities to improve pain management at the primary care level.

METHODS: A physician database was used to choose a representative sample of Southern Ontario family physicians to conduct an electronic audit of their pain management practice using personal digital assistant (PDA) technology. Participants completed an initial detailed questionnaire designed to profile their usual chronic pain management practices. They were then asked to capture data on approximately 20 consecutive patients who consulted them in the office for a chronic pain problem. Patients with acute pain ( $\leq 3$ months) and/or who had previously consulted a pain specialist were excluded. Physicians then submitted their practice profile and patient results to an electronic database for collation and analysis.

RESULTS: Between February 2009 and May 2009, 41 physicians participated in the practice audit and submitted data on 736 patients. Overall, family physician respondents noted that they spent significantly more time with chronic pain patients than with patients who had other ailments. Participating physicians also felt the need to make compromises with respect to the optimal care of chronic pain, mentioning costs, discomfort with adequate dosing of pain medications and the lack of available multidisciplinary treatment resources as significant barriers. Although $82 \%$ of physicians stated that they were satisfied with their patients' treatment plans, $79 \%$ of patients noted that their ongoing pain was severe enough that it interfered with function.

CONCLUSIONS: Primary care physicians noted several barriers to the optimal management of chronic pain. As well, despite treatment, patients 
continued to report that pain had a significant impact on their activities of daily living.

\section{P35}

CHRONIC PAIN, A COMPOSITE OF MANY CONCURRENT DIAGNOSES - PEELING THE LAYERS OF THE ONION

Pamela Barton, BSc(Hons) MD FRCPC, Alberta Health Services Chronic Pain Centre; Division of Physical Medicine and Rehabilitation, University of Calgary; Geoffrey Schultz, PhD, Alberta Health Services Chronic Pain Centre; John Jarrell, MD FRCSC MS, Alberta Health Services Chronic Pain Centre; Department of Obstetrics and Gynecology, University of Calgary; Noorshina Virani, BScPT MD FRCPC, Alberta Health Services Chronic Pain Centre; Division of Physical Medicine and Rehabilitation, University of Calgary; Ted Findlay, DO CCFP, Alberta Health Services Chronic Pain Centre, Calgary, Alberta

AIM: To determine the specific ICD-10 diagnoses which occur in patients referred to the musculoskeletal pain program of an adult ambulatory interdisciplinary chronic pain program.

METHODS: All patients admitted to the Musculoskeletal Program of the Calgary Health Region Chronic Pain Centre between July 1, 2000 and October 31, 2003 and discharged prior to April 30, 2007 were included. Patients were characterized by general demographics and severity of illness based on a number of standardized measures. The three consulting physicians ( 2 physiatrists and 1 osteopath) used the same diagnostic paradigms for documenting diagnoses. A "pick list" of relevant primary diagnoses: descriptive by body area affected, pathological, biomechanical and psychosocial, as well as secondary diagnoses, was developed and the most appropriate ICD-10 code was applied to each condition with the help of a medical records coding consultant. Charts were reviewed by a medical records technician who documented the diagnoses of each patient based on the initial consultation and subsequent follow up notes.

RESULTS: 172 patients with musculoskeletal pain met study criteria. Their mean age was 45.3 (SD 9.6) years. $29 \%$ were male and $71 \%$ female. Mean scores were 5.9/10 (SD 2.2) for average pain levels, 17.6 (SD 10.9) for Beck Depression Inventory and 37.2 (SD 13.4) for Pain Disability Index. Individual patients had a mean of 15.26 (SD 6.13) relevant pain diagnoses and conditions. In this cohort, 79 diagnoses and conditions were encountered at frequencies ranging from 5 to 165 .

CONCLUSIONS: These patients present with multiple diagnoses which must be considered in developing an appropriate treatment program. The term "chronic pain" is inadequate as a diagnosis.

\section{P36 \\ SELF-EFFICACY IN HEADACHE MANAGEMENT: A QUASI- EXPERIMENT}

Suzanne M. Basiuk, RN, MN, CNN(C); Dr. Karen L. Then, $\mathrm{CCN}(\mathrm{C})$, ACNP, PhD; Dr. James A. Rankin, ACNP, PhD, University of Calgary; Dr. Werner J. Becker, MD, FRCPC, Neurology, University of Calgary; Dr. Tak S. Fung, Ph.D. Statistics, University of Calgary, Calgary, Alberta AIM: To assertain the effectiveness of a headache self-management program offered to clients during the wait-time between referral to a multidisciplinary headache program and consult appointment with a neurologist. This study addressed some gaps in the literature by measuring clients who chose to participate in a self-management program versus random assignment, and it addressed the measurement of headache specific self-efficacy. The primary research objective was to compare headache management selfefficacy scores for clients at baseline, to posttest scores after participation in the headache self-management program.

METHODS: Clients of Calgary Headache Assessment and Management Program, Education Session were recruited; those who chose to attend the SelfManagement Workshop constituted the experimental group. All subjects were given a self-administered, pre-test questionnaire at baseline, including the CESD-R, HDI, HIT-6 and HMSE. The post-test questionnaire was administered during the scheduled neurologist consult. Headache self-efficacy was measured to determine the effectiveness of the self-management program and to compare clients who attended this program to those who chose not to attend. RESULTS: Data were collected on 231 subjects, 23 in the intervention and 208 in the comparision group. Self-efficacy improved for the entire sample $(\mathrm{p}=0.041)$, headache frequency decreased $(\mathrm{p}=0.048)$, quality of life improved $(p=0.003)$ and disability improved for the comparison group but not the intervention group $(\mathrm{p}=0.041)$.

CONCLUSIONS: Small sample size in the intervention group did not allow for meaningful comparisons therefore few differences between groups were found. Benefits seen may have been related to Education Session attendance rather than the intervention itself.

\section{P37}

TEMPORARY SPINAL STIMULATION FOR PERIOPERATIVE MANAGEMENT OF CRPS

Dr. Ian Beauprie, MD FRCPC; Dr. Rob Brownstone, MD, PhD, FRCS; Dr. Justin Paletz, MD, FRCS, QEII Health Sciences Centre, Halifax, Nova Scotia

AIM: CRPS, neuropathic and phantom pain can be refractory to conventional analgesia and worsen if surgery is done on the affected area. We present a case in which intraoperative neurostimulation was used to prevent exacerbation of pain in a patient with CRPS.

METHODS: A 42 year old man sustained a hand injury from a drilling rig resulting in bone and tendon injury to his index finger and amputation of his middle finger. Phantom pain, neuropathic stump pain, and features of CRPS were seen. Conventional blocks and medical management had limited success. A percutaneous trial of epidural dorsal root stimulation of C6 and C7 roots produced good effect. A previously scheduled DIP fusion was done nine days later, with the stimulation maintained at optimal settings through the general anesthetic.

RESULTS: The patient wakened with no hand pain and only discomfort from the iliac crest harvest site. The lead was removed on postop day 2 and noted no hand pain in the subsequent week.

CONCLUSIONS: Interdisciplinary cooperation between plastic surgery, neurosurgery and pain clinic allowed a trial of stimulation to serve as state of the art multimodal analgesia. Controversy exists regarding the optimum analgesic techniques to reduce perioperative flare of CRPS, but neuromodulation should be considered among the techniques for further study.

\section{P38}

HOW DO YOU WRITE PAIN? A PRELIMINARY STUDY OF NARRATIVE THERAPY FOR PEOPLE WITH CHRONIC PAIN

Cary A. Brown, PhD, Dept of Occupational Therapy, Faculty of Rehabilitation Medicine, University of Alberta; Bruce D. Dick, PhD, Depts. of Anesthesiology and Pain Medicine \& Psychiatry, University of Alberta, Edmonton, Alberta

AIM: Chronic pain in the 21st century has been called a health problem of epidemic proportions that, for a small but significant percentage of the population, appears tenaciously resistant to intervention (1). This preliminary study examines if the activity of time specific free-form writing on assigned topics specific to the experience of pain affects patients' perceived level of disability and self-efficacy, selection of positive coping skills, beliefs about pain, and feelings of anger about their current position. Additionally, to better understand the pain experience, we identified emergent themes from the written narratives.

METHODS: Patients were recruited from a multidisciplinary pain treatment program in a large urban centre. Standardized instructions, congruent with Pennebaker's work (2) were given for five discrete writing tasks, each twenty minutes long. Participants did sequential writing tasks at approximately one week intervals. Self-report measures of coping strategies, pain beliefs, pain-related disability, and affect were recorded at the first and last writing session, and at one and three month follow-up. We also carried out thematic analysis of the participants' free-form writing.

RESULTS: We initially saw changes in coping styles, along with reductions in levels of anger and catastrophizing. These changes seemed to correspond closely with the completion of the writing exercises. The initial changes did not persist over the three month follow-up. Four predominant themes emerged across participants' narratives: control, anger, withdrawal from others, and the role of activity.

CONCLUSIONS: These results suggest that narrative writing holds potential benefit for pain coping, and to reduce unhelpful cognitions and behavioural patterns associated with chronic pain.

FOOTNOTES/REFERENCES:

1. Liddle SD, Baxter GD and Gracey JH (2007) Chronic low back pain: patients' experiences, opinions and expectations for clinical management. Disability and Rehabilitation 29(24):1899-1909. 
2. Pennebaker JW (1997) Writing about emotional experiences as a therapeutic process. Psychological Science 8(3):162-66.

\section{P39}

MINOCYCLINE ATTENUATES CENTRAL SENSITIZATION IN MEDULLARY DORSAL HORN IN RATS

Chen Yu Chiang, MD; Kazunori Itoh, PhD, Department of Oral Physiology, Faculty of Dentistry, University of Toronto; Jonathan O. Dostrovsky, PhD; Barry J. Sessle, MDS, PhD, Department of Oral Physiology, Faculty of Dentistry, and Department of Physiology, Faculty of Medicine, University of Toronto, Toronto, Ontario AIM: Our recent studies in a dental inflammatory pain model suggest that blockade of $\mathrm{P}_{2} \mathrm{X}_{7}$ receptors or $\mathrm{p} 38$-MAPK can attenuate central sensitization induced in rat medullary dorsal horn $(\mathrm{MDH})$ nociceptive neurons by inflammatory irritant mustard oil (MO) application to the tooth pulp (Chiang et al., 2008; Xie et al., 2007); both $\mathrm{P} 2 \mathrm{X}_{7}$ receptor and p38-MAPK activities are intimately related to spinal dorsal horn microglial activity. Since minocycline, a derivative of tetracycline, has been used as a potent blocker of microglial activity, the aim of this study was to test if intrathecal superfusion of minocycline attenuates the $\mathrm{MO}$-induced central sensitization in $\mathrm{MDH}$.

METHODS: In urethane/alpha-chloralose-anesthetized adult male rats, the activity of nociceptive-specific neurons was recorded in $\mathrm{MDH}$. Neuronal spontaneous and mechanically-evoked properties were assessed at baseline. Then minocycline $(0.5 \mathrm{mM})$ or phosphate-buffered saline (PBS, as control) was continuously superfused $(0.6 \mathrm{ml} / \mathrm{hr})$ over the caudal medulla, and $\mathrm{MO}$ was applied to the first maxillary molar pulp, and assessments of neuronal properties were made at $10 \mathrm{~min}$ intervals.

RESULTS: After PBS pretreatment, $\mathrm{MO}$ application produced prolonged and significant neuroplastic changes reflecting central sensitization, i.e., increases in neuronal mechanoreceptive field size and pinch/pressureevoked responses and decrease in activation threshold (all $\mathrm{P}<0.01-0.001$, $\mathrm{n}=6$ ). Following pretreatment with minocycline, $\mathrm{MO}$ no longer produced significant changes in these properties (all $\mathrm{P}>0.1-0.3, \mathrm{n}=6$ ).

CONCLUSIONS: These results indicate that activation of microglia may play an important role in the initiation of central sensitization in nociceptive dorsal horn neurons.

Supported by NIH DE-04786 and by CIHR MOP-82831.

\section{P40}

\section{INTRANASAL FENTANYL VERSUS PLACEBO FOR PAIN IN CHILDREN DURING CATHETERIZATION FOR VOIDING CYSTOURETHROGRAPHY}

Seen Chung, MD, Division of Pediatric Emergency Medicine, The Hospital for Sick Children, Department of Pediatrics, University of Toronto, Toronto, Ontario; Ruth Lim, MD, Division of Pediatric Radiology, Division of Nuclear Medicine and Molecular Imaging, Department of Radiology, Massachusetts General Hospital; Ran D. Goldman, MD, Division of Pediatric Emergency Medicine, BC Children's Hospital, Department of Pediatrics, University of British Columbia, Child \& Family Research Institute (CFRI), Vancouver, British Columbia

AIM: To determine if intranasal (IN) fentanyl is effective at decreasing the pain that children feel during the catheterization for voiding cystourethrography (VCUG) when compared with sterile water.

METHODS: We performed a prospective, double-blinded, randomized control trial, using IN fentanyl $(2 \mathrm{mcg} / \mathrm{kg}$ ) compared to sterile water (same volume as fentanyl $2 \mathrm{mcg} / \mathrm{kg}$ ) in children 4-8 years of age who were scheduled for elective VCUG in one urban pediatric tertiary center.

RESULTS: Using the Face Pain Score - Revised, children receiving IN fentanyl scored 2.58 (1.93-3.25 95\% CI) while those receiving sterile water scored $2.86(2.20-3.5195 \% \mathrm{CI})$ showing no statistically significant difference. There were no adverse events.

CONCLUSIONS: Although we were unable to show a statistically significant difference between our study and control groups we believe that this may be due to the technique (positioning, delivery device) and timing of the administration of the IN fentanyl as well as the multi-factorial causes of distress during VCUG. IN fentanyl may be a safe and effective medication in the pediatric population and requires further investigation.
P41

A RANDOMIZED, PLACEBO-CONTROLLED, TITRATION-TOEFFECT, CROSSOVER STUDY OF A COMBINATION OF OXYCODONE AND NALOXONE IN PATIENTS WITH CHRONIC LOW BACK PAIN

C. Cloutier, M.D., CHUS-Hopital Fleurimont, Sherbrooke, Quebec; I. Sutton, M.D., Health Sciences Center, Winnipeg, Manitoba; L. Robinson, M.D., Ottawa; J. Taliano, M.D., St. Catharines; W. O'Mahony, M.D., Corunna Medical Research Centre, Corunna; M. Csanadi, M.D., C\&L Research, Fort Erie; G. Cohen, M.D., Brittania Medical Centre, Mississauga; D. Sinclair, M.D., Aylmer; M. Awde, M.D., London; S. Henein, M.D., SKDS Research Inc., Newmarket; P.S. Piraino, Ph.D.; J. Eisenhoffer, M.D.; Z. Harsanyi, MBA; A.C. Darke, Ph.D.; K.J. Michalko, Pharm.D., Purdue Pharma, Pickering, Ontario

AIM: To examine the efficacy and safety of OXN versus placebo in chronic low back pain patients.

METHODS: Patients requiring opioid therapy underwent a 2-7d opioid washout before randomization to $10 / 5 \mathrm{mg}$ OXN or placebo $\mathrm{q} 12 \mathrm{~h}$, and titrated weekly according to efficacy and tolerability to 20/10,30/15 and 40/20 mg q12h. After 4 weeks, patients crossed over to the alternate treatment for another 4 weeks. Acetaminophen/codeine 300/30mg q4-6h prn was provided for rescue.

RESULTS: Of 83 randomized patients, 54 (65\%) comprised the perprotocol population. OXN resulted in significantly lower VAS $(48.6 \pm 23.1$ vs. $55.9 \pm 25.4 \mathrm{~mm}, \mathrm{p}=0.0296)$ and 5 -point ordinal $(2.1 \pm 0.8$ vs. $2.4 \pm 0.9$, $\mathrm{p}=0.0415)$ pain intensity scores during the last week of treatment than placebo. The overall Pain and Sleep score was significantly better with OXN versus placebo $(200.2 \pm 128.2$ vs. $257.4 \pm 127.8, p=0.0046)$. The total Pain Disability score approached statistical significance between treatments $(34.3 \pm 15.6$ vs. $37.5 \pm 15.2, \mathrm{p}=0.0511)$. OXN did not diminish Bowel Function Index compared to placebo. No differences were observed for the Quebec Back Pain questionnaire or SF-36. 56\% of patients $(p=0.0127)$ and $57 \%$ of investigators $(p=0.0218)$ preferred OXN versus placebo (Patients:24\%, Investigators:28\%) (no preferencePatients:20\%, Investigators:15\%), and both rated the effectiveness of OXN as higher than placebo (Patients: $p=0.0216$; Investigators: $\mathrm{p}=0.0258)$. Patient $(\mathrm{p}=0.0102)$ and investigator $(\mathrm{p}=0.0035)$ Global Impression of Change scores were significantly better for OXN. There were no differences in the number of reported AEs between treatments $(\mathrm{p}=0.0679) .79 \%$ of patients chose to continue receiving OXN in a longterm open-label evaluation.

CONCLUSIONS: OXN is effective for management of chronic low back pain.

\section{P42}

EVALUATING A COMPREHENSIVE PAIN MANAGEMENT PLAN (CPMP) TO MEASURE HEALTH SCIENCE STUDENTS' KNOWLEDGE, SKILLS, AND ATTITUDES FOR COLLABORATIVE PAIN MANAGEMENT

Lynn Cockburn, BSc(OT), MSPH, PhD, Dept. of Occupational Science \& Occupational Therapy; Lalitha Raman-Wilms, BSc(Phm), Pharm.D., FCSHP, Leslie Dan Faculty of Pharmacy; Thuan Dao, DMD, MSc, PhD, Faculty of Dentistry, University of Toronto Centre for the Study of Pain; Judy Watt-Watson, RN, PhD, Lawrence Bloomberg Faculty of Nursing, University of Toronto Centre for the Study of Pain; Leila Lax, M.Ed., PhD(c), Faculty of Medicine; Helen Grad, MScPHM, Faculty of Dentistry; Michael McGillian, RN, PhD, Lawrence Bloomberg Faculty of Nursing, University of Toronto Centre for the Study of Pain; Judith Hunter, BSc(PT), MSc, PhD, Dept. of Physical Therapy, University of Toronto Centre for the Study of Pain, University of Toronto, Toronto, Ontario

AIM: Effective pain management requires health professionals (HP) to understand pain assessment and management, as well as their roles in collaborating to provide comprehensive pain care. We previously developed and implemented a mandatory integrated pain curriculum for pre-licensure students from six HP programs at University of Toronto. As part of a series of outcomes we developed a method for evaluation of a Comprehensive Pain Management Plan (CPMP) to determine whether acquired knowledge 
and skills are integrated and understood for potential translation to future collaborative practice.

METHODS: Students $(n=857)$ were randomly assigned interprofessional teams $(n=81)$. Each team of $8-10$ students developed a CPMP for an assigned case. The CPMPs were scored by a minimum of 2 independent raters. The CPMP evaluation tool, validated in 2004, was developed from components required in a comprehensive assessment plan given to all students. Each CPMP was given a score out of 15 .

RESULTS: The majority of plans were scored $\geq 10 / 15$. They included comprehensive, realistic content and goals, evidence of multiprofessional assessment, family involvement, and appropriate interprofessional contributions in outcome decisions. The interrater reliability in scoring the plans was high $(\geq 95 \%)$.

CONCLUSIONS: Students can effectively integrate their understanding of HP roles and knowledge of pain assessment and management toward a realistic team practice care plan. The rating process was acceptable for the evaluation of IPE learning outcomes for a large group of students. The CPMP evaluation tool was useful to assess knowledge and attitudes for collaboration pain care.

Supported by the University of Toronto Centre for the Study of Pain, and the Council of Health Science and Social Work Deans.

\section{P43}

CLIENT EVALUATIONS OF A BRIEF REHABILITATION ORIENTED SELF-MANAGEMENT EDUCATION CLASS

Cliona Corbett, MScPT; Martha Butler, BHScOT, Chronic Pain Centre, Calgary Pain Program, Alberta Health Services, Calgary, Alberta

AIM: To evaluate client perceptions of the utility of a four week chronic pain education course on topics related to physical rehabilitation.

METHODS: 'SMART Moves' is offered within a context of a publicly funded interdisciplinary rehabilitation treatment program. A total of 64 clients participated in it between July 2008 and May 2009 and completed a final session Evaluation Form. SMART Moves consists of four ninety minute classes led by a physical therapist, occupational therapist or kinesiologist, providing education and application of strategies to daily activities. Topics include: establishing activity tolerances; increasing activity safely; monitoring activity and self-talk; neutral spinal posture and basic body mechanics; activity analysis; pacing and scheduling; basic nutrition; and deep breathing.

RESULTS: $72 \%$ of clients indicated that they were better able to manage their pain as a result of their participation in this course. 57\% indicated that their fear of participating in activities had decreased and $75 \%$ indicated that they were able to incorporate appropriate body mechanics into their selfcare, productive and leisure activities. They also indicated that they were better able to prioritize (92\%) and schedule (82\%) activities; establish activity baselines (70\%); and monitor self-talk (78\%). Approximately half of the participants reported making appropriate dietary changes.

CONCLUSIONS: The majority of participants agreed that SMART Moves introduced strategies that allowed them to better manage their pain.

\section{P44}

\section{EXPLAINING PAIN: CLIENT EVALUATION}

Arlene D. Cox, Ph.D., R.Psych., Chronic Pain Centre, Calgary Pain Program, Alberta Health Services, Calgary, Alberta

AIM: To evaluate client perception of the helpfulness of a two hour presentation designed to inform about the neurophysiology of pain and introduce pain management strategies.

METHODS: A total of 329 clients attended 28 presentations between November 21, 2008 and June 30, 2009 and completed an Evaluation Form at the end of the presentation. The presentation consists of one hour of information about the concept of nociception versus pain, the factors which contribute to the experience of pain and the neurophysiological changes that occur when pain persists. The second hour describes research supported techniques that clients can use to influence their pain experience. Explaining Pain is often the first treatment intervention within our publicly funded interdisciplinary pain management program.

RESULTS: $70 \%$ of the participants agreed or strongly agreed that the presentation was helpful. $65 \%$ of the clients agreed or strongly agreed they were better able to understand their chronic pain. $58 \%$ of the participants agreed or strongly agreed they could start to better manage their chronic pain.
Over $70 \%$ of clients found the following specific concepts helpful or very helpful - "Your brain makes the most sensible story," "Your brain isn't always right," and "Chronic pain changes the nervous system." $71 \%$ of clients found the description of "realistic goals" for chronic pain and techniques for changing their pain helpful.

CONCLUSIONS: The majority of clients perceive the Explaining Pain presentation of significant help in increasing their understanding of chronic pain and awareness of strategies to influence their experience.

\section{P45}

\section{LISTENING TO THE VOICE OF PAIN IN HOME CARE SETTINGS}

Anne L. Dewar, RN PhD; Paula Tognazzini, MSN; Hanneke Croxen, MSN, School of Nursing, University of British Columbia, Vancouver, British Columbia

AIM: Purpose: This research identified issues home care nurses and other health professionals confronted when managing acute and chronic pain in the home setting and identified ways to address these issues.

METHODS: Participants: A total of 29 participants were interviewed from the following disciplines: home care nursing, nurse practitioners, physiotherapy, occupational therapy, social work and medicine. The majority of the participants were nurses. Method: Using an open-ended interview guide, data were collected through in-depth focus groups and individual interviews. Data were analyzed using unitizing and categorizing methods. RESULTS: The two major issues identified were: i) differing values, beliefs and knowledge levels between nurses, patients and their families and, ii) role and communication practices between acute care and community health care organizations. Unless there is a co-morbid condition or treatment requirements, patients with chronic pain are not usually seen in the home and must manage on their own. Selected populations such as older patients, patients with substance abuse and mental health problems provided unique challenges. Participants identified that good pain assessment in the home requires knowing how, and if, pain medications, opioids in particular, are being taken.

CONCLUSIONS: Improved communication between organizations, and health professionals can assist patients and their families to achieve more effective pain management. Opioids were the pharmacological treatment that impacted on all aspects of care and, although often helpful to patients, misconceptions about these medications underscores the need for education at all levels.

\section{FOOTNOTES/REFERENCES:}

1. Thorne, S. Reimer Kirkhan, C, MacDonald-Emes J (1997). Interpretive description: A non-categorical qualitative alternative for developing nursing knowledge. Research in Nursing and Health, 2:169-177.

2. Lincoln Y, Guba E (1985). Naturalistic Inquiry, Sage Newbury Park CA.

\section{P46}

THE IMPACT OF SPINAL CORD STIMULATION ON SUBSEQUENT OPIOID MEDICATION USE

I. C. Fedoroff, PhD, Dept. of Psychiatry; C. Cleary, MD, Dept. of Anesthesiology; M. Ong-Lam, MD, FRPC (C), Dept. of Medicine; W. Mcdonald, MD, FRCPC, Dept. of Anesthesiology, St. Paul's Hospital, Vancouver, British Columbia

AIM: Spinal Cord Stimulation (SCS) is a neuromodulation technique used in the management of severe chronic pain, including neuropathic pain conditions such as complex regional pain syndrome (CRPS), and failed back surgery (FBSS) (Kemler et al., 2000; Kumar et al., 2007). Opioid analgesics are often taken by patients who are candidates for SCS. Unfortunately these drugs can have a significant negative side-effect profile. This study compares the impact of SCS on CRPS and other neuropathic pain conditions with respect to opioid medication use, levels of pain and quality of life.

METHODS: As part of a multidisciplinary assessment patients $(n=49)$ completed a questionnaire detailing the name, daily and weekly dose of all medications currently taken. This questionnaire was repeated at six, twelve and twenty-four month follow-up. Each opioid was converted to an equivalent dose of oral Morphine.

RESULTS: Opioid use at pre-implant was similar between diagnostic groups (CRPS vs. other neuropathic pain) and decreased at 6 months and continued to stay below pre-implant levels. The pattern of use by diagnosis showed some differences between groups. Patients with neuropathic pain 
used less opioids than the CRPS patients at 12 \& 24 months. Corresponding pain levels and satisfaction with quality of life are also tracked over this time period.

CONCLUSIONS: These results indicate that patients (particularly those with neuropathic pain) receiving a SCS may experience other benefits such as reducing opioid use thus potentially reducing the incidence of opioid induced side-effects and could be a marker of improved quality of life.

\section{P47}

\section{FIBROMYALGIA: ADDRESSING CHALLENGES IN} DIAGNOSIS AND MANAGEMENT IN CANADIAN MEDICINE

M. Fitzcharles, MD, McGill University, Montreal, Quebec;

L. Galimova, MD, University of Manitoba, Winnipeg, Manitoba;

R. Jovey, MD, University of Toronto; G. Ko, MD, University of

Toronto, Toronto, Ontario; P. MacDougall, MD, Dalhousie

University, Halifax, Nova Scotia; P. Squire, MD, University of British

Columbia, Vancouver, British Columbia; S. Toth, MD, University of

Calgary, Calgary, Alberta; E.N. Thompson, MD, University of

Ottawa, Ottawa, Ontario; J-L Tremblay, MD, Université de Montréal, Montreal, Quebec

AIM: Fibromyalgia (FM), a legitimate condition with objective neurophysiologic abnormality identified in the research setting, remains a challenge in the clinical domain. Our objective was to identify attitudes and practice patterns of Canadian health care providers treating FM patients, and to suggest areas where improvement will enhance clinical care.

METHODS: A Canadian task force comprised 8 regional 4-hour meetings of 139 Canadian health care professionals, representing various disciplines, led by 8 chairs. Following 2 formal presentations addressing pathogenesis, diagnosis and treatment options, discussion was focussed towards challenges and recommendations regarding FM clinical care from the Canadian perspective. All discussions were recorded and a global summary was compiled.

RESULTS: Knowledge translation of pathophysiological mechanisms of FM remains poor, resulting in continued clinical uncertainty. Both diagnosis and management of FM patients is problematic. Identified challenges include the insecurity of health care professionals in managing patients with chronic pain in general, and FM in particular, absence of an objective test for diagnosis and clinical outcome, the need to balance efficacy, side effects and adherence to treatments, lack of a gold standard of treatment, confusion regarding international guidelines, and clinical constraints of physician time and resources. Recommendations were focussed predominantly towards the need for education, beginning at the undergraduate level and extending across all health care providers and patients, improvement in access to pharmacological and non-pharmacological therapies, and timely access to pain specialists if needed. Recognition of the validity of FM is still lacking by authorities such as governing bodies and insurance providers.

CONCLUSIONS: Although ideal care for FM patients is in a multidisciplinary model, still mostly lacking in the Canadian health care system, most FM patients can be well managed in the primary care setting, provided health care workers are adequately educated. Recognition of FM by the medical community and the general public is improving, but with slower acceptance by governing bodies and insurers.

\section{P48}

\section{SELF-MANAGEMENT GROUP: CLIENT EVALUATION}

Penny Ford, PhD; Colleen Miller, PhD; Dan Li, BSc, Chronic Pain Centre, Calgary Pain Program, Alberta Health Services, Calgary, Alberta

AIM: To evaluate client perception of the helpfulness of a treatment group designed to teach cognitive-behavioral skills to improve client selfmanagement of chronic pain.

METHODS: A total of 235 clients attended 42 treatment groups between October, 2004 and June, 2009 and completed an Evaluation Form. The group consisted of a total of 16 hours of cognitive-behavioral treatment (two hours per week for eight weeks) provided by a psychologist, social worker, or occupational therapist. The psycho-educational group format involved education concerning five major self-management skills (self-monitoring, pacing activities, relaxation strategies, cognitive strategies, communication skills), group member discussion, and home practice of skills. The treatment group was offered within the context of a publicly-funded interdisciplinary pain rehabilitation treatment program.
RESULTS: In terms of client evaluation, $86 \%$ of the clients agreed or strongly agreed that the treatment group was helpful. In addition, $76 \%$ of the clients agreed or strongly agreed that as a result of the Self Management Group, they were better able to manage their chronic pain. In terms of specific skills, $86 \%$ of clients agreed relaxation was helpful while $71 \%$ agreed that self-monitoring was helpful. On average $6 \%$ of clients found the strategies or concepts not helpful. Qualitative analysis of client's written comments on the Evaluation Form suggested that clients valued the treatment group and experienced the group as beneficial.

CONCLUSIONS: Clients perceive that a professionally led cognitivebehavioral treatment group is of significant help and value in selfmanaging their chronic pain.

\section{P49}

\section{RELAXATION GROUP: CLIENT EVALUATION AND OUTCOME}

Penny Ford, PhD; Colleen Miller, PhD; Dan Li, BSc, Chronic Pain Centre, Calgary Pain Program, Alberta Health Services, Calgary, Alberta AIM: To evaluate client perception of the helpfulness and outcome of a treatment group designed teach relaxation skills to improve client selfmanagement of chronic pain.

METHODS: Between December 2008 and August 2009, eight treatment groups were offered. Forty-one clients completed an Evaluation Form and 61 clients completed a weekly Outcome Form. The group consisted of a total of six hours of relaxation skills practice provided by a psychologist, social worker, or occupational therapist. The experiential group format involved practice of six relaxation skills (breathing, body scan, progressive muscle relaxation, autogenics, visualization, pain transformation). The treatment group was offered within the context of a publicly-funded interdisciplinary pain rehabilitation treatment program.

RESULTS: In terms of client evaluation, $88 \%$ of clients agreed or strongly agreed that the treatment group was helpful. In addition, $73 \%$ of clients agreed or strongly agreed that as a result of the group, they were better able to manage their chronic pain. In terms of specific relaxation skills, $93 \%$ of clients found breathing helpful, whereas only $63 \%$ of client found pain transformation helpful. In terms of client outcome, across all six sessions, $58 \%$ of clients' pain levels decreased with practice of relaxation skills. Qualitative analyses of clients' written comments highlight that clients valued the treatment group and experienced the group as beneficial.

CONCLUSIONS: Clients perceive that a professionally led relaxation skills treatment group is of significant help and value in self-managing their chronic pain, and report reduced pain levels.

\section{P50}

\section{NATIONAL GUIDELINE DEVELOPMENT - SAFE AND EFFECTIVE USE OF OPIOIDS FOR CHRONIC NON-CANCER PAIN}

Andrea D. Furlan, MD, PhD, Institute for Work \& Health, Toronto, Ontario; Rhoda Reardon, OT, College of Physicians and Surgeons of Ontario; Clarence Weppler, BSc Pharm, College of Physicians and Surgeons of Alberta; Emma Irvin, BA, Institute for Work \& Health; Angela Mailis-Gagnon, MD, MSc, Comprehensive Pain Program, University Health Network, Toronto, Ontario; Meldon Kahan, MD, Department of Family Medicine, University of Toronto, Toronto, Ontario

AIM: In 2007, the College of Physicians and Surgeons of Ontario (CPSO) realized the need to update their 2000 Chronic Pain Guideline. CPSO coordinated surveys and an environmental scan, and confirmed the need to update the guideline and pointed to the most pressing need to update the chapter of Opioids for Chronic Non-Cancer Pain. In the Fall 2007, the National Opioid Use Guideline Group (NOUGG) was created, with representation from all medical regulatory authorities in Canada.

OBJECTIVE: NOUGG's primary goal is to assist physicians to effectively manage patients with chronic non-cancer pain and prescribe opioids in a safe and effective manner.

METHODS: In 2008, a group of researchers initiated a systematic search of the scientific literature including randomized trials and observational studies. The researchers drafted the recommendations that were reviewed by a National Advisory Panel (NAP). In addition a National Faculty was convened to develop a national implementation strategy. 
RESULTS: Sixty three randomized trials, 213 observational studies, and 2 recently published clinical practice guidelines were used to draft the recommendations. NAP included 49 experts in pain medicine and addiction medicine, and used 3 rounds of review to reach consensus. The National Faculty includes 32 individuals from 9 Provinces and 1 Territory.

CONCLUSIONS: Many activities are planned in Ontario and in Canada to disseminate and implement the guideline to clinicians, pharmacists, policy makers, insurers and the public. The recommendations contained in this guideline will have management and policy implications.

\section{P51 \\ RELATIONSHIPS BETWEEN ACTIVITY PACING AND ADJUSTMENT AMONG INDIVIDUALS WITH PERSISTING PAIN}

Heather Getty, PhD, CPsych; Allan Shapiro, PhD, CPsych; Patricia Morley-Forster, MD; Robert Teasell, MD, St. Joseph's Health Care London, London, Ontario

AIM: Despite an emphasis on activity pacing in treatment programs for chronic pain, there has been limited research on relationships between activity pacing and adjustment to chronic pain. The present study examined relationships between various forms of activity pacing and different aspects of adjustment among pain patients. Relationships between activity pacing and widely-researched psychosocial variables known to be important in adjustment to pain (e.g., experiential avoidance, catastrophizing, fear of pain) were also explored to further understand links between activity pacing and patient outcomes.

METHODS: 350 patients from tertiary chronic pain programs and rheumatology clinics completed self-report measures of activity pacing, a harddriven workstyle, and Type A behaviour. They also completed measures of pain intensity, functional disability, work status, and distress. Measures of activity pacing were also correlated with psychosocial variables prominent in models of chronic pain, including experiential avoidance, pain catastrophizing, and fear of pain.

RESULTS: Measures of pacing, a hard-driven workstyle, and Type A behaviour correlated meaningfully with various aspects of adjustment including pain intensity, disability, and distress. Activity pacing was more strongly related to emotional distress than pain intensity or disability. Activity pacing was also related to lower levels of experiential avoidance, pain catastrophizing, and fear of pain.

CONCLUSIONS: The ability to pace physical activity is a multifaceted construct that is related to better outcomes among individuals with persisting pain. Activity pacing is also meaningfully related to a number of psychosocial variables known to influence adjustment to pain. Further research is needed to test more sophisticated, causal models linking pacing and outcomes among pain patients.

\section{P52}

\section{PERSISTENT SEXUAL AROUSAL SYNDROME (PSAS) AND GENITAL PAIN}

Allan S. Gordon, MD, FRCP(C), Neurologist and Director, Wasser Pain Management Centre, Toronto, Ontario

AIM: Persistent sexual arousal syndrome can refer to the experience of genital arousal that is not associated with sexual stimulation of any kind. These feelings do not go away on their own and cause the individual pain or distress. Pain is not considered to be the prime feature. The author discusses the syndrome in 5 women in whom it was elicited only after detailed questioning. METHODS: Five women have recently been referred to the pelvic pain unit with genital pain. During the detailed evaluation they were found to have PSAS as well.

RESULTS: One young woman was referred with urinary symptoms of interstitial cystitis and was found to have clitoral pain, vulvar pain and dyspareunia as well as PSAS. A second was referred because of a complex history resulting in symptoms of pudendal neuralgia. She had clitoral, vulvar and deeper pain. On direct questioning the pain condition was preceded by PSAS. A third presented with right sided genital pain including clitoral pain. Investigations suggested right pudendal neurlagia. Post-decompression she developed active symptoms of PSAS. The fourth woman presented with general and genital pain and dyspareunia. She had clitoral pain and tumescence vulvar pain and PSAS. The fifth woman had interstial cystitis with urgency and bladder neck pain as well as PSAS verging on hypersexuality with clitoral sensitivity.
CONCLUSIONS: The etiology of the PSAS remains unclear. In all cases they had significant and debilitating genital pain.

These women have been thoroughly investigated and are receiving a multimodal therapeutic regime. PSAS may be more common than is thought and should be enquired after in all women with genital pain.

\section{P53}

\section{PHYSIOLOGICAL AND BIOCHEMICAL CHANGES IN A NOVEL MODEL OF LOW BACK PAIN}

James L. Henry, PhD; Kiran Yashpal, PhD, McMaster University, Hamilton, Ontario; Hee-Jeong Im, PhD, Rush University, Chicago, USA; Howard Vernon, DC, Canadian Memorial Chiropractic College, Toronto, Ontario

AIM: The aim of this study was to measure physiological and biochemical changes induced in the rat by unilateral facet joint compression.

METHODS: Male Sprague Dawley rats were anaesthetized with ketamine and the right L5/6 facet joint was exposed. In model animals the joint was compressed to $\sim 1 \mathrm{~mm}$ by a metal clamp applied for three minutes.

RESULTS: Nociceptive scores to cutaneous application of von Frey filaments as well as to deep axial tissue stimulation, with a blunt algometer, were observed in model but not sham control animals, starting on day 7 and progressively continuing until the end, day 28 . Western blot analysis demonstrated a transient unilateral increase in spinal phosphorylated extracellular receptor kinase (ERK) at 7 days, with progressively less at days 14 and 28. Spinal TNFalpha and IL1beta were increased at 28 days but not at 7 or 14 days.

CONCLUSIONS: The data indicate that compression of one facet joint in the rat produces signs of mechanical hypersensitivity in the rat and that inflammatory mediators are expressed differentially at different times during model development. This is a novel model of low back pain and may provide a means for understanding mechanisms of low back pain as well as a model for development of new treatments for low back pain.

\section{P54}

\section{A SCOPING STUDY OF THE ECONOMIC IMPACT OF CHRONIC PAIN}

James L. Henry, PhD, Department of Psychiatry and Behavioural Neurosciences, McMaster University, Hamilton; Annette Wilkins, MSc, University of Toronto, Toronto; Elizabeth M. Uleryk, MLS, Hospital for Sick Children, Toronto, Ontario; Eamonn Wall, BSc, McGill University, Montreal, Quebec

AIM: The aim was to investigate personal and broader economic costs associated with chronic pain.

METHODS: Using scoping study methodology, article abstracts gathered through a Medline literature search and consultation with two key informants were read, documented and screened for relevance. Relevant articles were then collected, read and summarized into an annotated bibliography. RESULTS: This scoping study incorporated information from the Medline search but also scoped the full scientific literature as well as the grey literature. A specific screening tool was developed, tested, modified and applied to survey this literature, and another tool was developed to disseminate the information gathered through a number of stakeholder channels. Of 262 abstracts derived from the search, 117 were selected for further review. Data extracted were then attributed to the following categories: direct costs, indirect costs, impact on family and friends, cost-effectiveness of pain treatments, pain prevention and knowledge translation.

CONCLUSIONS: Significant detrimental economic effects were noted, as were the severe human costs of chronic pain. Through combination of factors such as unemployment, reliance on medications and dependence on family and friends, the ability to lead functional lives according to standard life habits is significantly reduced for chronic pain patients. These translate into huge economic losses, doing so at the hands of daily struggles, social isolation, severe anxiety, depression and, for some, suicide. Unlike systematic reviews and meta-analyses that focus largely on specific pharmacological treatments, mainly for specific types of chronic pain, the broad survey provided by a scoping review exposed gaps in activity, where new research is needed, and areas of demand for services, and also provides stakeholder engagement in assessment of the literature and in dissemination of information. 
P55

TRANSLATING PAIN NEUROSCIENCE THEORY INTO A CLINICAL/RESEARCH TOOL: CHARACTERIZING THE THERMAL GRILL RESPONSE

ludith Hunter, PhD, Department of Physical Therapy; Maria Brunello, BSc, Department of Physiology; Dranga Ruxandra, BASc, Institute of Biomaterials and Biomedical Engineering; Milos Popovic, $\mathrm{PhD}$, Institute of Biomaterials and Biomedical Engineering; Jonathan Dostrovsky, PhD, Department of Physiology, University of Toronto, Toronto, Ontario

AIM: The thermal grill illusion (TGI) is a paradoxical burning percept induced by the simultaneous application of innocuous warm and cool stimuli in an interlaced pattern. TGI may evaluate thermosensory disinhibition - one proposed mechanism of central neuropathic pain (CNP). Thus the TGI may be a psychophysical test to categorize patients with CNP. However, TGI has only been tested on the hand and only pain intensity after short duration stimuli has been measured. We evaluated 1) the TGI in 4 anatomic areas (palm, back, calf, and plantar surface of foot) and, 2) four methods for response characterization.

METHODS: Thermal stimuli were produced by a $1 \times 6$ matrix of Peltiercontrolled thermodes. Three bar configurations were tested: all bars $40^{\circ} \mathrm{C}$ (warm), all bars $20^{\circ} \mathrm{C}$, and alternating bars $20^{\circ} \mathrm{C} / 40^{\circ} \mathrm{C}$ (TG). Four reporting methods were used: a) Pain intensity during stimulation (on-line VAS); b) Unpleasantness at 5s, 45s and 90s (11- point NRS); c) Pain and unpleasantness immediately after each run (NRS), and d) Quality during and after stimulus (modified MPQ-SF).

RESULTS: 1) There were significant differences in the intensity and quality of TG pain across the body sites. 2) There were two unique temporal profiles of continuous pain ratings. 3) Each bar configuration was perceived as significantly more unpleasant than painful. 4) The TGI unpleasantness had a unique time course compared to that in response to warm or cool stimuli. CONCLUSIONS: Measuring BOTH pain AND unpleasantness DURING a prolonged 60 s TG stimulus may provide useful information about individual differences in the TGI.

FOOTNOTES/REFERENCES: Craig AD, Bushnell MC. The thermal grill illusion: unmasking the burn of cold pain. Science 1994; 265:252-255. Supported by grants from Toronto Rehab (MP). JH was funded by a fellowship from the Canadian Paraplegic Association Ontario and a NSERC/CIHR Collaborative Health Research Projects (CHRP) grant: NSERC \# CHRPJ 350980-2008; CIHR \# CPG 87507.

\section{P57}

\section{FAMILIES AND CHRONIC PAIN: A PILOT META-STUDY OF QUALITATIVE RESEARCH}

Sandra LeFort, PhD, MN, RN; Shirley Solberg, PhD, MN, RN; Joanne Smith-Young, MN, RN, Memorial University of Newfoundland, School of Nursing; Nicole Snow, MN, RN, Centre for Nursing Studies, St. John's, Newfoundland and Labrador, PhD student, University of Alberta, Edmonton, Alberta

AIM: Most research on families and chronic pain has been from a quantitative perspective and measures such outcomes as marital satisfaction, affective changes in other members, beliefs about chronic pain, and quality of life. The aim of this project was to conduct a pilot meta-study of published qualitative research in order to identify some of the effects on families when a family member has chronic pain so as to better conceptualize this problem.

METHODS: We conducted a search of databases MEDLINE, CINAHL, EMBASE, and PsycINFO for qualitative studies using key terms chronic pain and effects on family or family members to locate the studies. We used Paterson et als. guide.

RESULTS: Eighteen studies were located that met our inclusion criteria. Many of the studies focused on how the person with chronic pain perceived the family to be affected, but others were from the perspective of the partner/spouse or in the case of children with chronic pain from the parents' perspective. A variety of methodologies were employed and different theoretical orientations informed these studies. Findings suggest that, within families, having a member with chronic pain has an effect on changing relationships and roles within families, social functioning, and placing restrictions on certain family members. Positive effects were noted such as developing greater empathy or deepening relationships.
CONCLUSIONS: In conclusion, findings from qualitative studies expand the understanding gained from quantitative research of the effects of chronic pain on families.

FOOTNOTES/REFERENCES:

1. Paterson, B. et al. (2001). Meta-study of qualitative health research: a practical guide to meta-analysis and meta-synthesis. thousand oaks: CA: Sage.

\section{P58}

\section{IS PERCEPTION REALITY? PERCEIVED LIMB REPRESENTATION AND CLINICAL PRESENTATION IN COMPLEX REGIONAL PAIN SYNDROME (CRPS)}

Jennifer Lewis, PhD, MSc; Petra Schweinhardt, PhD, MD, McGill University, Montreal, Quebec

AIM: Pain in a limb is the primary feature of CRPS. (1) Those with CRPS have a distorted perception of that limb in terms of size and shape and many express strong feelings of hate and have a desire to amputate it. $(2,3,4,5)$ Prevalence of these disturbances is high. $(2,6)$ Clinically, patients with altered perceptions have difficulty engaging with their affected limb, which can be detrimental to rehabilitation. The aim of this part of a wider study is to establish whether there is a relationship between body perception disturbances expressed by CRPS patients and clinical presentation.

METHODS: To measure the extent of disturbances in body perception, those with CRPS rated various aspects about their affected limb via the body perception disturbance scale (BPDS). Clinically objective signs of swelling using a volumeter and touch via $2 \mathrm{pt}$ discrimination of the affected (A) and unaffected (UA) hands were measured.

RESULTS:

Results table

\begin{tabular}{|c|c|c|c|c|c|c|c|}
\hline ID & $\begin{array}{l}\text { Age/gen- } \\
\text { derl arm } \\
\text { affected }\end{array}$ & $\begin{array}{c}\text { Disease } \\
\text { duration } \\
\text { months }\end{array}$ & $\begin{array}{c}\text { Pain } \\
\text { rating } \\
0-100 \\
\text { VAS }\end{array}$ & $\begin{array}{c}\text { A IUA \% } \\
\text { volumeter } \\
\text { Difference }\end{array}$ & $\begin{array}{c}\text { A/UA } \\
\text { Subjective } \\
\text { perceived } \\
\text { size }\end{array}$ & $\begin{array}{l}\text { A / UA dis- } \\
\text { crimination } \\
\text { threshold } \\
\text { difference } \\
\quad(\mathrm{mm})\end{array}$ & $\begin{array}{c}\text { BPDS } \\
\text { rating } \\
\text { (Max } \\
\text { score } \\
48 \text { ) }\end{array}$ \\
\hline CRPS01 & 59/f/L & 4.5 & 60 & $\begin{array}{c}10 \% \\
\text { increase }\end{array}$ & $\begin{array}{c}\text { Not } \\
\text { assessed } \\
(\mathrm{n} / \mathrm{a})\end{array}$ & $n / a$ & $n / a$ \\
\hline CRPS02 & $36 / \mathrm{m} / \mathrm{L}$ & 19 & 80 & $\begin{array}{c}16 \% \\
\text { increase }\end{array}$ & $\begin{array}{l}\text { hand per- } \\
\text { ceived as } \\
\text { smaller }\end{array}$ & $10 \mathrm{~mm}$ & 26 \\
\hline CRPSO3 & 30/f/L & 66 & 80 & $\begin{array}{c}13 \% \\
\text { decrease }\end{array}$ & $\begin{array}{c}\text { Hand twice } \\
\text { as large }\end{array}$ & $2 \mathrm{~mm}$ & 23 \\
\hline
\end{tabular}

CONCLUSIONS: Perceived size is different from that of objective assessment. We acknowledge that these preliminary data are too small to make statistical comparisons.

FOOTNOTES/REFERENCES:

1. Scadding J., 1999 Textbook of Pain, 835-849.

2. Forderreuther, S., Sailer, U., \& Straube, A. 2004, Pain, vol. 110(3) 756 761.

3. Lewis, J. S. et al. 2007, Pain, vol. 133(1-3) 111-119.

4. Moseley, L. 2005, Neurology, vol. 65(1) 773.

5. Galer, B. S., Butler, S., \& Jensen, M. P. 1995, J Pain Symptom Manage. vol.10(5) 385-391.

6. Galer, B. S. \& Jensen, M. 1999, J.Pain Symptom.Manage. vol. 18(3) 213-217. 


\section{P59}

PHARMACO-EPIDEMIOLOGY OF CHRONIC NON CANCER PAIN (CNCP) PATIENTS ASSESSED AT THE POINT OF ENTRY TO A TERTIARY CARE PAIN CLINIC

Angela Mailis-Gagnon, MD, MSc, FRCPC(PhysMed), Comprehensive Pain Program, Toronto Western Hospital, University of Toronto, Centre for the Study of Pain, Krembil Neuroscience Center, Toronto Western Hospital; Balaji Yegneswaran, MD, Comprehensive Pain Program, Toronto Western Hospital; S. Fatima Lakha, MSc, Comprehensive Pain Program, Toronto Western Hospital, University of Toronto, Centre for the Study of Pain; Ada Louffat, MD, Comprehensive Pain Program, Toronto Western Hospital; Amol Deshpande, MD, MBA, Comprehensive Pain Program, Toronto Western Hospital, Toronto, Ontario

AIM: To describe the opioid prescribing patterns of community physicians for CNCP patients entering a tertiary pain clinic.

METHODS: Cross-sectional study of 455 consecutive CNCP patients over one year period. High Opioid Users (HOU) received $>200 \mathrm{mg}$ Morphine Equivalents (ME) daily. Patients were classified in Group I (pure biomedical pathology), Group II (mixed biomedical causes and psychological factors) and Group III (no detectable physical pathology but psychological factors were considered important) (DSM IV TR2000 classification).

RESULTS: Female to male ratio was $1.2 / 1$. Opioids were prescribed in $55.6 \% ; 1 / 5$ opioid users was HOU; $52.7 \%$ of Group I patients were opioid users but consumed the lowest level of opioids $(\mathrm{F}=58.1 \pm 75.7 \mathrm{ME} ; \mathrm{M}=$ $93.9 \pm 124.4 \mathrm{ME}$ ), while $62.7 \%$ of Group III patients with no detectable pathology used opioids and $1 / 3$ were HOU. Men received substantially higher doses of opioids and were 3 times more likely to be opioid users and 2.5 times more likely to be $\mathrm{HOU}$ as compared to females. Canadian born males and females were 5 and 3.75 times respectively more likely to be HOU as compared to foreign born. Oxycodone containing preparations were by far the most commonly prescribed opioids. Patients were much more likely to be prescribed opioids than NSAIDS for MSK pathology and anti-epileptics for neuropathic problems.

CONCLUSIONS: The data shows that the typical HOU patient is a Canadian born male, $40-55$ years of age, unemployed, with significant psychiatric co-morbidity and little biomedical pathology, who receives primarily oxycodone preparations \pm other opioids.

\section{P60}

\section{PAIN MANAGEMENT IN PRIMARY CARE}

Yolanda Martens van Hilst, RN, Chronic Pain Lead; Dr Isabel Martin, MD, CCFP, Physician Lead, Calgary Foothills Primary Care Network; Dr Chris Spanswick, MB, ChB, FRCA, FFPMRCA, Medical Leader, Calgary Pain Program, Alberta Health Services Chronic Pain Centre; Lorraine Bucholtz, RN, BN, Director, Service Delivery, Calgary Foothills Primary Care Network; Dr Rick Ward, MD CCFP FCFP, Physician Lead, Chronic Disease Management, Calgary Foothills PCN, Calgary Foothills Primary Care Network, Calgary, Alberta AIM: A. Description of the initiative

Primary Care Networks $(\mathrm{PCN})$ are a tri-partite relationship between the Alberta Health Services (AHS), Alberta Health and Wellness (AHW) and the Alberta Medical Association (AMA). Of the Calgary population, 20\% have chronic pain and $3 \%$ have severe chronic pain. It is estimated approximately 48,000 patients within the Calgary Foothills PCN catchment area may have chronic pain. Calgary Foothills PCN physicians identify a need for further resources for patients. The Chronic Pain Centre, Calgary Pain Program, Alberta Health Services (CPC) showed interest in increasing access for the patient with chronic pain through developing partnerships with primary care and education. The Calgary Foothills PCN and CPC launch a pain management program on September 1, 2009.

METHODS: B. Objectives

- To develop a strong integrated service for patients with non-complex chronic pain

- To improve access for patients with chronic pain while offering direct support for physicians and other health care providers

- To optimize multi-disciplinary care for chronic pain patients

- To decrease the number of non complex patients waiting for assessment at the CPC
- To develop physician and multidiscipline team chronic pain leaders throughout the CFPCN

RESULTS: C. Project description

- Multi-professional primary care teams skilled in managing patients with chronic pain

- Tele-chronic pain consultation service

- CFPCN non-complex chronic pain management primary care clinic

- Increase chronic pain primary care education opportunities

- Podcast education on chronic pain topics

- Lunch and learn sessions

- MainPro-C course

- Identify and assertively treat acute care injuries ( $<6$ weeks) and potentially decrease the incidence of the development of chronic pain

- Utilize chronic disease management and living well or other community programs

- Work closely with the CPC to estimate the long-term impact of the program on health care resource

CONCLUSIONS: The Calgary Foothills Primary Care Network and AHS Chronic Pain Centre launched a Primary Care pain management program on September 1, 2009.

\section{P61}

\section{THE EXPERIENCE OF LEARNERS IN THE UNIVERSITY OF TORONTO INTERFACULTY PAIN CURRICULUM SIMULATION TRIAL}

Michael McGillion, RN, PhD; Sara Promislow, PhD; Judy WattWatson, RN, PhD; Judith Hunter, BScPT, PhD; Jennifer Stinson, RN, PhD, University of Toronto; Fiona Campbell, MD, FRCPC, Toronto Hospital for Sick Children; Helen Grad, MScPhm; Andrea Cameron, BSc Phm MBA; Lalitha Raman-Wilms, PharmD FCSHP; Thuan Dao, DMD, PhD; Leila Lax, BScAAM Med; Sheila O'Keefe-McCarthy, MN, PhD student; Lynn Cockburn, PhD; Robyn Davies, MAppScPT, FCAMT; Cindy Shobbrook, RN, MN, ACNP; Louise Rose, MN, PhD, University of Toronto, Toronto, Ontario

AIM: Health care professionals have misbeliefs about pain that contribute to ineffective pain assessment. As part of the 2009 University of Toronto Interfaculty Pain Curriculum (UT-IPC) trial, this study explored the experiences of pre-licensure health sciences students in two different simulationbased interventions designed to improve learners' knowledge of pain-related misbeliefs and pain assessment. These included standardized patients (SP) and deteriorating patient-based simulation (DPS).

METHODS: One hundred and fifty inter-professional students were randomized to a three-hour SP or DPS intervention. Participants completed a post-intervention questionnaire with open-ended questions regarding their intervention experiences, perceived knowledge acquisition, and anticipated changes in practice.

RESULTS: Qualitative questionnaires $(\mathrm{n}=122)$ were coded for major themes by two independent raters with a high level of inter-rater agreement. Salient themes among participants' responses from both arms of the study (SP and DPS) point to a perceived increase in knowledge about pain misbeliefs and management. Participants in both groups reported an increase in their understanding of different professional approaches and roles, and anticipated the use of an interdisciplinary approach in patient care. Direct comments on the simulation-based methods were limited $(n=18)$; however, some preference for the SP method was apparent $(n=10)$.

CONCLUSIONS: The findings suggest that both DPS and SP are viable, effective and satisfactory methods for pre-licensure inter-professional education on pain-related misbeliefs, with comparable impact on learning.

\section{P62}

\section{METHADONE PAIN PROGRAM - LESSONS LEARNED}

Don McIntosh, BSP., Clinical Pharmacist; Chris Spanswick, MB, ChB FRCA, FFPMRCA, Calgary Chronic Pain Centre, Alberta Health Services, Calgary, Alberta

AIM: 1. Review outome of rotating patients to methadone from other opioids for the treatment of refractory chronic pain.

2. Examine obstacles and solutions in an attempt to optimize analgesia and minimize side effects from methadone therapy.

3. Confirm analgesic potency conversion ratio vs. that in published literature. 
4. To develop a clinical pathway to ensure safe practice.

METHODS: Combined retrospective and prospective study to gain qualitative and quantitative data with respect to outcomes including pain measures, morphine equivalent daily dose, final methadone dose, side effects and global impression of change.

Method of rotation was achieved with a modified 3-stage rotation as originally specified by M. Lynch, Pain Res Manage, Vol 10 No. 3 Autumn 2005.

RESULTS: A majority of patients described a positive experience with $63 \%$ of patients reporting better pain control, $21 \%$ returned to their previous opioid and $16 \%$ described little difference between methadone and their previous opioid. Two patients described their pain as worse.

Average conversion ratio appeared to be approximately $10: 1$. The majority of patients converted over a 3 week period to methadone with few requiring a more extended conversion period. A small percentage of patients seemed to find beneficial effect from a combination of a second opioid with methadone. In addition, there was an impression of improvement in aberrent behaviour once stabilized on methadone.

CONCLUSIONS: For a select group of patients, a rotation to methadone was beneficial in terms of analgesia, reduced side effects, maintenance of stable dosing and reduction of aberrent drug behaviour. Published data on dose equivalence (Lynch) appear to represent a safe methodology in conversion to methadone. It is possible to establish a clinical pathway to rotation in this patient group.

FOOTNOTES/REFERENCES:

1. Lynch, ME. A review of the use of methadone for the treatment of chronic non-cancer pain. Pain Research \& Management Vol 10 No 3 p 133-144, 2005.

\section{P63}

\section{SLEEP GROUP: CLIENT EVALUATION}

Colleen Miller, PhD; Penny Ford, PhD; Dan Li, BSc, Chronic Pain Centre, Calgary Pain Program, Alberta Health Services, Calgary, Alberta

AIM: To evaluate client perception of the helpfulness of a treatment group designed teach cognitive-behavioral skills to improve self-management of insomnia secondary to chronic pain.

METHODS: A total of 33 clients attended eight treatment groups between April 2008 and July 2009 and completed an Evaluation Form. The group consisted of 7.5 hours of education of cognitive-behavioral skills ( 1.5 hours per session over eight weeks) provided by a psychologist, social worker, or occupational therapist. The didactic group format involved education concerning cognitive-behavioral skills for insomnia (such as sleep habits, sleep restriction, cognitive strategies, and relaxation imagery). The treatment group was offered within the context of a publicly funded interdisciplinary pain rehabilitation treatment program.

RESULTS: In terms of client evaluation, $73 \%$ of the clients agreed or strongly agreed that the treatment group was helpful. In addition, $73 \%$ of the clients agreed or strongly agreed that as a result of the Sleep Group, they were better able to manage their sleep. Also, $73 \%$ or more of the clients found the following knowledge or skills helpful: sleep facts and sleep cycle, daily sleep diary and sleep habits. As well, 33\% of clients found imagery based relaxation not helpful and 21\% found sleep restriction not helpful. Qualitative analysis of client's written comments on the Evaluation Form highlight that clients valued the treatment group and experienced the group as beneficial.

CONCLUSIONS: Clients perceive that a professionally led cognitivebehavioral treatment group is of significant help and value in self-managing their sleep.

\section{P64}

\section{FAMILY WORKSHOP: CLIENT EVALUATION}

Colleen Miller, PhD; Penny Ford, PhD; Dan Li, BSc, Chronic Pain Centre, Calgary Pain Program, Alberta Health Services, Calgary, Alberta

AIM: To evaluate participants' perception of the helpfulness of a treatment workshop designed to improve clients and family members' adjustment to chronic pain.

METHODS: A total of 172 participants attended 21 treatment workshops between September 2001 and July 2008 and completed an Evaluation Form. The workshop consisted of one three-hour session utilizing a narrative therapy approach provided by either two psychologists or a psychologist and a social worker. The workshop format involved facilitating conversations amongst participants around three questions. The questions asked about the influence of pain on their lives, the influence of cultural ideas about pain on their experience of pain, and how they gained influence over the effects of pain. The treatment workshop was offered within the context of a publicly funded interdisciplinary pain rehabilitation treatment program.

RESULTS: In terms of participants' evaluations, on average, $95 \%$ agreed or strongly agreed that the treatment workshop was helpful. In addition, $92 \%$ agreed or strongly agreed that they had a better understanding of the effects of pain on their lives and relationships, $78 \%$ agreed or strongly agreed that they had more awareness of how cultural ideas influence how they view and cope with the pain and $81 \%$ agreed or strongly agreed that they had more awareness of how they were coping with the pain. Qualitative analyses of participants' written responses highlight that they experienced the workshop as beneficial.

CONCLUSIONS: Clients and their family members perceive that a professionally led narrative therapy treatment workshop is of significant help and value to them.

\section{P65}

\section{A QUALITATIVE ANALYSIS OF HEALTH PROFESSIONALS' ACUTE PAIN ASSESSMENT NARRATIVES ABOUT HOSPITALIZED CHILDREN}

Judith Rashotte, RN, PhD, Children's Hospital of Eastern Ontario, Ottawa; Janet Yamada, RN, PhD(c), The Hospital for Sick Children; Denise Harrison, RN, PhD, University of Toronto; Geraldine Coburn, RN, MN, The Hospital for Sick Children; Laura Abbott, MSc, The Hospital for Sick Children, Toronto; Janice Cohen, PhD, C. Psych, Children's Hospital of Eastern Ontario, Ottawa; Bonnie Stevens, RN, PhD, The Hospital for Sick Children; University of Toronto; Melanie Barwick, PhD, C. Psych; Fiona Campbell, MD, BSc, FRCA, The Hospital for Sick Children, Toronto, Ontario; Christine Chambers, PhD, R. Psych, Dalhousie University; IWK Health Centre, Halifax, Nova Scotia; Greta Cummings, RN, PhD; Carole Estabrooks, RN, PhD, University of Alberta, Edmonton, Alberta; G. Allen Finley, MD, FRCPC, FAAP, Dalhousie University; IWK Health Centre, Halifax, Nova Scotia; Celeste Johnston, RN, DEd, FCAHS, McGill University, Montreal, Quebec; Tricia Kavanagh, RN, $\mathrm{PhD}(\mathrm{c})$, University of Toronto, Toronto, Ontario; Margot Latimer, RN, PhD, Dalhousie University, Halifax, Nova Scotia; Shoo Lee, MD, PhD, FRCPC, Mt. Sinai Hospital, Toronto, Ontario; Sylvie Le May, RN, PhD, Universite de Montreal, Montreal, Quebec; Patrick J. McGrath, PhD, FRSC, Dalhousie University; IWK Health Centre, Halifax, Nova Scotia; Christina Rosmus, RN, MSc, The Montreal Children's Hospital, Montreal, Quebec; Doris Sawatzky-Dickson, RN, MN, RLC, Children's Hospital of Winnipeg, Winnipeg, Manitoba; Shannon Scott, RN, PhD, University of Alberta, Edmonton, Alberta; Souraya Sidani, RN, PhD, Ryerson University; Jennifer Stinson, RN, PhD, The Hospital for Sick Children; Robyn Stremler, RN, PhD, University of Toronto, Toronto, Ontario; Anne Synnes, MD, FRCPC, Children's \& Women's Health Centre of BC; Anna Taddio, BScPhm, PhD, University of Toronto, Toronto, Ontario; Edith Villeneuve, MD, FRCPC, CHU Sainte-Justine, Montreal, Quebec; Fay Warnock, RN, PhD, University of British Columbia, Vancouver, British Columbia; Andrew Willan, PhD, The Hospital for Sick Children, Toronto, Ontario

AIM: To explore and describe health professionals' acute pain assessment narratives documented in hospitalized children's charts.

METHODS: Documented pain assessment narratives were extracted from 3,846 patient charts from the Canadian Paediatric Pain Research database, developed for the CIHR Team in Children's Pain (Stevens et al., 2008). All documented narratives were collected over a 6 -month period from from 32 participating inpatient hospital units ( 4 units at each of 8 participating Canadian paediatric hospitals). Data were analyzed using a summative approach (Hsieh \& Shannon, 2005) to qualitative content analysis guided by Krippendorff (1980) and Miles and Huberman (1994).

RESULTS: Any form of pain assessment within a previous 24-hr period was recorded in 2,630 (69\%) of 3,846 of patient charts reviewed. Of these charts, 26\% ( $\mathrm{n}=1,011)$ had a narrative assessment only, 13\% $(\mathrm{n}=514)$ had a 
narrative assessment plus a pain assessment tool and 29\% $(n=1,105)$ had a pain assessment tool only. Narrative pain assessments were organized as a percentage of the total number of chart entries $(\mathrm{N}=5,412$ in 2,630 charts) and addressed: location of pain: 495 (9\%) and behavioural indicators (e.g. crying) 2,288 (42\%). Narratives also included pain management interventions provided: pharmacological: 989 (18\%); psychological (e.g., comfort measures) 532 (10\%) and physical (e.g., positioning) 507 (9\%).

CONCLUSIONS: Documentation of pain assessment narratives and the use of pain assessment tools were used equally in hospitalized children. Further exploration as to whether these narratives provide clinically useful information to enhance paediatric pain assessment and management is warranted.

\section{P66 \\ HELPING PARENTS WHEN THEIR CHILD OR ADOLESCENT HAS CHRONIC PAIN}

Kathy Reid, MN, NP, Nurse Practitioner, Pediatric Chronic Pain Service, Stollery Children's Hospital; Dr. Bruce Dick, PhD, Assistant Professor, Departments of Anesthesiology and Pain Medicine and Psychiatry, University of Alberta, Clinical Psychologist, Pediatric Chronic Pain Service, Stollery Children's Hospital; Dr. Mark Simmonds, MB FRCA FRCP, Assistant Clinical Professor in Anesthesia and Pain Medicine, University of Alberta

AIM: Parents of children with chronic illnesses often express worry about their children. When an adolescent has chronic pain, parental worry may contribute to disability (1). Parents of children with chronic pain report increased levels of depression, anxiety, and parenting distress (2,3) and restrictions in their own social activities (4). Parental catastrophic thinking about pain may contribute to pain associated disability in the child with chronic pain $(5,6)$. It is important to explore parental understanding of chronic pain, parents' willingness to accept various treatment options for their children, and to ensure that appropriate services are in place to meet both child and parental needs. More research into methods to help parents best support their children in developmentally appropriate ways is needed (7).

METHODS: Parents ( $n=29$ ) were surveyed before their first visit to a pediatric pain clinic regarding their informational needs and treatment expectations.

RESULTS: All parents (mostly mothers) rated information about causes of pain, treatment options, coping strategies, effects of pain on both body and mood as 'important' or 'very important'. They indicated that receiving reading materials was 'important' or 'very important' (83\%); and attending information sessions was 'important' or 'very important' (55\%). Having the pain team "be there" for them was 'important' or 'very important' (93\%). CONCLUSIONS: From this information, clinic programs have been developed to meet parents' needs, including "Pain 101 for Parents", modified reading materials, and sessions with parents to assist them in understanding the biopsychosocial pain model.

FOOTNOTES/REFERENCES:

1. Guite, JW, logan, DE, McCue, R, Sherry, DD, \& Rose, JB. (2008) parental beliefs adn worries regarding adolescent chronic pain. Clinical Journal of Pain 25:3, 223-32.

2. Jordan, AL, Eccleston, C., \& Osborn, M. (2007) Being a parent of the adolescent with complex chronic pain: an interpretive phenomenological analysis. European Journal of Pain, 11, 49-56.

3. Eccleston, C., Crombez, G., Scotford, A., Clinch, J., \& Connell, H. (2004). Adolescent chronic pain: Patterns and predictors of emotional distress in adolescents with chronic pain and their parents. Pain, 108(3), 221-229.

4. Hunfeld, J., Perquin, C., Duivenvoorder, H., Hazenbroek-Kampschreur, A., Passchier, J., van-Suijlekom-Smit, L., \& van der Wouden, J., (2001). Chronic pain and its impact on quality of life in adolescents and their families. Journal of Pediatric Psychology, 26(3), 145-153.

5. Goubert, L., Eccleston, C., Vervoort, T., Jordan, A., \& Crombez, G. (2006). Parental catastrophizing about their child's pain: the parent version of the pain catastrophizing scale (PSC-P); a preliminary validation. Pain, 123, $254-263$.

6. Lynch, A.M., Kashikar-Zuck, S., Goldschneider, K.R., \& Jones, B. (2006). Psychosocial risks for disability in children with chronic back pain. The Journal of Pain, 7, 244-251.

7. Palermo, TM \& Eccleston, C (2009) Parents of children and adolescents with chronic pain. Pain doi:10.1016/j.pain.2009.05.009. In press.

\section{P67}

METHODOLOGY OF A WEB-BASED OBSERVATIONAL STUDY TO EVALUATE THE IMPACT OF OPIOID TOLERABILITY ISSUES ON CHRONIC PAIN MANAGEMENT

Kevin Rod, MD, CCFP, DAAPM, DCAPM, University of Toronto, Toronto Poly Clinic, Toronto; Joseph Kozak, MD, CCFP, FCFP, West Park Hospital, Etobicoke, Ontario; Krista Payne, B.A. (Hons), M.Ed, United BioSource Corporation, Montreal, Quebec; Rosanna S.

Prinzo, B.Sc.(Hons.), Janssen-Ortho Inc.

AIM: An observational study enrolling approximately 200 chronic pain patients from 15 centres, is being conducted across Canada to assess the clinical and economic impact of opioid tolerability related outcomes on chronic pain treatment patterns, including adherence.

METHODS: To capture a thorough representation of opioid exposure, eligibility criteria are: opioid naive or opioid experienced patients diagnosed with non-malignant chronic pain requiring opioids for $>=4$ days per week. Eligible patients are invited to participate by their physician during routine care appointments at family or pain medicine practices. Interested and eligible patients are directed to a website where they provide consent and then complete a weekly on-line questionnaire documenting their chronic pain experience over a 3 month period. The anonymized, password protected, web-based survey can be completed at home; data entry reminders are issued via email and telephone. At the end of the study, physicians collect opioid prescription regimen data retrospectively from the charts of each consenting patient and enter these data into the study website.

RESULTS: Assessments include pain severity via the Numerical Rating Scale, opioid treatment adherence, concomitant medication surveillance, impact of opioid tolerability on activities of daily living, medical resource use, quality of life and productivity.

CONCLUSIONS: Data will inform unmet care needs and health economic analyses.

\section{P68}

THE DEVELOPMENT AND IMPLEMENTATION OF AN INTERPROFESSIONAL ORIENTATION PROGRAM FOR THE DELIVERY OF OUTPATIENT CHRONIC PAIN SERVICES: IMPROVING RESOURCE UTILIZATION

Gail Sloane, RN, BScN, MHSc (Bioethics); Doug Cane, Phd(Psychology); June Trenholm, BSc(Physiotherapy); Shelley LeDrew, BSc, Capital Health District Authority

AIM: The aim of this poster is to examine the role of a new orientation program in the delivery of outpatient chronic pain services. It is also to examine the impact of no-shows on the overall delivery of scarce chronic pain care. Further to report the patient evaluation of the program.

METHODS: Some evidence is available in the chronic pain literature identifying the impact of patient and/ or family orientation programs in outpatient healthcare service delivery. The impetus to develop this new program at the chronic pain clinic was the significant number of patient no-shows and extensive chronic pain waitlist. Using existing resources an inter-professional orientation program for new patients to the chronic pain clinic was offered once a month. The patients were asked to complete program evaluations and no-show rates were collected on a monthly basis. RESULTS: We report the no-show data from the year prior to the orientation program and then data from the year after the program was initiated. Further we report the patient evaluation data including quantitative and qualitative data. Additionally, we report the operational issues that impact the consistent delivery of the orientation program.

CONCLUSIONS: 1) Patient no-show rates have significant impact on appropriate healthcare resource use in the delivery of outpatient chronic pain services.

2) The development and implementation of an inter-professional orientation program has provided an active process to address resource use concerns in the delivery of outpatient chronic pain services.

3) The data supports the assertion that the implementation of the chronic pain clinic orientation program has both practical and ethical implications in the delivery of a high demand service.

4) Upfront communication prior to entry into the chronic pain clinic provides opportunity for questions and concerns to be discussed prior to the medical assessment. 
5) Identification of this resource use issue has implications for other $\mathrm{CP}$ Centres across Canada as the demand for chronic pain services increases. FOOTNOTES/REFERENCES:

1) The Global challenge of Health Care Rationing : State of Health (Coulter,A. \& Ham, eds.(2000)

2) An Ethical Analysis of Crisis in Chronic Pain Care: Facts, Issues and Problems in Pain Medicine; Part I (Giordano, J, \& Schatman, M.E. (2008)

\section{P69}

EPIDERMAL NERVE FIBER MORPHOLOGY, NEUROPEPTIDE CONTENT, AND IMMUNE ACTIVITY IN CHILDREN WITH SELF-INJURIOUS BEHAVIOR AND NEURODEVELOPMENTAL DISORDERS

Frank Symons, PhD; Gwen Wendelschafer-Crabb, MS; William Kennedy, MD, University of Minnesota; Elizabeth Gilles, MD, Children's Hospital, St. Paul, University of Minnesota; James W. Bodfish, PhD, University of North Carolina at Chapel Hill, USA AIM: The purpose of this preliminary clinical study was to examine the morphology and neuropeptide density of epidermal nerve fibers and mast cell granulation state quantified through skin biopsy samples from children with neurodevelopmental disorders and chronic self-injurious behavior (SIB) secondary to intellectual disability.

METHODS: A cross-sectional design was used with $3 \mathrm{~mm}$ skin biopsies collected from each participant $(\mathrm{N}=4)$ from non-self-injurious body sites and compared with site-matched existing normal control skin samples. The study was conducted at an outpatient clinic. The primary dependent measure for the morphology analyses was the coefficient of variation (CV) to quantify the mean gap length between epidermal nerve fibers for each subject and mast cell granulation status was quantified as an indicator of immune activity.

RESULTS: Visual microscopic examination and quantitative analysis of the microscopy images suggested there were morphological abnormalities (increased CV) in the epidermal nerve fibers among the chronic SIB cases. Substance P (SP) fiber density was increased with 2 to 3 times as many fibers in SIB subjects as control subjects. Mast cells were extensively degranulated throughout the tissue samples.

CONCLUSIONS: The underlying pathophysiology associated with chronic self-injury among children with neurodevelopmental disorders is poorly understood. Our findings, although preliminary and not confirmatory, suggest that additional empirical work is needed to clarify the relation between sensory innervation of the skin, pain, and self-injury to improve assessment and treatment outcomes.

\section{P70}

\section{A CENSUS SURVEY OF COMMUNITY NURSES VIEWS REGARDING PAINFUL LEG ULCERATION}

Tarnia Taverner, PhD(c), MSc, RGN; Michelle Briggs, PhD, MSc, BSc, RGN; S. Jose Closs, PhD, Mphil, BSc (Hons), RGN, The University of Leeds, School of Healthcare

AIM: To investigate community nurses views about the management of painful leg ulceration.

METHODS: A census survey of the population of community nurses employed by a primary care trust in England, UK. Data were collected using a postal questionnaire. SPSS computer software was used to analyze the data. Ethics committee approval was obtained from the Leeds Local Research Ethics Committee.

RESULTS: 115 completed questionnaires were returned ( $\mathrm{rr}=32 \%)$. The majority of respondents were female $91.8 \%, n=102$. Over a third of the nurses had not attended any pain management training. Approximately half of the nurses indicated that they were not measuring and assessing pain appropriately. A significant majority of the nurses demonstrated they used preconceived ideas rather than patient pain report, to base their clinical decisions. CONCLUSIONS: The study results demonstrated that patients with painful leg ulceration were not getting appropriate pain assessment and/or management. Moreover, the results of the survey suggest that the nurses have a limited understanding regarding neuropathic pain. Only when healthcare professionals understand and acknowledge the nature of the pain in this patient group, can the pain be managed effectively.
P71

PAIN MANAGEMENT PRACTICES FOR CRITICALLY ILL CRANIOTOMY PATIENTS: A RETROSPECTIVE STUDY

Jane Topolovec-Vranic, PhD; Marlene Santos, MD; Gabriela Tataru, RN; Michael D. Cusimano, MD, St. Michael's Hospital, Trauma and Neurosurgery Program, Toronto, Ontario

AIM: There exists an assumption that patients who have undergone a craniotomy procedure do not experience significant post-operative pain. The purpose of this study was to examine pain assessment and management practices in a trauma and neurosurgical intensive care unit (TNICU) for patients who have undergone craniotomy.

METHODS: A retrospective medical chart review of all patients in a TNICU who had undergone a craniotomy procedure over a six month period was conducted. Patients who were in the TNICU for less than 24 hours, or who died within 48 hours post-craniotomy were excluded. The following data were collected: clinical characteristics (age, gender, primary diagnosis and indication for craniotomy, details of the craniotomy procedure, ventilation status, date of craniotomy, TNICU and hospital length of stay); pain assessment documentation; analgesia ordered and given.

RESULTS: The medical charts of 75 patients were reviewed and data regarding the following were reported: frequency of pain documentation in the patients' charts; the severity and causes of documented pain; frequency and amount of analgesia ordered and administered; utilization of patient controlled analgesia.

CONCLUSIONS: Patients who have undergone a craniotomy can experience significant levels of pain. The findings from this study will help us to understand our own practices related to pain management for postcraniotomy patients thereby potentially identifying areas for intervention and improvement. For example, the bedside nurse may use the findings from the study to advocate for more pain medication on their patient's behalf as well as to develop standardized protocols for pain management in postcraniotomy patients.

\section{P72}

\section{INTRAEPIDERMAL AXONAL SWELLINGS IN EXPERIMENTAL DIABETIC NEUROPATHY ARE PREDICTIVE OF NEUROPATHIC PAIN}

Cory Toth, MD; Connie Ellis, N/A; Jose A. Martinez, MSc, University of Calgary, Calgary, Alberta; William H. Frey II, PhD, University of Minnesota, USA; Nicole Pradzinsky, N/A; Amanda Herring, N/A, University of Calgary, Calgary, Alberta

AIM: The development of neuropathic pain is associated with pathological changes in multiple nervous system regions. In skin, diabetic neuropathy leads to loss of intraepidermal nerves and the development of axonal swellings. We hypothesized that the formation of epidermal axonal swellings in diabetes contributes to the development of neuropathic pain behavior.

METHODS: We studied the epidermis in models of both type 1 (streptozotocin (STZ)-induced Sprague Dawley rats and CD1 mice) and type 2 diabetes (Leprdb/db mice and Zucker Diabetic Fat (ZDF) rats) over 5 (rats) or 8 (mice) months of diabetes. CD1 mice received either lifelong intranasal insulin (I-I) 0.87 IU daily or saline. Footpad tactile and thermal sensitivity were assessed every two weeks; footpad biopsies were performed serially, permitting quantification of intraepidermal nerve fiber density and axonal swelling ratios. Additional epidermal mRNA and immunohistochemical detection of NaV1.8 and CaV3.2 channels was performed.

RESULTS: Tactile allodynia and thermal hypersensitivity development varied between models. Axonal swelling appearance was concurrent with initial neuropathic pain behavior and their disappearance occurred in all models around time of pain resolution. NaV1.8 and CaV3.2 expression in diabetic skin peaked during neuropathic pain behavior and was strongly identified in axonal swellings. I-I suppressed neuropathic pain and the development of axonal swellings.

CONCLUSIONS: There is a coincidental appearance of axonal swellings and neuropathic pain behavior in multiple rodent models of diabetic neuropathy. Excessive expression of NaV1.8 and CaV3.2 channels may correlate with the development of hypersensitivity and facilitation of painful signaling. 


\section{P73}

THE NOVA SCOTIA CHRONIC PAIN COLLABORATIVE CARE NETWORK (NSCPCCN) MENTOR AND MENTEE WORKSHOP ASSESSMENT DATA

Peter MacDougall, PhD, MD, FRCPC; Sara Whynot, MLT(ASCP), Dalhousie University, Department of Anesthesia; Michele Chapell, RN, Dalhousie University, Halifax, Nova Scotia; Michael Cord, HBSc, MD, University of Toronto, Toronto; Spencer Tighe, MD, FRCPC, University of Ottawa, Ottawa, Ontario

AIM: The NSCPCCN is a mentor - mentee network designed to provide clinical support, continuing professional development (CPD) and knowledge translation (KT) to primary care practitioners (PCP's) in in the community. The network was initially launched as a pilot project in one health care district in Nova Scotia. The goal of this study was to determine the baseline characteristics of mentors and PCP mentees at the inauguration of the NSCPCCN through a two day workshop.

METHODS: A two day workshop was held to launch the NSCPCCN. The first day of the workshop consisted of training for mentor physicians. A questionnaire was provided to the mentors at the end of the session to determine the mentors understanding of the concept of mentoring in this framework. The second day of the workshop was devoted to matching mentor - mentee groups. Data was collected from the mentee physicians to determine the impact of chronic pain on their practice, initial satisfaction with chronic pain management, opioid prescribing and the rate of aberrant opioid behavior screening.

RESULTS: Mentorship data was expressed in Likert scales from 0 (strongly disagree) to 5 (strongly agree). Of the 7 mentors responding, 6 had no previous similar mentoring experience. Confidence in mentoring, understanding the values of the NSCPCCN and the expectations of the NSCPCCN averaged $3.9 / 5,3.4 / 5$ and $3.1 / 5$ respectively. The ability to describe mentoring models, know when to chose the most approrpiate mentor role and confidence in functioning as a mentor in this setting averaged 3.1/5, 2.3/5 and $3.4 / 5$.

The average number of visits for chronic pain was 43/month with a range of $2-125$. Visit duration ranged from 15 to 400 minutes. The average time without the 400 minute outlier was 22 minutes. Average non-compensated time was 13 minutes. Satisfaction with chronic pain management and opioid prescribing averaged $3.4 / 5$ and 3.7 , respectively. The average number of patients screened for aberrant opioid behavior and suspected of same are 22.6 and 5 respectively.

CONCLUSIONS: Mentors entering the NSCPCCN were unlikely to have acted as mentors in the past. However, the mentors had a reasonable grasp of the concepts of mentoring. Mentee practices demonstrate a wide variation in visits for chronic pain. Non-compensated time was similar to that reported previously (1). Aberrant opioid screening and suspicion of this behavior was much higher than in previous groups (1).

FOOTNOTES/REFERENCES:

1. Chappell et. al. Canadian Pain Society Annual Meeting 2009.

Abstract.

\section{P74}

\section{SEX DIFFERENCES IN THE EFFECTS OF ATTENTION ON THE} NEURAL RESPONSE TO NON-PAINFUL SENSORY STIMULI

Christine Popovich, BSc, University of Toronto; Colleen Dockstader, PhD; Douglas Cheyne, PhD; Rosemary Tannock, PhD, The Hospital for Sick Children, Toronto, Ontario

AIM: To determine whether males and females differ in attention modulation of sensorimotor mu rhythms in response to non-painful somatosensory information. Sex-related differences have been found in cortical oscillations (specifically, the $8-12 \mathrm{~Hz}$ mu frequency band) in response to painful stimuli, but it is unclear whether differences also occur in response to non-painful stimuli and whether there are sex differences in attention to sensory stimuli.

METHODS: We used magnetoencephalography to capture mu oscillation in the primary somatosensory cortex in response to non-painful transcutaneous median nerve stimulation (MNS) in 10 female and 10 male healthy adults, aged 21-36 years. Stimuli were presented in trains of four (ISI: 2s) followed by a 4 -sec gap for a total of 83 trains over 14 minutes. Participants completed two counterbalanced conditions: attend to a videoclip while ignoring MNS; attend to MNS and ignore the videoclip.
RESULTS: Females showed strong and prolonged mu suppression when attending to MNS stimuli, whereas males showed brief mu suppression followed by mu enhancement. Since mu suppression reflects stimulus processing and mu enhancement reflects cortical inhibition of that region, our findings indicate that females engage in intensive and extensive processing of the sensory stimuli, when directing attention to the stimuli, whereas males engage in brief sensory processing, then inhibit further processing. CONCLUSIONS: Sex-related differences in attentional processing of sensory stimuli might account in part for the well-documented greater pain sensitivity in females and their decreased response to pain-therapies involving redirection of attention away from nociceptive information.

\section{P75}

KNOWLEDGE TRANSLATION IN PAIN EDUCATION: IS THE MESSAGE BEING UNDERSTOOD?

Erica Weinberg, BSc, MSc, MPhil, MD, Rouge Valley Health System, Scarborough, Ontario; Philip A. Baer, MDCM, FRCPC, FACR, Canadian Rheumatology Association

AIM: To assess whether new clinical and scientific information potentially impacting pain management is being translated into daily clinical practice at the primary care level in Canada.

METHODS: Over 190 health care professionals, mostly primary care physicians, were surveyed at a number of CME events in 2009 for current knowledge in pain management. Multiple choice questions regarding prevalence of chronic pain, screening for opioid misuse risk, acetaminophen dosing, risk factors for NSAID-induced GI events, and codeine metabolism were posed.

RESULTS: In 2009, the majority of respondents were aware of the prevalence of chronic pain in Canadian adults. However, clinicians are still not fully aware of issues surrounding codeine metabolism, maximum safe acetaminophen dosing in chronic usage, and the increased GI risk of SSRIs used concomitantly with NSAIDs. Only $18.1 \%$ of clinicians used validated tools for screening opioid misuse risk prior to initiating opioids, and 20.3\% still do not routinely screen their patients at all.

CONCLUSIONS: Continuing medical education in proper pain management and risk stratification is still required.

FOOTNOTES/REFERENCES:

1. Food and Drug Administration; Organ-Specific Warnings; Internal Analgesic, Antipyretic, and Antirheumatic Drug Products for Over theCounter Human Use; Final Monograph. Federal Register / Vol. 74, No. 81 / Wednesday, April 29, 2009.

2. Chou R. et al. Clinical Guidelines for the Use of Chronic Opioid Therapy in Chronic Noncancer Pain. The Journal of Pain, Vol 10, No 2 (February), 2009: pp 113-130.

3. Macfarlane GJ et al. Managing low back pain presenting to primary care: Where do we go from here? Pain 122 (2006) 219-222.

\section{P76}

THE ILLNESS PERCEPTION QUESTIONNAIRE-CANCER PAIN CHINESE VERSION (IPQ-CAPC): THE PILOT TESTING IN TAIWANESE PATIENTS WITH CANCER-RELATED PAIN

Shu-Liu Guo, RN, PhD student; Doris Howell, RN, PhD; Judy Watt-Watson, RN, PhD, Lawrence S. Bloomberg Faculty of Nursing, University of Toronto, Toronto, Ontario

AIM: Studies suggested that pain intensity may be related to patients' beliefs about cancer pain and pain medication. Most measures examined cancer patients' beliefs have focused on barriers to pain management. Moss-Morris et al. developed the Illness Perception Questionnaire-revised (IPQ-R) based on Leventhal's Self-Regulatory Model. The multiple components of IPQ-R, which were labeled as Identity, Cause, timeline, Consequences, and Cure/ Control, was used to assess patients' representation about illness and also was determined the association with their health behaviour on various illnesses. IPQ-R has not been used to explore Taiwanese patients' beliefs about cancer pain that may influence pain perception. Therefore, the purpose of study is to examine the validity and feasibility of the Illness Perception Questionnaire-Cancer Pain Chinese version (IPQ-CaPC).

METHODS: The English version IPQ-CaP will be translated into Chinese and evaluated for relevance to Taiwanese cancer patients by 5 oncology pain experts. Content validity will be measured using a 4-point scale. The item-rating scale appears to be: $1=$ not relevant, $2=$ somewhat relevant, $3=$ quite relevant, $4=$ highly relevant. The translated IPQ-CaP will also be 
examined for its face feasibility by 10 cancer patients in Taiwan. Those same patients will be asked to repeat completing IPQ-CaPC after three days for test-retest reliability. One question for the face feasibility is how long you take to answer completely the questionnaire. The test-retest reliability with the Pearson's correlation will be determined.

RESULTS: This study will provide data about the relevance and feasibility of the Illness Perception Questionnaire-Cancer pain Chinese version (IPQ$\mathrm{CaPC}$ ) for this population as the first phase of a larger study on the influence of beliefs about cancer pain and management on the pain experience and analgesic use of Taiwanese patients with lung or colorectal cancer. CONCLUSIONS: A feasible and relevant measure is needed to explore beliefs about cancer pain and management of Taiwanese cancer patients with pain.

\section{P77}

\section{A DISSERTATION PROPOSAL: AN EXPERIMENTAL INVESTIGATION OF THE ROLE OF ANXIETY IN CHILDREN'S MEMORIES FOR PAIN AND PAIN PROCESSING}

Melanie Noel, MSc, Department of Psychology; Christine T. Chambers, PhD, Departments of Psychology and Pediatrics; Patrick J. McGrath, PhD, Departments of Psychology, Pediatrics, and Psychiatry, Dalhousie University and Centre for Pediatric Pain Research, IWK Health Centre; Raymond M. Klein, PhD, Department of Psychology, Dalhousie University; Sherry H. Stewart, PhD, Departments of Psychology, Psychiatry, and Community Health and Epidemiology, Dalhousie University, Halifax, Nova Scotia

AIM: The study will systematically examine the impact of state anxiety on the development of children's memories for a painful experience. It will also examine the role that these memories play in children's distress and coping during subsequent exposure to the same painful experience. Finally, more stable anxiety-related variables that have been shown to increase pain perception (e.g., trait anxiety and anxiety sensitivity) will be measured to determine the roles that these variables play in the development of children's memories for pain.

METHODS: One hundred healthy children aged 8 through 12 years will undergo an experimental pain task (the cold pressor task; CPT). Half of the children will be randomly assigned to complete a stressful task (Trier Social Stress Test for Children) prior to the CPT. Children will complete measures of pain intensity (Faces Pain Scale-Revised), pain affect (Facial Anxiety Scale; Facial Affective Scale), state and trait anxiety (State Trait Anxiety Index for Children; STAIC), anxiety sensitivity (Child Anxiety Sensitivity Index) and a memory interview immediately following the pain task and 2 weeks later. Children will repeat the pain task 1 month later to determine how their memories affect distress and coping during subsequent exposure to the same painful stimulus. Child distress and coping during completion of the pain task will be coded using the Child-Adult Medical Procedure Interaction Scale-Revised.

RESULTS: (pending)

CONCLUSIONS: The results will address current gaps in the literature and may be used to develop interventions that target anxiety and pain experienced by children during painful medical procedures thereby improving their health into adulthood.

\section{P78}

EXAMINATION OF MODULATORY INTERACTIONS BETWEEN SENSORY NEURONS AND CHONDROCYTES

Maral Tajerian, BSc, MSc, Alan Edward Center for Research on Pain, Neurology and Neurosurgery, McGill University; Magali Millecamps, PhD, Alan Edward Center for Research on Pain, Faculty of Dentistry, McGill University; Laura Stone, PhD, Alan Edward Center for Research on Pain, Faculty of Dentistry, McGill University, Montreal, Quebec

AIM: 1 . Determine if chondrocytes release modulators that alter neurite outgrowth.

2. Determine if chondrocytes release modulators that activate sensory neurons.

3. Determine if sensory neurons release modulators that activate chondrocytes. METHODS: Cell culture: Chondrocytes: The chondrocyte culture system and protocols for their phenotypic validation will be performed as described previously (1). Sensory neurons: Mouse DRG cultures will be derived as described by Malin et al (2). Co-culture: Chondrocytes will be seeded on the permeable membranes of Transwell cell culture inserts. A single culture media that can maintain both cell types will be used.

Chondrocyte modulation of neurite outgrowth: DRG cell bodies will be labeled with a preparation of the membrane dye DiI developed specifically for cell culture. The DiI will be incorporated into growing axons and can therefore be used for neurite detection. DRG cultures will be grown in the presence of inserts containing chondrocytes (or empty insert controls). Neurite outgrowth will be quantified 1, 3 and 6 days later as previously described (3).

Chondrocyte modulation of sensory neuron excitation: Neuronal activation will be assessed by $\mathrm{Ca} 2+$-imaging following application of chondrocyteconditioned media. We will use microspectrofluorimetry to monitor changes in $[\mathrm{Ca} 2+]$ i neurons loaded with $\mathrm{Ca} 2+$-sensitive dye fura-2. Cells loaded with fura-2 will be placed in a chamber mounted on an inverted microscope and conditioned media will be applied using. Changes in fluorescent emission at $510 \mathrm{~nm}$, following alternate excitation at 340 and 380 will be recorded using a cooled CCD camera. Images will be collected and analyzed using image analysis software.

Neuronal modulation of chondrocytes: Same as previous paragraph, except the cells will be reversed.

RESULTS: Pending

CONCLUSIONS: Significance of the proposed studies: There is an emerging literature suggesting complex bi-directional modulation between chondrocytes and the sensory nervous system. It has been shown, for example, that increased innervation of intervertebral discs is associated with chronic low back pain (4). In addition, abnormal nerve ingrowth is reported at the osteochondral junction of degenerating arthritic joints (5). These and other studies suggest that joints release modulators that stimulate neurons. FOOTNOTES/REFERENCES:

1. V. Lefebvre, S. Garofalo, G. Zhou et al., Matrix Biol 14 (4), 329 (1994).

2. S. A. Malin, B. M. Davis, and D. C. Molliver, Nature protocols 2 (1), 152 (2007)

3. L. Ulmann, J. L. Rodeau, L. Danoux et al., Eur J Neurosci 26 (1), 113 (2007).

4. MH. Coppes, Marani E, Thomeer RT, and Groen GJ. Spine 22 (20), 2342 (1997).

5. S. Suri, S. E. Gill, S. Massena de Camin et al., Ann Rheum Dis 66 (11), 1423 (2007). 
A

Abbott L . . . . . . . . . . . . . . . . P65

Allen K . . . . . . . . . . . . . . 17,17B,P29

Amaria K . . . . . . . . . . . . . . . P31

Antolak SJ . . . . . . . . . . . . . 26,26C

Applewhaite C................... P32

Arnold C . . . . . . . . . . . . . . . 15E

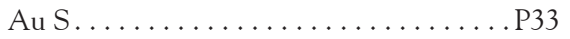

Awde M ................... P41

B

Baer PA ............ 24C,P34,P75

Barton P.................... P35

Barwick M ..................... P65

Basic S . . . . . . . . . . . P21,P22

Basiuk SM . . . . . . . . . . . . . P36

Beauprie I. . . . . . . . . . . . . 25,25B,P16,P37

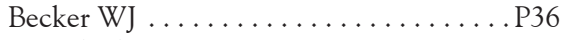

Bezuidenhout A ............17A,P28

Bodfish JW. . . . . . . . . . . . . . . . . . . . . P69

Bourgault P. . . . . . . . . . . . P2

Boyd J . . . . . . . . . . . . . . 17A,P28

Briggs M.................... P70

Briggs $\mathrm{N} \ldots \ldots \ldots \ldots \ldots \ldots \ldots \ldots . . \ldots \ldots 24$

Brown CA . . . . . . . . . . . 8,34,34A,P38

Brown $\mathrm{S} \ldots \ldots \ldots \ldots \ldots \ldots \ldots \ldots$ P31

Brownstone R . . . . . . . . . . P16,P37

Brunello M.................... P55

Bucholtz L . . . . . . . . . . . . . . . . P60

Bushnell MC ................. 18A,18B

Butler M............... P32,P43

Buzon A..................... P24

Byrne J .................... P24

\section{$\mathrm{C}$}

Caddell K.....................P2

Cairns BE.................. P33

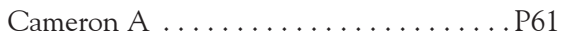

Campbell F. . . . . . . . . P23,P31,P61,P65

Campbell-Yeo M . . . . . . . . .......P2

Cane D. . . . . . . . . . . 32,32C,P68

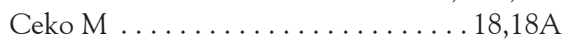

Cenac N. . . . . . . . . . . . 20,20B

Chalaye P...............................

Chambers CT. . . . . 14,14B,P17,P19,P65,P77

Chapell M . . . . . . . . . . . . . . 24A,P73

Chary S . . . . . . ......... 17A,P28

Cheng P............... 21,21B

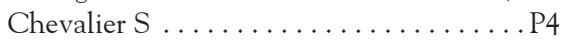

Cheyne D. . . . . . . . . . 24B,P7,P74

Chiang CY..................... P39

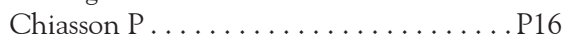

Chung S.................. P40

Clark AJ . . . . . . . . 17,17A,25,25A,P28

Cleary C. . . . . . . . . . . . . . . . . P46

Clements J . . . . . . . . . . . . . . 15E

Closs SJ .................... P70

Cloutier C . . . . . . . . . . . . . . . . P41

Coburn G.................... P65

Cockburn L . . . . . . . . . . . . P42,P61

Codrington AM. ................ P4

Cohen $\mathrm{G} \ldots \ldots \ldots \ldots \ldots \ldots \ldots \ldots$ P41

Cohen J . . . . . . . . . . . . . . . . . P65

Corbett C. . . . .......... P32,P43

Cord M. . . . . . . . . . . . . 24A,P73

Cotton V . . . . . . . . . . . . . . . 18,18B

Couturier L. . . . . . . . . . . . . . . . . P18

Cox $\mathrm{AD} \ldots \ldots \ldots \ldots \ldots \ldots . . \ldots$ P44
Craig K................. 14,14A

Croxen H................... P45

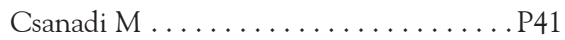

Cummings G . . . . . . . . . . . . P65

Cusimano MD ................ P71

$\mathrm{D}$

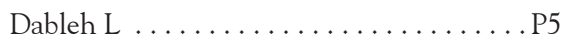

Dan Li ................... P48,P49

Dao T................. P42,P61

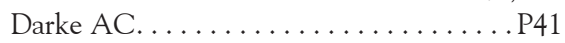

Davies R........................................ 61

Davis KD . . . . . . . . . . 3,3A,P7

Dennis C-L . . . . . . . . . . . . 17B,P29

Deshpande A . . . . . . . . . . . . . . . P59

Devoize L . . . . . . . . . . . . . . . . P3

Dewar AL. . . . . . . . . . . . . . . . . . P45

Dick BD . . . . . . . . 19,19B,31,31C,P38,P66

Dike N . . . . . . . . . . . . 17A,P28

Dockstader C . . . . . . . . . . . . 24. 24,P7,P74

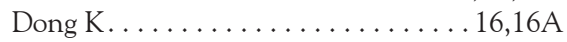

Dong $\mathrm{X} \ldots \ldots \ldots \ldots \ldots \ldots \ldots \ldots$ P33

Dostrovsky JO . . . . . . . . . . P39,P55

Dubin RE ........... 17,17C,P30

Eisenhoffer $J \ldots \ldots \ldots \ldots \ldots \ldots \ldots . . \ldots$ P41

Ellis C................... 15D,P72

Esfahani F................... P26

Estabrooks C ................. P65

Etropolski M . .............. 15A

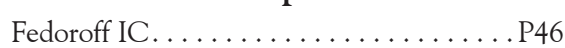

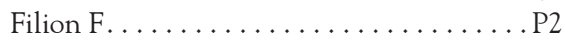

Findlay $\mathrm{T} \ldots \ldots \ldots \ldots \ldots \ldots \ldots, \mathrm{F}, \mathrm{P} 35$

Fine $\mathrm{PG} \ldots \ldots \ldots \ldots \ldots \ldots \ldots \ldots$

Finley GA . . . . . . . . . . . . . P65

Fitzcharles M ............... P47

Fleming J ..................... 30

Flor H. . . . . . . . . . . 3,3B,12A

Ford P . . . . . . . . . P48,P49,P63,P64

Forster I . . . . . . . . . . . . . . 10

Frey II WH. . . . . . . . . . . 15D,P72

Fung TS .................................

Furlan AD ........... 4,4A,P50

Fuss $S$.

\section{G}

. 18,18C

Gagnon B. . . . . . . . . . . . . 1,1B

Galimova L .................. P47

Garfield H .................... P25

Getty H . . . . . . . . . . . . . P51

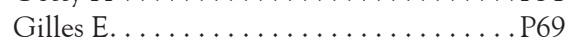

Ginting J . . . . . . . . . . . . 27,27C

Goldman RD . . . . . . . . . . . . . P40

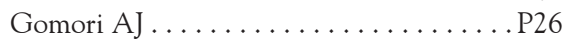

Gordon AS . . . . . . . 26,26A,P52

Grad H................ P42,P61

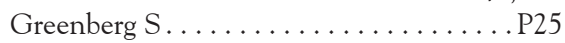

Guo S-L ............... P8,P76

\section{$\mathrm{H}$}

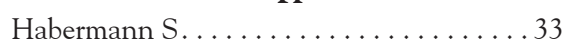

Hadjistavropoulos T. . . . . . . . . . . P14

Hagen N. . . . . . . . . . . . . . 1, 1C

Hanis R ................. 17A,P28

Hapidou EG. . . . . . . . . . . . . . P13

Harman K . . . . . . . . . . . 17,32,32B

Harris CA. . . . . . . . . . . . . . . 15C

Harrison D . . . . . . . . . . . . . . . P65
Harrison MB ................ 18E

Harsanyi Z . . . . . . . . . . . . ................ 4

Harstall C. . . . . . . . . . . . . . . . 5

Häussler J . . . . . . . . . . . . . . . 15A

Hayton K...................... P19

Helyes Z . . . . . . . . . . . . . . . . 20,20A

Henein S . . . . . . . . . . . . . P41

Henry JL. . . . . . . . . P P,P12,P27,P53,P54

Herring A. . . . . . . . . . . . . P72

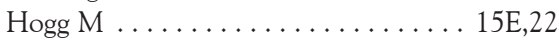

Holmes A.................... 15E

Hopman WM. ................. 18E

Horton R . . . . . . . . . . . . . . . P9

Howell D . . . . . . . . . . . . P8,P76

Huguet A ................... P10

Hunter J . . . . . . . . . . . . P42,P55,P61

\section{I}

$\operatorname{Im~H}-\mathrm{J} \ldots \ldots \ldots \ldots \ldots \ldots \ldots \ldots$ P53

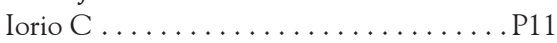

Irvin $\mathrm{E} \ldots \ldots \ldots \ldots \ldots \ldots \ldots \ldots$ P50

Isaac $\mathrm{L} \ldots \ldots \ldots \ldots \ldots \ldots \ldots \ldots$ P23

Itoh $K \ldots \ldots \ldots \ldots \ldots \ldots \ldots \ldots$. . . . . . . . . .

\section{$\mathrm{J}$}

Jarrell J . . . . . . . . . . . . . . P35

Jeavons M. . . . . . . . . . . . . P31

Johnston C. . . . . . . . . . . P2,P65

Jovey R. .

$\mathrm{K}$

Kahan M .................... P50

Kastanias P................... P24

Katz J . . . . . . . . . . . . . . 18C,P23

Katz L. . . . . . . . . . . . . . 27,27B

Katzman MA .................. P11

Kavanagh T .................. P65

Kelly K.................... 15A

Kennedy W . . ................. P69

Kewley E .................... P31

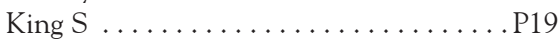

Klein RM . . . . . . . . . . . . . . P77

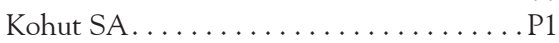

Konstantatos A . . . . . . . . . . . 15E

Kozak J . . . . . . . . . . . . . P34,P67

Kumar U .................... P33

Kuperwasser B .............. 15A

\section{L}

LaChapelle D. . . . . . . . . . . . . . . 19

LaFond $\mathrm{L} \ldots \ldots \ldots \ldots \ldots \ldots \ldots \ldots \ldots \ldots$. . . . . . . . . . . . .

Lafrenaye S. . . . . . . . . . . . P18

Lai YH . . . . . . . . . . . . . P8

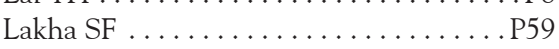

Lalloo C . . . . . . . . . . . . . . . . P12

Lange B . . . . . . . . . . . . . . 15A

Lapedis M. . . . . . . . . . . . . 18A

Latimer M . . . . . . . . . . . . . . P65

Lavoie S . . . . . . . . . . . . . . 19,19A

Lax L . . . . . . . . . . . . . . . . . . P42,P61

Le May $\mathrm{S} \ldots \ldots \ldots \ldots \ldots \ldots \ldots \ldots$. . . . . . . . . . . . . . . .

LeDrew $\mathrm{S} \ldots \ldots \ldots \ldots \ldots \ldots \ldots \ldots$. . . . . . . . . . . . . . . . . P68

Lee $S \ldots \ldots \ldots \ldots \ldots \ldots \ldots \ldots \ldots$ P65

LeFort $S \ldots \ldots \ldots \ldots \ldots \ldots \ldots$ 15,23,P57

Lewis J . . . . . . . . . . . . . . . P58

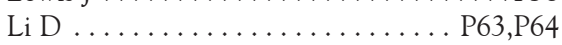

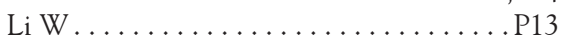

$\operatorname{Lim} \mathrm{R} \ldots \ldots \ldots \ldots \ldots \ldots \ldots . \ldots \ldots$

Lints-Martindale A . . . . . . . . . . P14

Louffat A . . . . . . . . . . . . . . P59 
Love B . . . . . . . . . . . . . . . . P15

Lynch ME. . . . . . . . . . . . . . 29,29A

\section{$\mathrm{M}$}

MacDougall P. . . . . 24,24A,29,29D,P47,P73

MacKay B. . . . . . . . . . . . . . . . P10

MacLean C. . . . . . . . . . . . . . . . P10

Mailis-Gagnon A. . . . . . . . . 4,4B,P50,P59

Maixner W. . . . . . . . . . . . . . . . 13

Malakhi S. ................. 18C

Marchand S . . . . . . . . . . . . . P P,P18

Martin AL ................. 18C,P23

Martin I . . . . . . . . . . . . 6,6B,P60

Martinez JA . . . . . . . . . . . . . . . P72

McCarvill T . . . . . . . . . . . . . . . P16

McCormick FM . . . . . . . . . 17B,P29

Mcdonald W . . . . . . . . . . . . . . P46

McDougall JJ . . . . . . . . . . . 15B,23,23A

McFetridge-Durdle J . . . . . . . . . . . P20

McGillian M . . . . . . . . . . . 2, 2, 12,P42,P61

McGrath PA . . . . . . . . . . P7,P31

McGrath PJ . . . . . . P10,P17,P19,P65,P77

McIntosh D . . . . . . . . . . . . . . . P62

Michalko KJ...................P41

Millecamps M ................. P78

Miller C . . . . . . . . . . . . . P P48,P49,P63,P64

Miró J . . . . . . . . . . . . . . . . P10

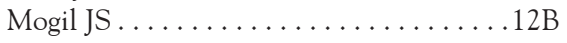

Montgomery L . . . . . . . . . . . . . 17A,P28

Moon EC . . . . . . . . . . . . . . . . P17

Morin M.................. P18

Morley-Forster P . . . . . . . . . . . . . 18D,P51

Moulin DE ........... 1,1A,11,18D

$\mathrm{N}$

Namaka MP....................P26

Noel M. . . . . . . . . . . . . . . . . P19,P77

Nuyt A-M . . . ...................

\section{$\mathrm{O}$}

O'Donnell ML . . . . . . . . . . . . . . . . . . 15E

O'Keefe McCarthy S . . . . . . . . . . 14,P20,P61

O'Mahony W. . . . . . . . . . . . . . P41

O'Sullivan R . . . . . . . . . . . . . 29,29B

Okamoto A . . . . . . . . . . . . 15A

Ong MC . . . . . . . . . . . . . . P21

Ong-Lam M . . . . . . . . . . . . . . . P22,P46

Osmun LD . . . . . . . . . . . . . . . P6

Ower K.................... 18D

$$
\text { P }
$$

Pagé $G \ldots \ldots \ldots \ldots \ldots \ldots \ldots \ldots \ldots$ P23

Paletz J . . . . . . . . . . . . . . . P37

Pawluk E ...................... P11

Payne K . . . . . . . . . . . . . . . . . . . P67

Peng P . . . . . . . 9,21,21A,26,26B

Piraino PS ......................

Popovic M ....................... P55

Popovich C . . . . . . . . . . . . . . . 24,24B,P74

Pradzinsky N . . . . . . . . . . . 15D,P72

Prinzo RS ...................... P67

Promislow $S \ldots \ldots \ldots \ldots \ldots \ldots \ldots \ldots$. . . . . . . . . . . . . . . .

Prosser A . . . . . . . . . . . . . . . . . 15E

\section{$\mathrm{R}$}

Racine $N \ldots \ldots \ldots \ldots \ldots \ldots \ldots \ldots$. . . . . . . 25

Raman-Wilms L. . . . . . . . . . . . P42,P61

Rankin JA .................... P36

Rashiq S............... 16,16C

Rashotte J.....................P65

Reardon R .................... P50

Reddy N. . . . . . . . . . . . . . . . 17A,P28

Reid KL . . . . . . . . . . . . . . 31,31B,P66

Renfrew MJ . . . . . . . . . . . . 17B,P29

Reyes M................ 17A,P28

Riddell RP . . . . . . . . . . . . . P1,P6,P9,P25

Ritvo S................... 18C

Robinson L. . . . . . . . . . . . . . . P41

Rod K...................... P67

Rose L . . . . . . . . . . . . . . . . . . P61

Rosmus C...................... P65

Russell F................ 15,15B,20

Ruxandra D ................... P55

\section{$\mathrm{S}$}

Sagar D. . . . . . . . . . . . . . . 28,28B

Samosh A. . . . . . . . . . . . . . . 18,18D

Santos M . . . . . . . . . . . . P71

Sawatzky-Dickson D . . . . . . . . . . . P65

Schuelert N . . . . . . . . . . . . 28,28A

Schultz G............. 17A,P28,P35

Schweinhardt P . . . . . . 3,3C,18A,23A,P58

Scott S . . . . . . . . . . . . . . . . P65

Seltzer Z ..................... 2

Sessle BJ . . . . . . . . . . . . . . . . . . P39

Shapiro A.................... P51

Shapiro DY .............. 15,15A

Shir Y................. 13,P4

Shobbrook C ..................P61

Sidani S . . . . . . . . . . . . . . . . P65

Silaj A .................... P24

Simmonds MK . . . . . 31,31A,32,32A,P66

Sinclair D . . . . . . . . . . . . . . . P41

Skrobik Y . . . . . . . . . . . . . . 16,16B

Sloane G . . . . . . . . . . . . 29,29C,P68

Smith-Young J . . . . . . . . . . . . . . . . P57

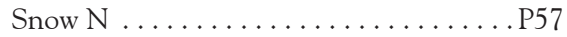

Solberg S . . . . . . . . . . . . . . P57

Spanswick C .....6,6A,17A,P28,P60,P62

Squire P . . . . . . . . . . . . . . . . . . . .

Steup A . . . . . . . . . . . . 15A

Stevens B . . . . . . . . . . . . . P65

Stewart SH. . . . . . . . . . . . . . P77

Stinson J. . . . . . . P1,P10,P23,P31,P61,P65

Stone L...................... P78

Stremler R . . . . ................ P65

Stuart JH .................... P6

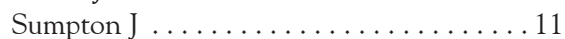

Sutton I .................... P41

Symons F . . . . . . . . . . . . . . . . . . P69

Synnes A . . . . . . . . . . . . . P65

$\mathrm{T}$

Taddio A . . . . . . . . . . . . . . . . P65

Taenzer P . . . . . . . . 5,9,17A,25,P28
Tajerian M .................. P78

Taliano J. . . . . . . . . . . . . . . P41

Tannock R . . . . . . . . . . . 24B,P7,P74

Tataru G. . . . . . . . . . . . . . . . . P71

Taverner T . . . ............. P70

Teasell R....................P51

Then KL..................... . P36

Thompson E-N ................. P47

Tighe $\mathrm{S} \ldots \ldots \ldots \ldots \ldots \ldots \ldots 24 \mathrm{~A}, \mathrm{P} 73$

Tkachuk GA . . . . . . . . . . . . 15,15C

Tognazzini P.................. P45

Topolovec-Vranic J . . . . . . . . . . . . P71

Toth C . . . . . . . . . . . . 15,15D,P72

Toth S . . . . . . . . . . . . . P47

Tougas M .................... P10

Tremblay J-L. . . . . . . . . . . . . . . . . P47

Trenholm J . . . . . . . . . . . . . . . . . . P68

Tripp DA . . . . . . . . 18,27,27A,27D

Tsirgielis C . . . . . . . . . . . . . P11

Turcotte DA.................. P26

\section{$\mathrm{U}$}

Uleryk EM ...........

van Hilst YM . . . . . . . . . . . . . . 6,6B,P60

Van Hove I. . . . . . . . . . . . . . . . . 15A

Van Vlack CK . . . . . . . . . . . . . . . . 17C,P30

van Zanten S . . . . . . . . . . . . . . P10

VanDenkerkhof EG ............... 18E

Vermani M................... P11

Vernon H.................... P53

Villemure C . . . . . . . . . . . . . . 18B

Villeneuve E. .................. P65

Virani N..................... 35

\section{$\mathrm{W}$}

Walker $S \ldots \ldots \ldots \ldots \ldots \ldots \ldots$. 18,18E

Wall E ...................... P54

Ward R..................... P60

Wardell G. . . . . . . . . . . . . . . . . P34

Ware MA ............. 28,28C,P4

Warnock F . . . . . . . . . . . . . P65

Watson JT ................ 18D

Watters C..................... P10

Watt-Watson J . . . . . . 24,P8,P42,P61,P76

Weber H. . . . . . . . . . . . . . . . 15A

Weinberg E ........... 24,24C,P75

Wendelschafer-Crabb G . . . . . . . . . . P69

Weppler C . . . . . . . . . . . . . 4,4C,P50

Whissel S . . . . . . . . . . . . . . 24,P2,P73

Whynot S. . . . . . . . . . . . . 24A,P73

Wilkins A.................... P54

Williamson OD ........7,7B,11,15,15E

\section{$\mathrm{Y}$}

Yamada J. . . . . . . . . . . . . . . . . . . P65

Yashpal K.................. 553

Yegneswaran B................ P59

\section{$\mathrm{Z}$}

Zhan S ....................... 15B

Zhu YF...................... 27 


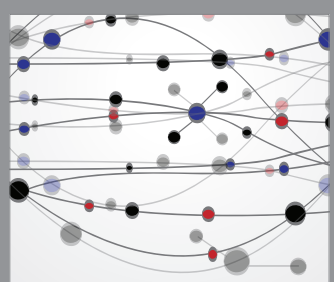

The Scientific World Journal
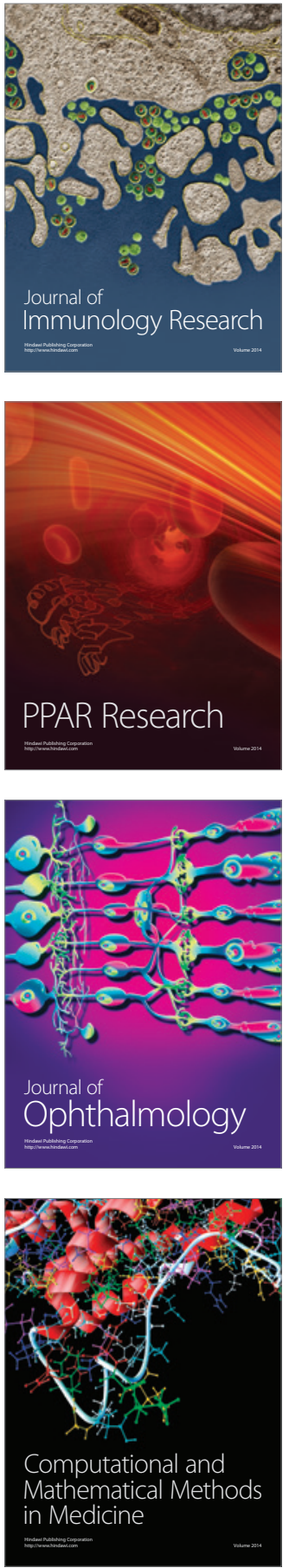

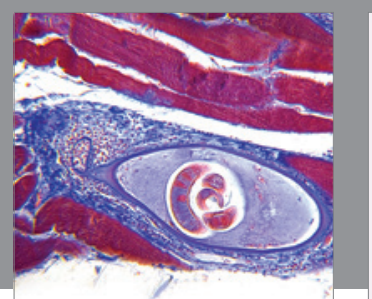

Gastroenterology Research and Practice

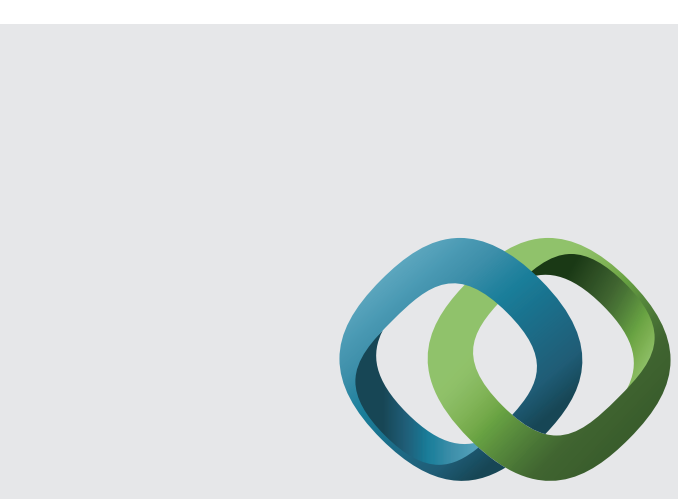

\section{Hindawi}

Submit your manuscripts at

http://www.hindawi.com
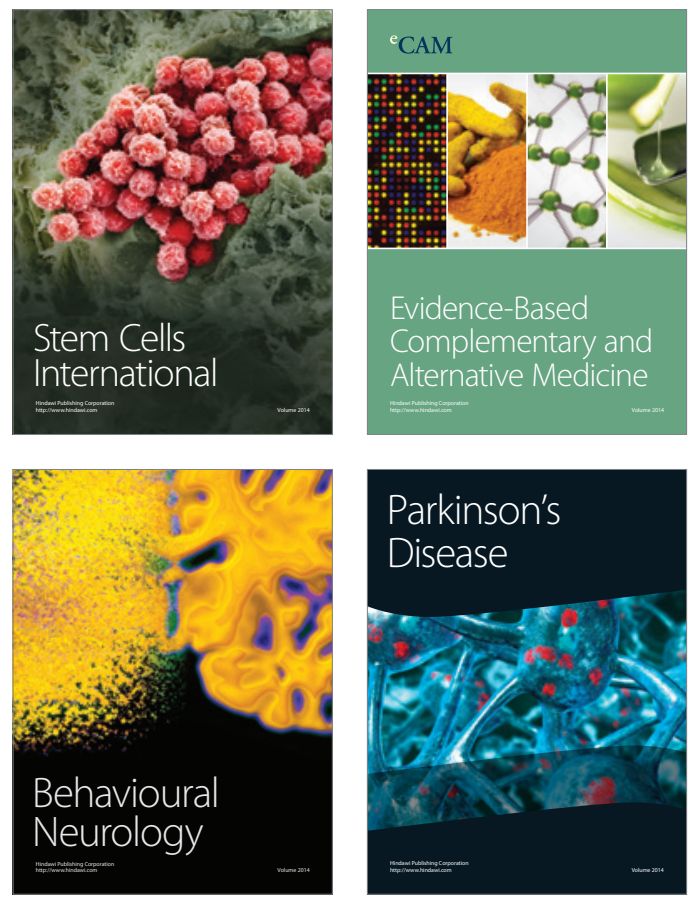
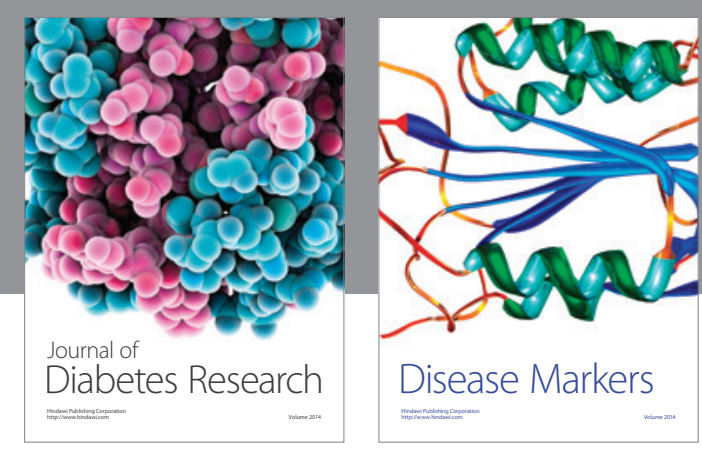

Disease Markers
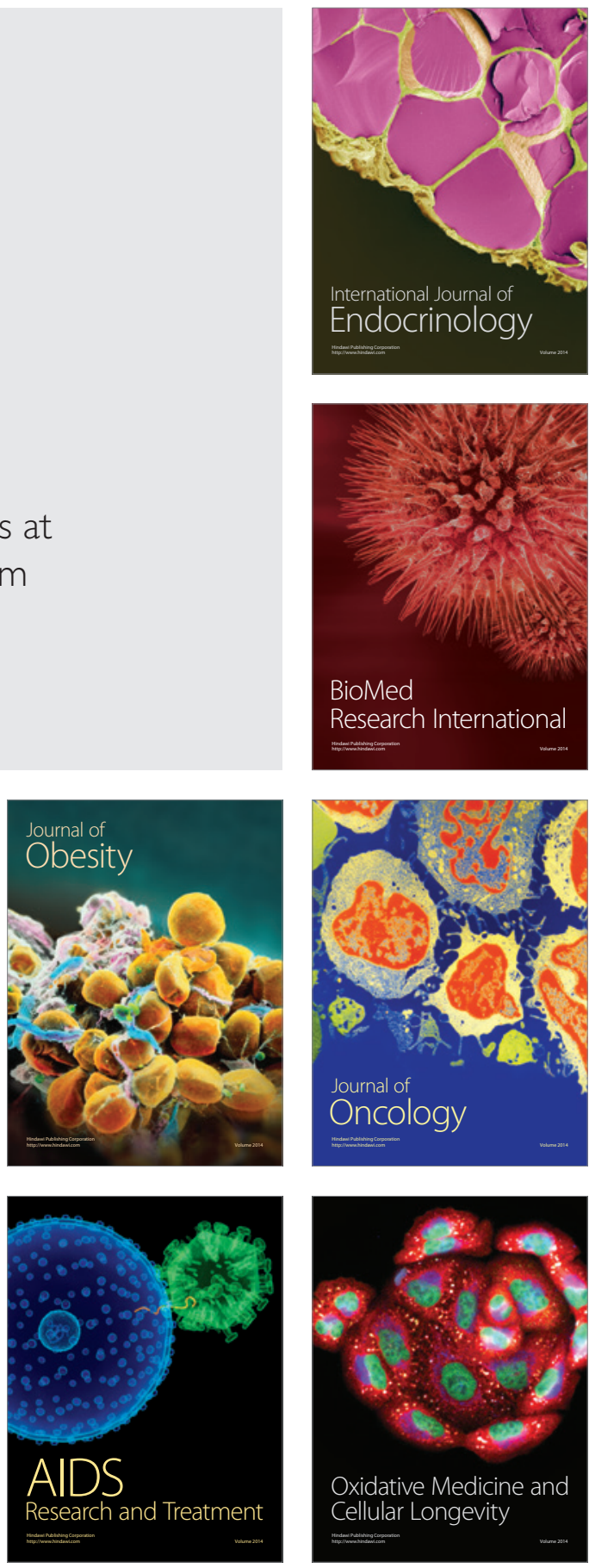